Supporting Information:

\title{
Iron-Catalyzed Cycloaddition of Amides and 2,3-Diaryl-2H-azirines to Access Oxazoles via C-N Bond Cleavage
}

\author{
Mi-Na Zhao,* Gui-Wan Ning, De-Suo Yang, Ming-Jin Fan, Sheng Zhang, Peng Gao, \\ Li-Fang Zhao
}

Shaanxi Key Laboratory of Phytochemistry, College of Chemistry and Chemical Engineering, Baoji University of Arts and Sciences, Baoji, Shaanxi 721013, P. R. China

\section{E-mail: zhaomina@bjwlxy.edu.cn}

\section{CONTENTS}

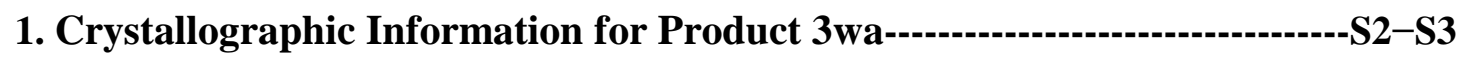

2. ${ }^{1} \mathrm{H}$ NMR (400 $\left.\mathrm{MHz}, \mathrm{CDCl}_{3}\right)$ and ${ }^{13} \mathrm{C}$ NMR (100 MHz, CDCl $)$ Spectra---S4-S67 


\section{Crystallographic Information for Product 3wa}

The single crystal of compound 3wa was prepared from its solution in dichloromethane/petroleum ether $(\mathrm{v} / \mathrm{v}=1: 1)$ and allowed to stand undisturbed at room temperature. Yellow block crystals suitable for single-crystal X-ray diffraction were obtained by slow evaporation of the filtrate after several days.

The single crystal X-ray experiment was performed on an Agilent Xcalibur Eos Gemini diffractometer equipped with a graphite-monochromatized $\mathrm{Cu} \mathrm{K} \alpha$ radiation $(\lambda$ $=1.5418 \AA$ ). The data integration and reduction were processed with CrysAlisPro software. Absorption correction based on multiscan was performed using the SADABS program. The structures were solved by the direct method and refined by means of full-matrix least-squares procedures on $F^{2}$ with SHELXL-2018 program. All nonhydrogen atoms were refined anisotropically.

Compound 3wa was crystallized in triclinic space group $P-1$. The $\mathrm{C}-\mathrm{H}$ distances range from 0.93 to $0.96 \AA$ for 3wa. The $\mathrm{C}-\mathrm{C}$ distances are from 1.165 to $1.685 \AA$ in 3wa. The $\mathrm{C}-\mathrm{Cl}$ distance is $1.719 \AA$ in 3wa. The $\mathrm{C}-\mathrm{O}$ distances range from 1.342 to $1.42 \AA$ for 3wa. The C-N distances range from 1.269 to $1.42 \AA$ for 3wa. Other details of crystal data, data collection parameters, and refinement statistics are given in Table S1.

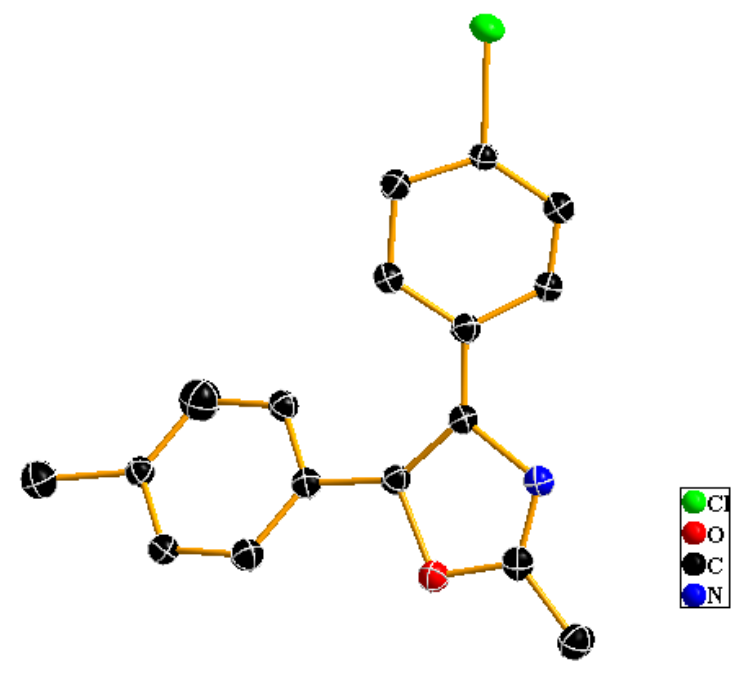

Fig. S1 General view of molecular structure of 3wa (thermal ellipsoids of all non-hydrogen atoms are drawn at the $50 \%$ probability level). 
Table S1 Crystallographic data and structural refinements for compound 3wa

\begin{tabular}{|c|c|}
\hline Compound & $3 \mathbf{w a}$ \\
\hline Empirical formula & $\mathrm{C}_{17} \mathrm{H}_{14} \mathrm{ClNO}$ \\
\hline Formula weight & 283.74 \\
\hline Temperature/K & $100.02(10)$ \\
\hline Crystal system & Triclinic \\
\hline Space group & $P-1$ \\
\hline$a / \AA$ & $7.0804(2)$ \\
\hline$b / \AA ̊$ & $9.5861(2)$ \\
\hline$c / \AA ̊$ & 10.9064(3) \\
\hline$\alpha /^{\circ}$ & $111.617(2)$ \\
\hline$\beta /^{\circ}$ & $94.734(2)$ \\
\hline$\gamma /{ }^{\circ}$ & $91.393(2)$ \\
\hline Volume $/ \AA^{3}$ & $684.65(3)$ \\
\hline$Z$ & 2 \\
\hline$\rho_{\text {calc }} \mathrm{g} / \mathrm{cm}^{3}$ & 1.376 \\
\hline$\mu / \mathrm{mm}^{-1}$ & 2.411 \\
\hline$F(000)$ & 296.0 \\
\hline Crystal size $/ \mathrm{mm}^{3}$ & $0.9 \times 0.11 \times 0.1$ \\
\hline Radiation & $\mathrm{CuK} \alpha(\lambda=1.54184)$ \\
\hline $2 \Theta$ range for data collection $/^{\circ}$ & 8.764 to 131.97 \\
\hline Index ranges & $-8 \leq \mathrm{h} \leq 8,-11 \leq \mathrm{k} \leq 11,-12 \leq 1 \leq 10$ \\
\hline Reflections collected & 5529 \\
\hline Independent reflections & $2391\left[\mathrm{R}_{\mathrm{int}}=0.0224, \mathrm{R}_{\text {sigma }}=0.0303\right]$ \\
\hline Data/restraints/parameters & $2391 / 228 / 207$ \\
\hline Goodness-of-fit on $F^{2}$ & 1.047 \\
\hline Final $R$ indexes $[I>=2 \sigma(I)]$ & $R_{1}=0.0441, w R_{2}=0.1157$ \\
\hline Final $R$ indexes [all data] & $R_{1}=0.0466, w R_{2}=0.1182$ \\
\hline $\mathrm{CCDC}$ & 2036963 \\
\hline
\end{tabular}

${ }^{a} R_{1}=\Sigma\left|\mathrm{F}_{\mathrm{o}}\right|-|\mathrm{Fc}| / \Sigma\left|\mathrm{F}_{\mathrm{o}}\right| \cdot{ }^{b} w R_{2}=\left[\Sigma w\left(\mathrm{~F}_{\mathrm{o}}^{2}-\mathrm{F}_{\mathrm{c}}\right)^{2} / \Sigma w\left(\mathrm{~F}_{\mathrm{o}}{ }^{2}\right)^{2}\right]^{1 /}$ 
2. ${ }^{1} \mathrm{H}$ NMR $\left(400 \mathrm{MHz}, \mathrm{CDCl}_{3}\right)$ and ${ }^{13} \mathrm{C}$ NMR $\left(100 \mathrm{MHz}, \mathrm{CDCl}_{3}\right)$ Spectra
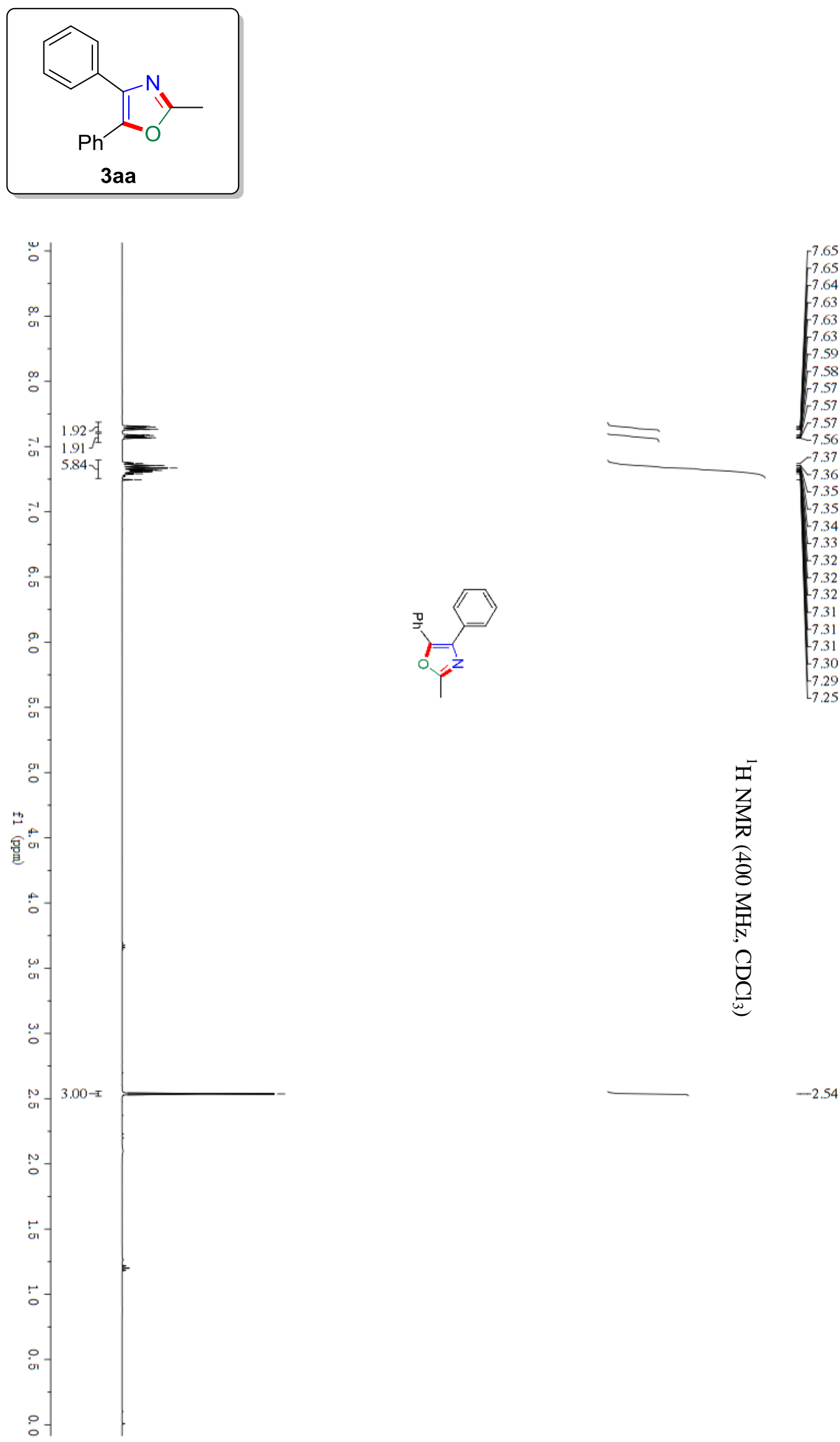

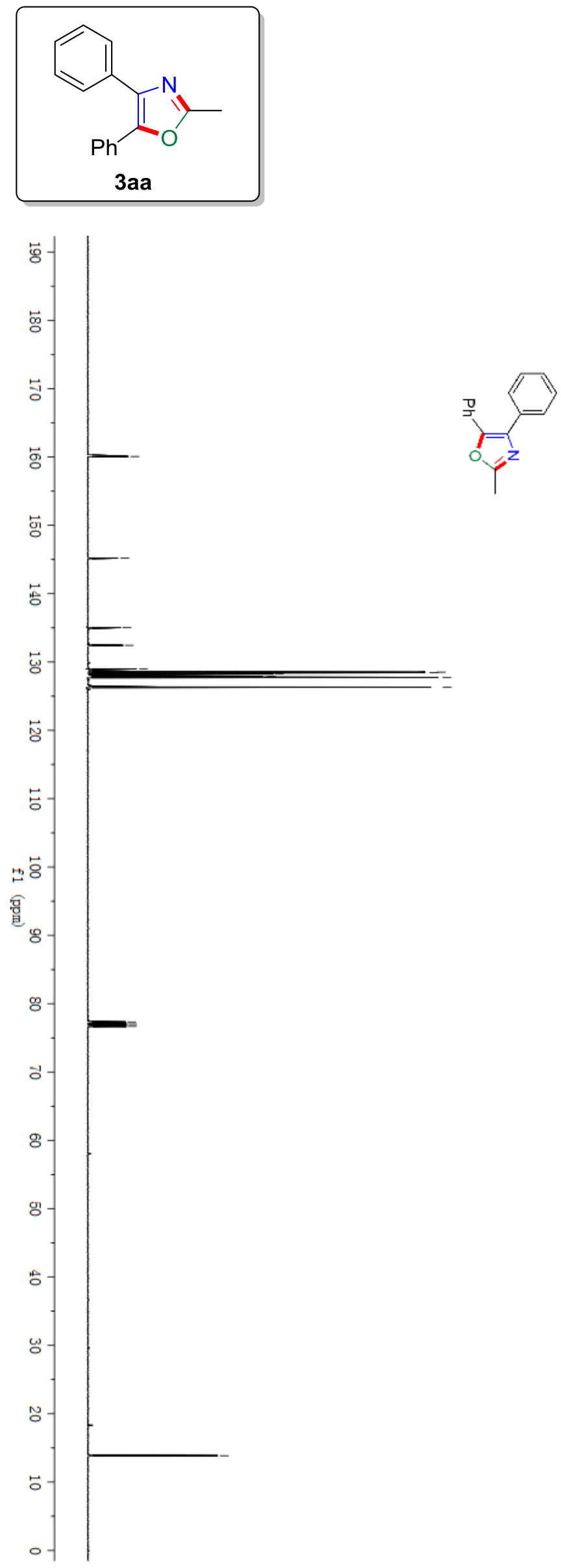

$-160.07$

$-145.21$

135.05 132.44 $\begin{array}{r}128.99 \\ \hline\end{array}$

$-128.52$

$-128.43$

$-128.25$

127.89

127.75
126.33

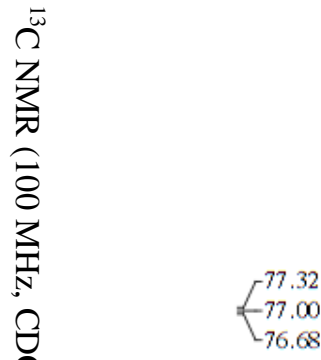



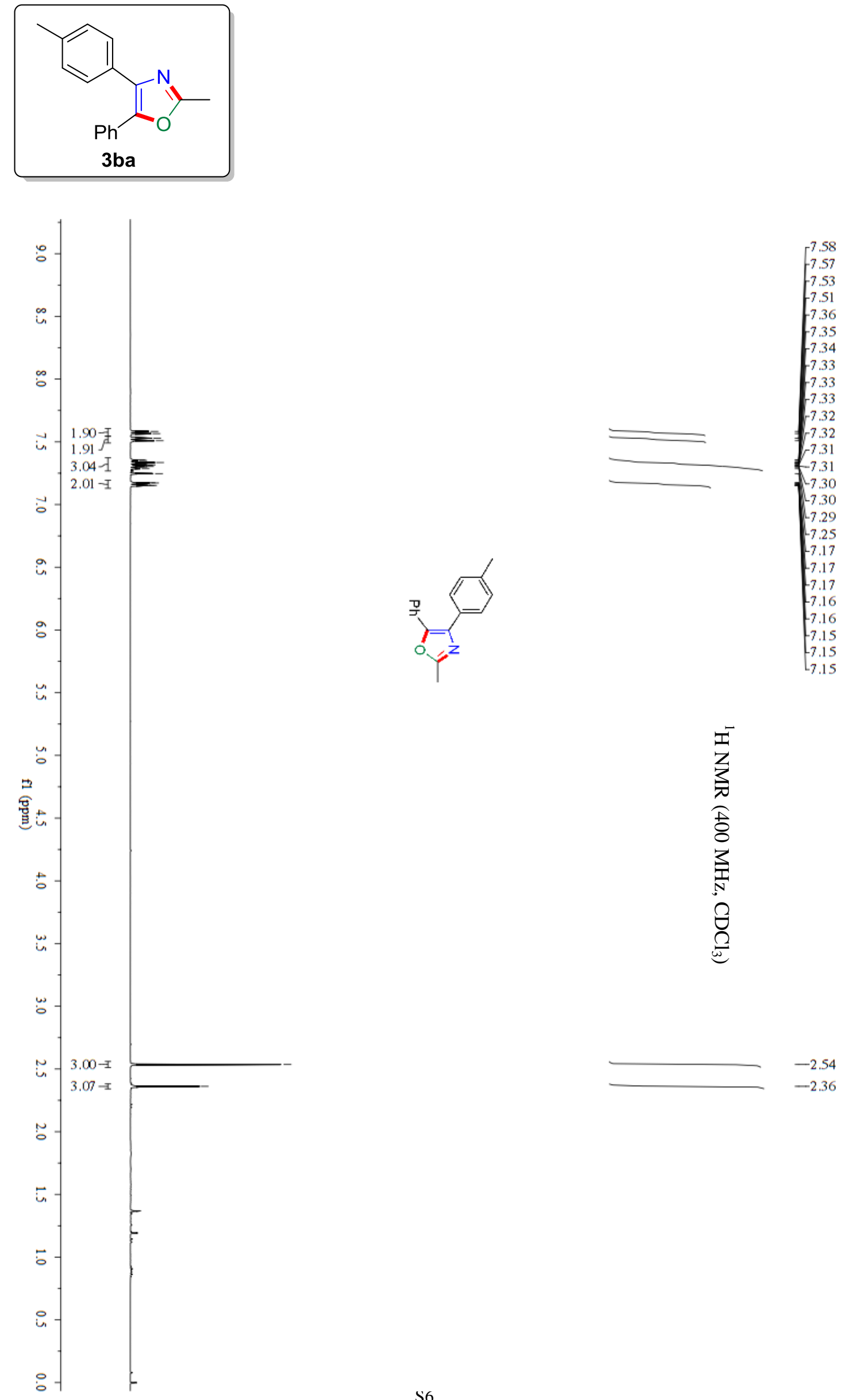

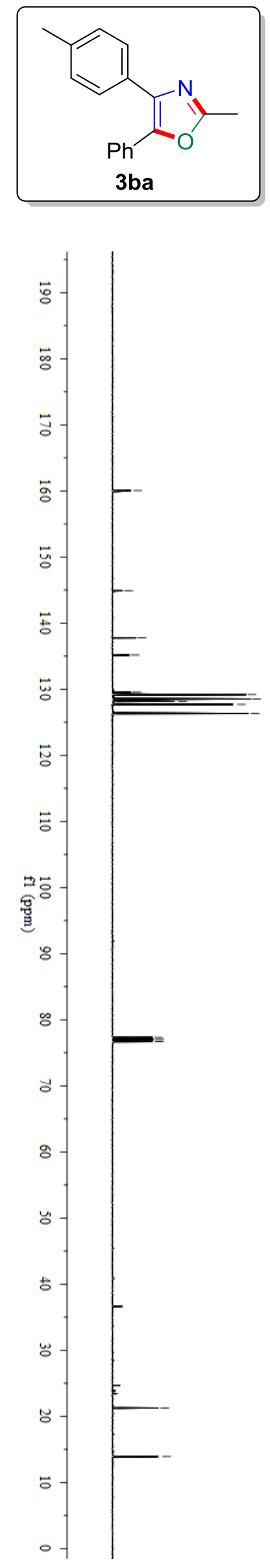

$-160.06$

$-144.92$

137.76

$\int_{[135.17}$

129.54

$-129.19$

- 128.54

$-128.17$

$-127.70$

77.32
-77.00
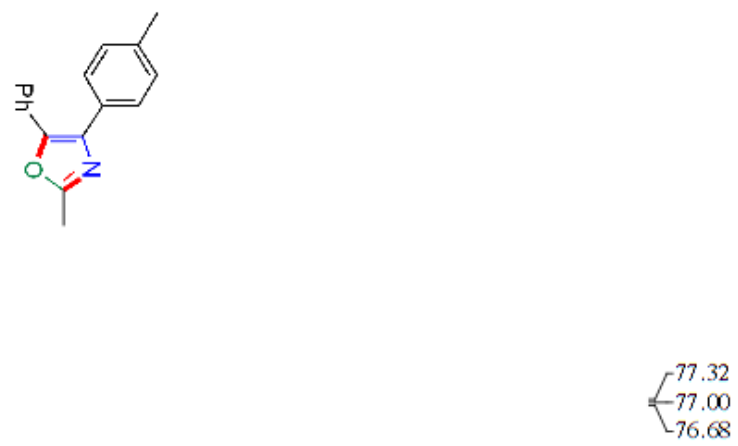

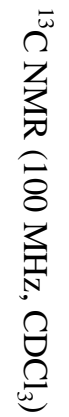

$-21.27$

$-13.91$ 

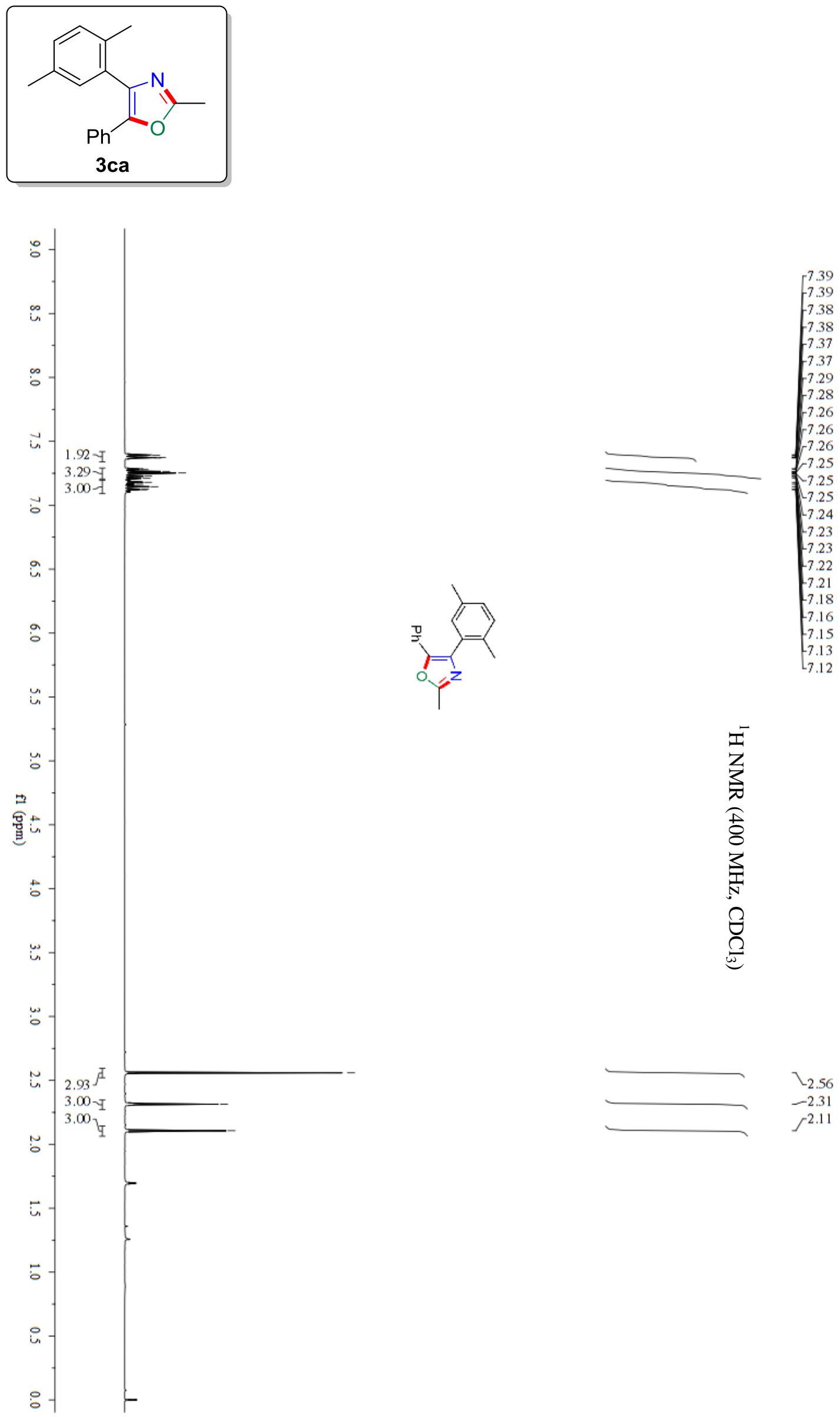

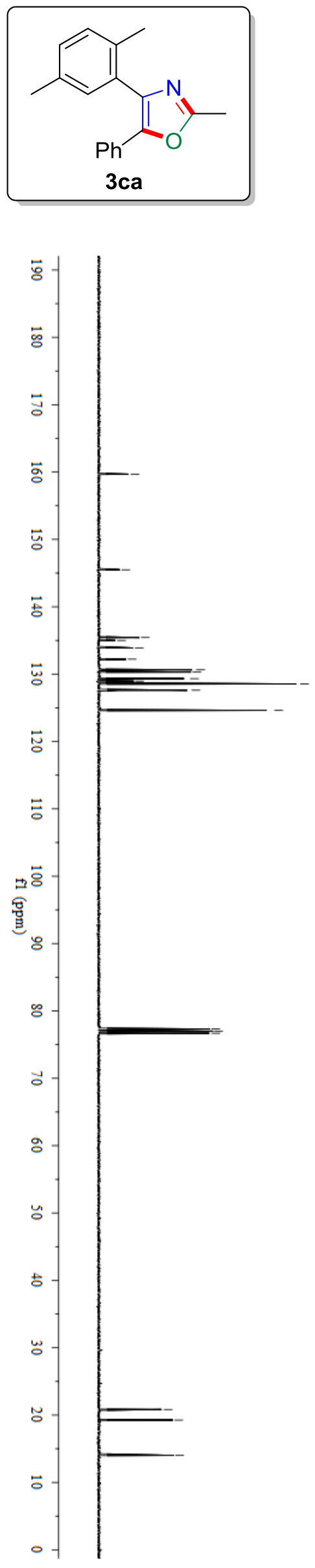

$-159.69$

135.44 $-135.00$ f) 133.89

132.22
130.65

率 130.30

$-129.33$

$-128.95$

-128.54
-127.61

$-124.62$

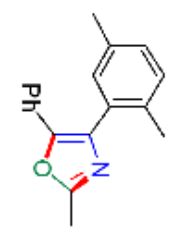

$\left\{\begin{array}{l}77.32 \\ -77.00 \\ 76.68\end{array}\right.$

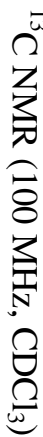



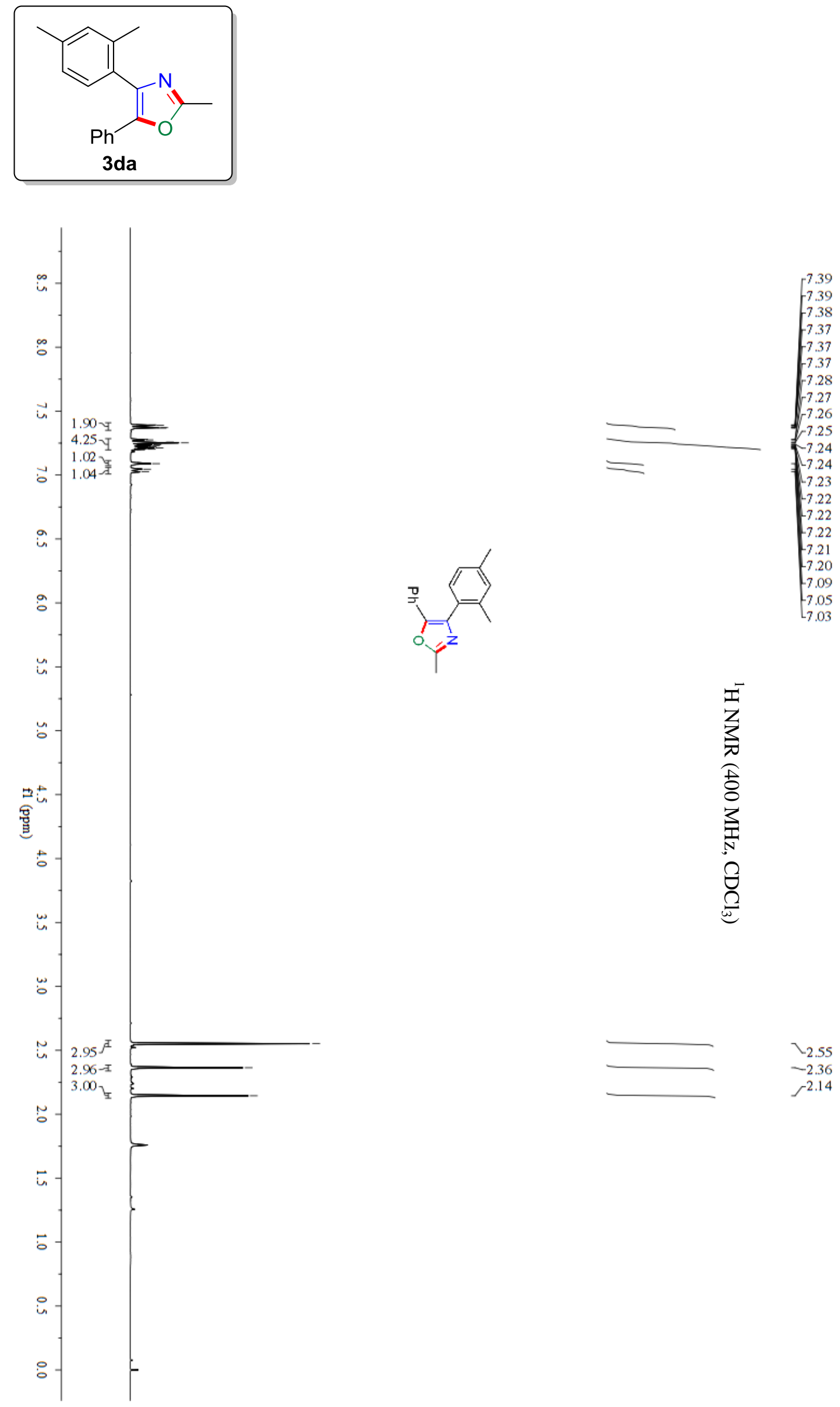

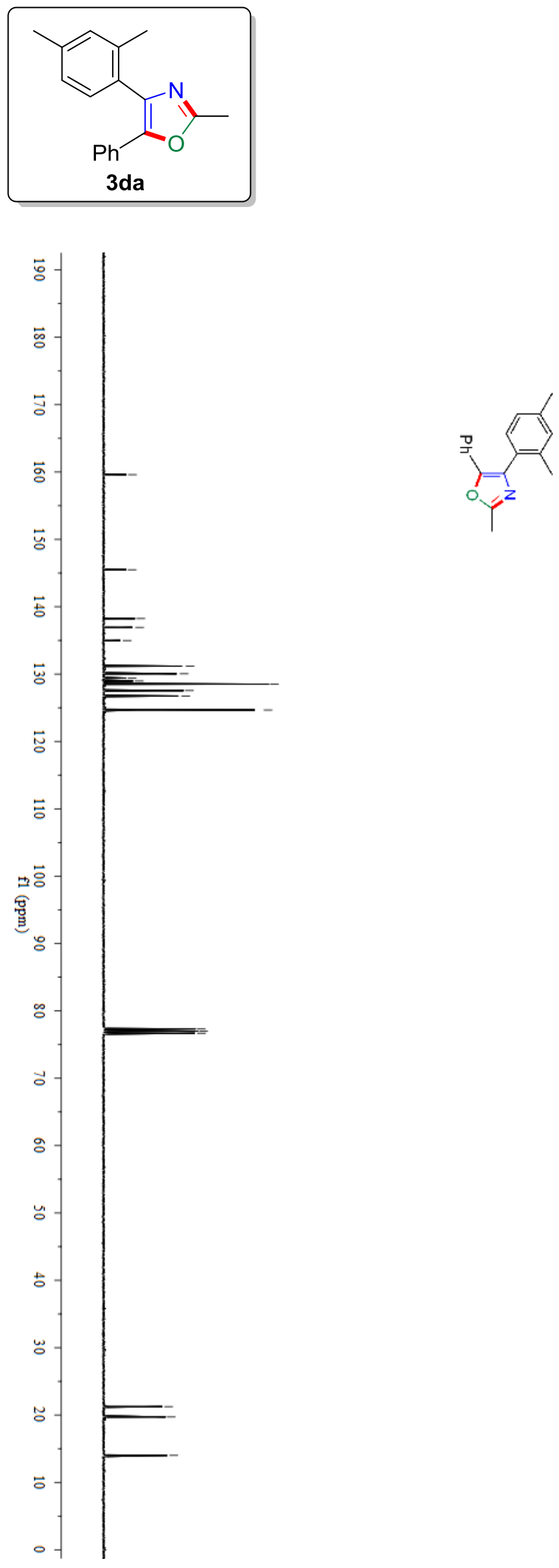

$-159.61$

$-145.50$

138.25

] 136.94 J 134.98

$\Gamma_{-130.05}^{131.19}$

-129.41
-128.97

- 128.51

$-127.56$

$-126.75$

$-124.67$

77.32
-77.00

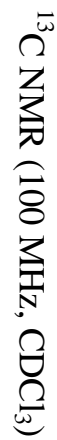

-21.25
-19.71

$-14.01$ 

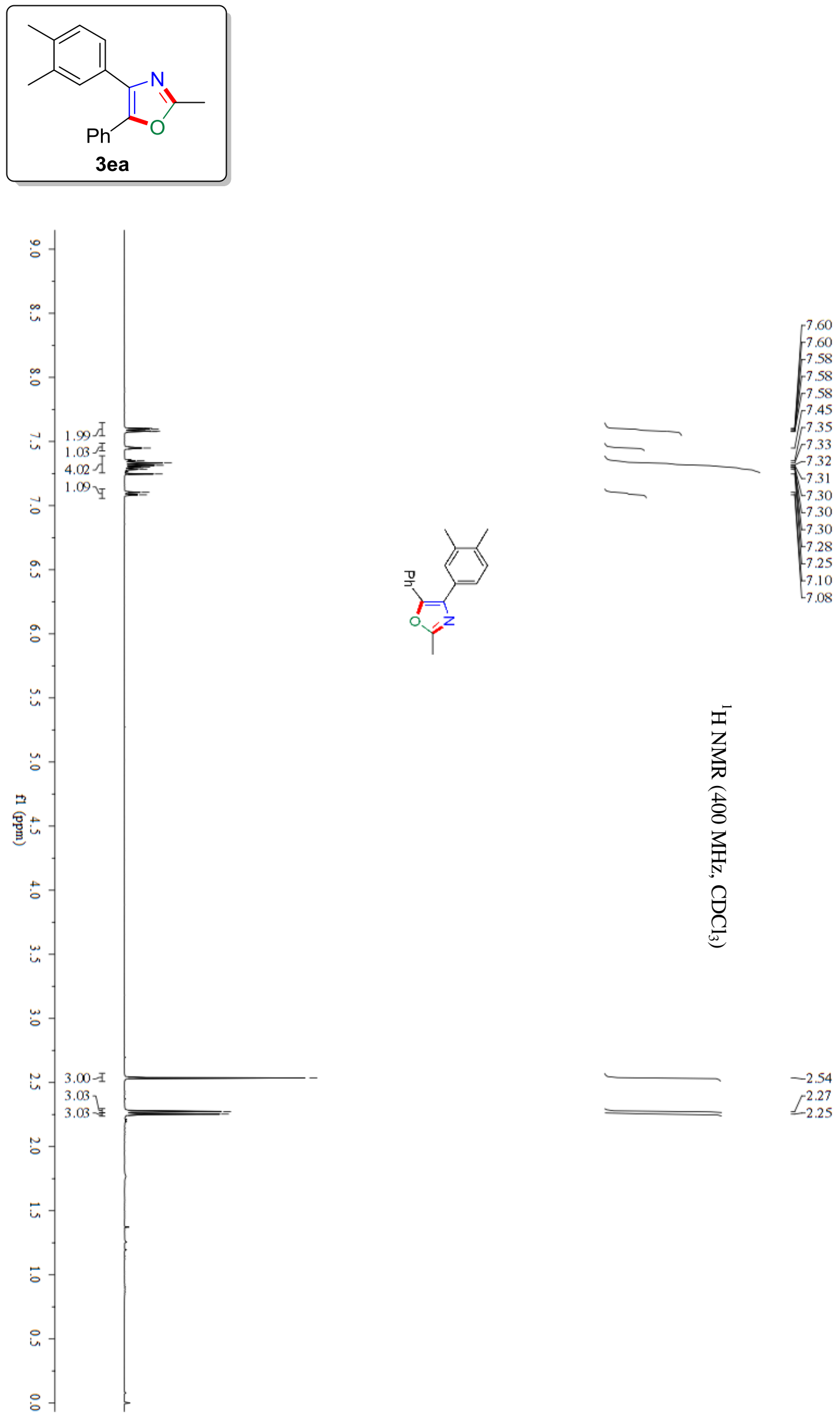

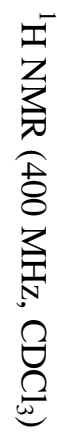



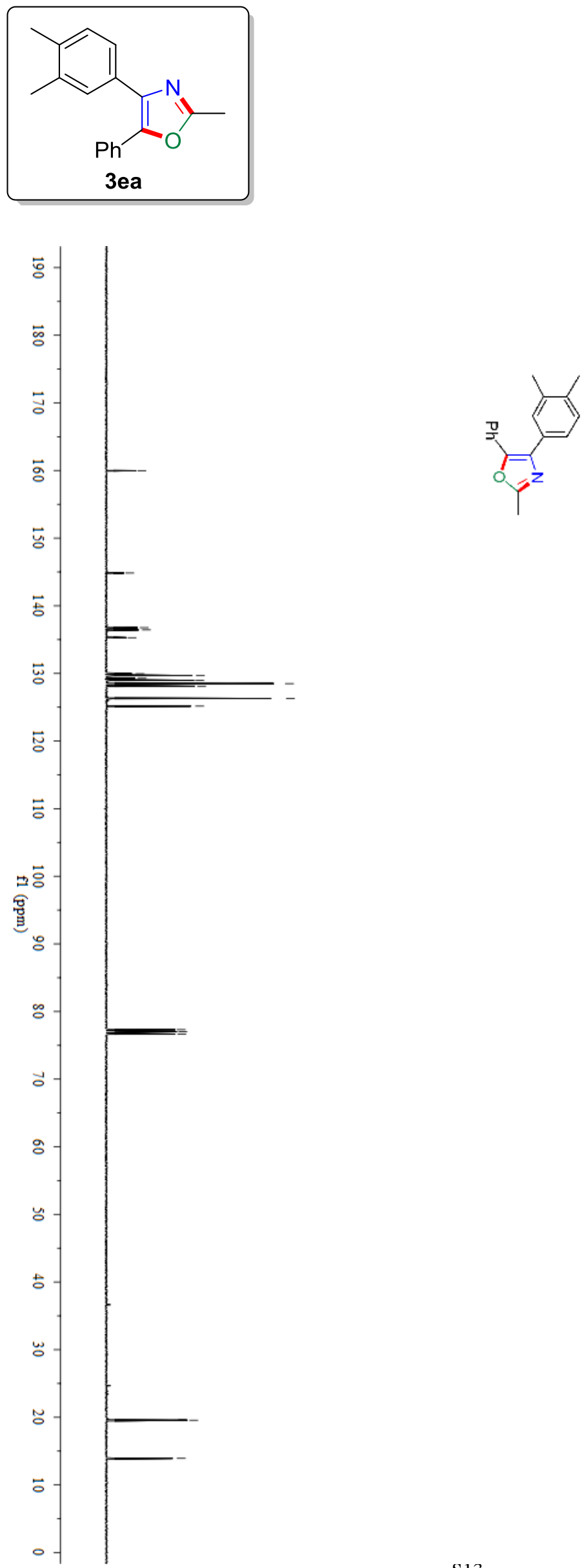

$-159.98$

$-144.84$

136.76
-136.44

136.44
-135.28

129.95

$-129.68$

$-129.27$

$-128.97$

$-128.49$

$-128.10$

125.16

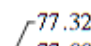

$\int_{-77.00}^{77.32}$

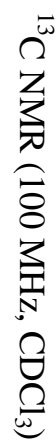

${ }_{-76.68}^{-77.00}$

$K_{19.56}^{19.63}$

$-13.93$ 

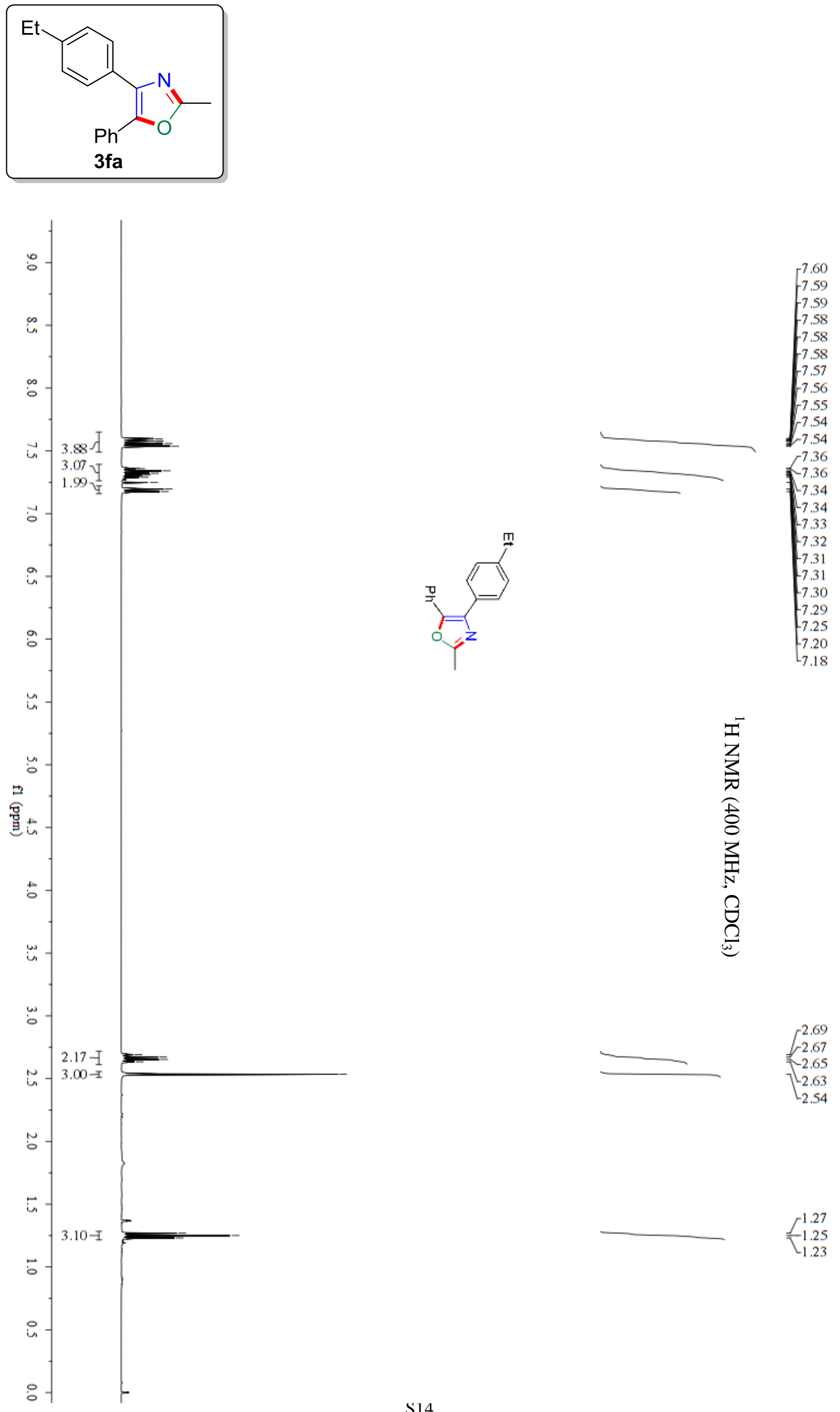

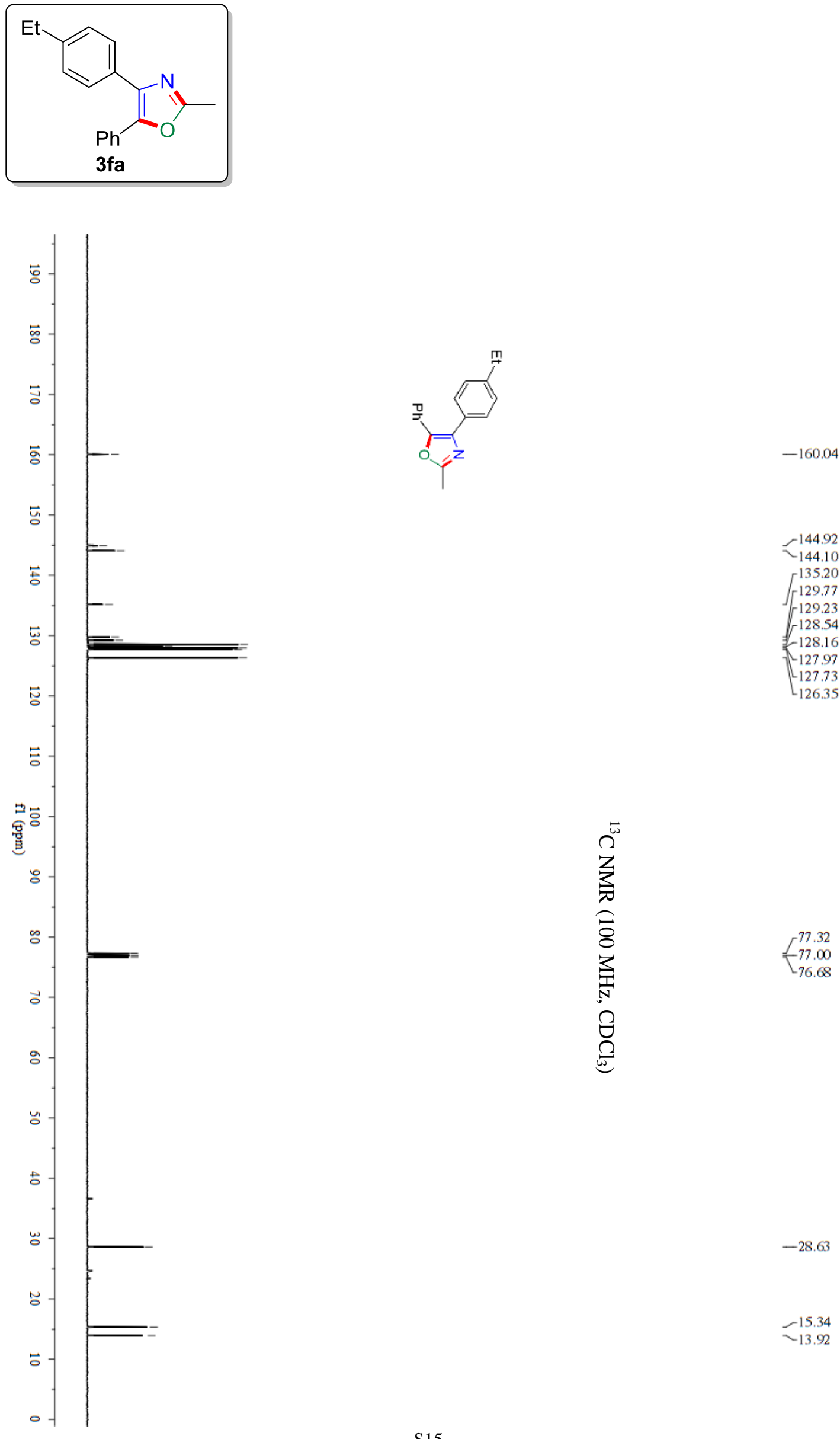

$-144.92$

$-144.10$ 135.20
129.77 129.77 129.23 $-128.54$ b) 128.16

$-127.97$

$-127.73$

126.35

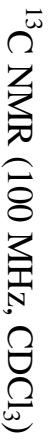

$\left\{\begin{array}{l}77.32 \\ -77.00\end{array}\right.$

$\backslash_{76.68}$

$-28.63$

$-15.34$

$\sim 13.92$ 

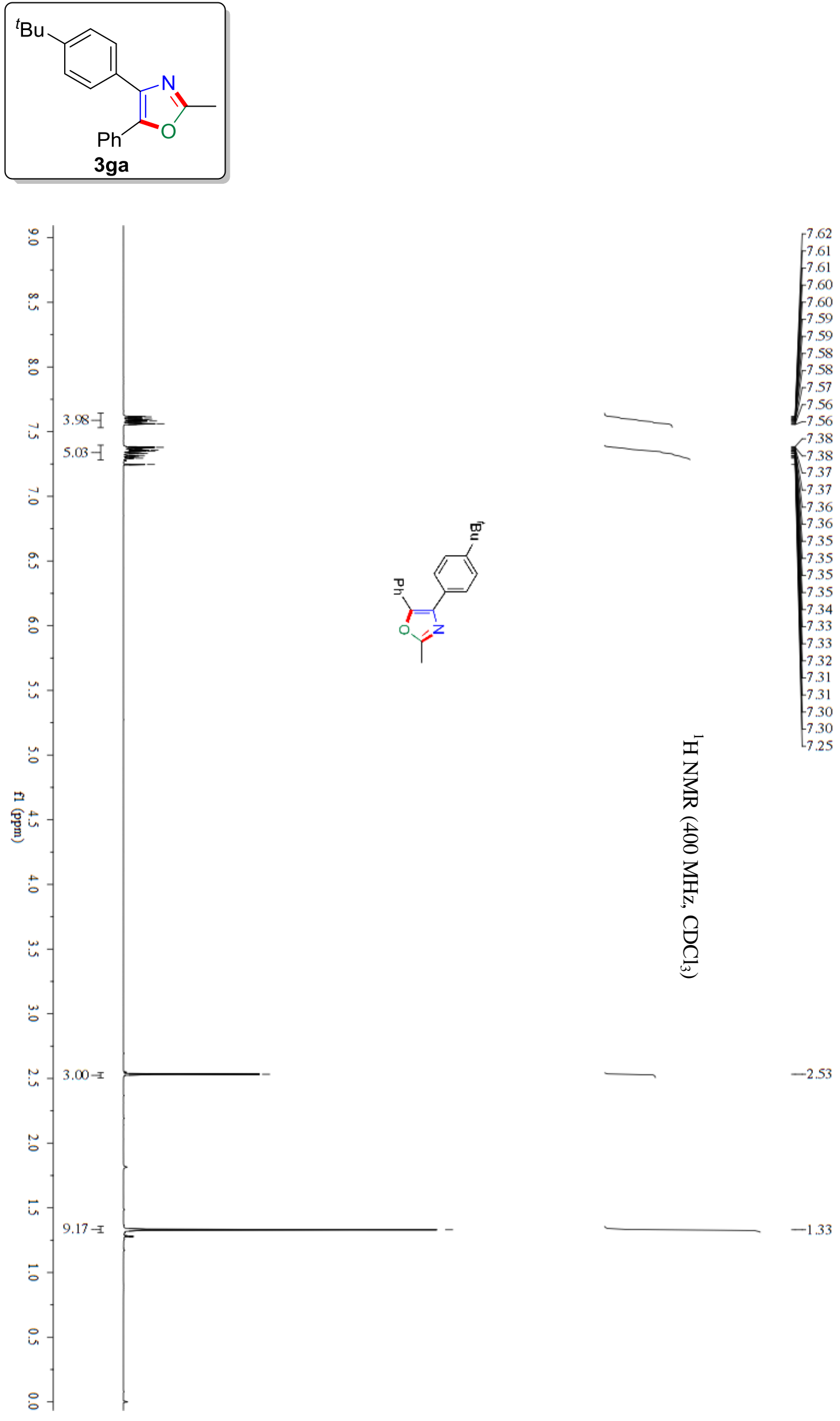

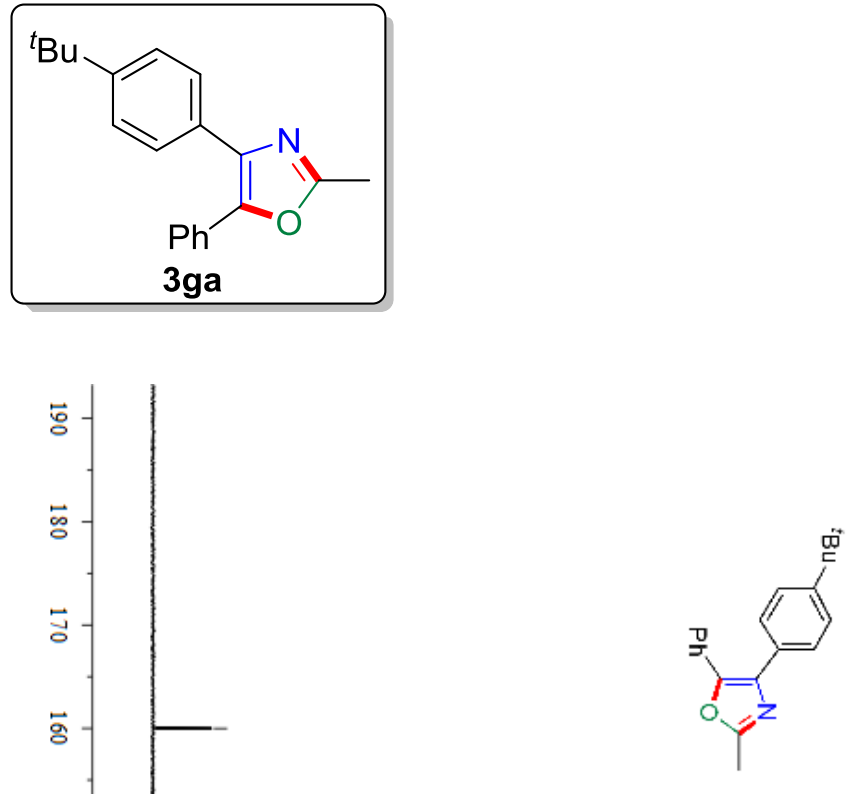

$-159.99$

$-150.96$

$-144.94$

135.12

$-129.52$

129.30

$-128.55$

128.17

7. -127.37

$-126.41$

$L_{125.39}$

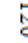

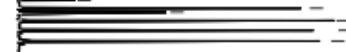

ت

它

密

兽

\%

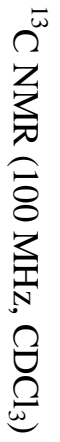

77.32
$-\quad 77.00$

$\backslash 76.68$

$-34.62$

$-31.27$ 

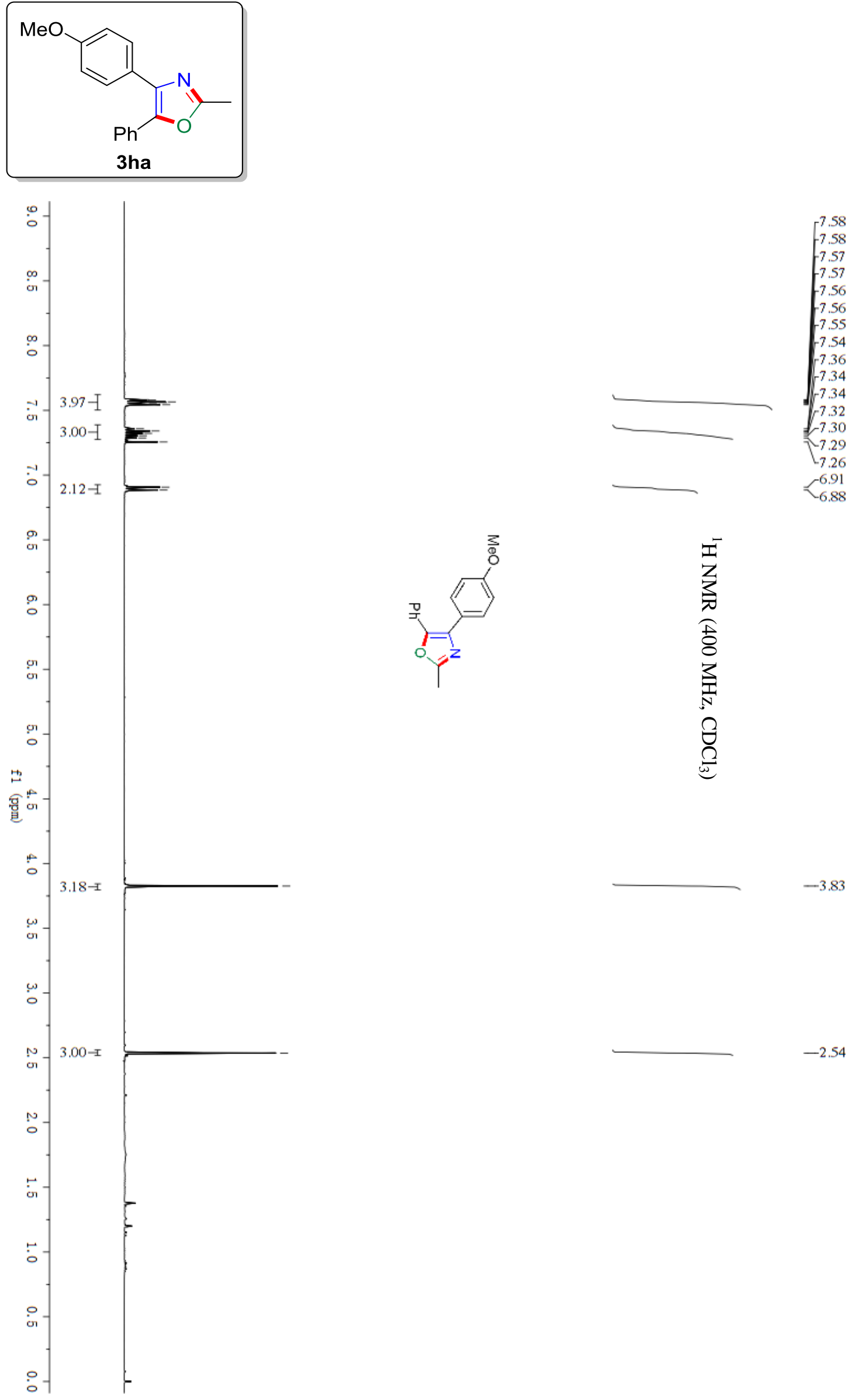

$-3.83$ 

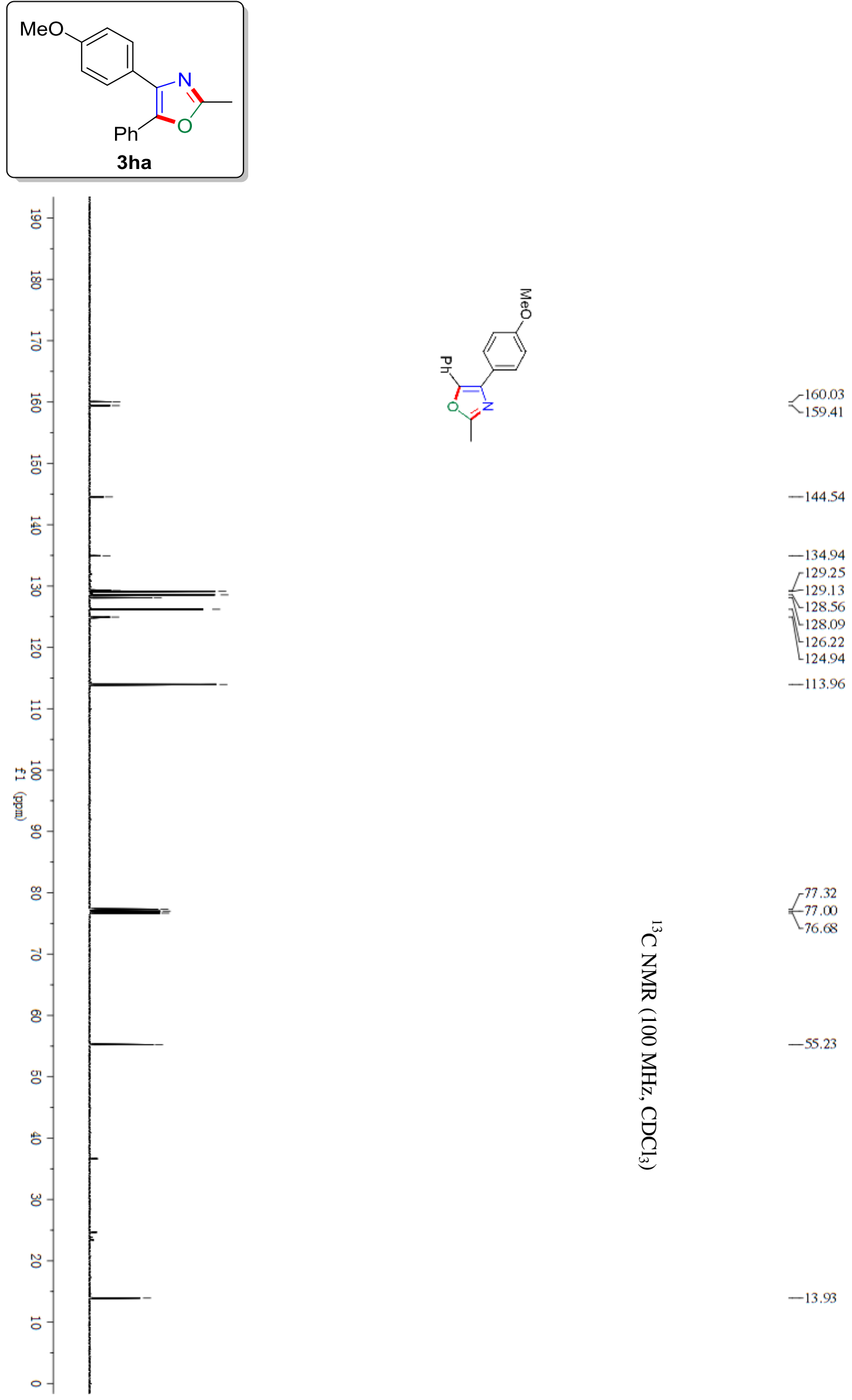

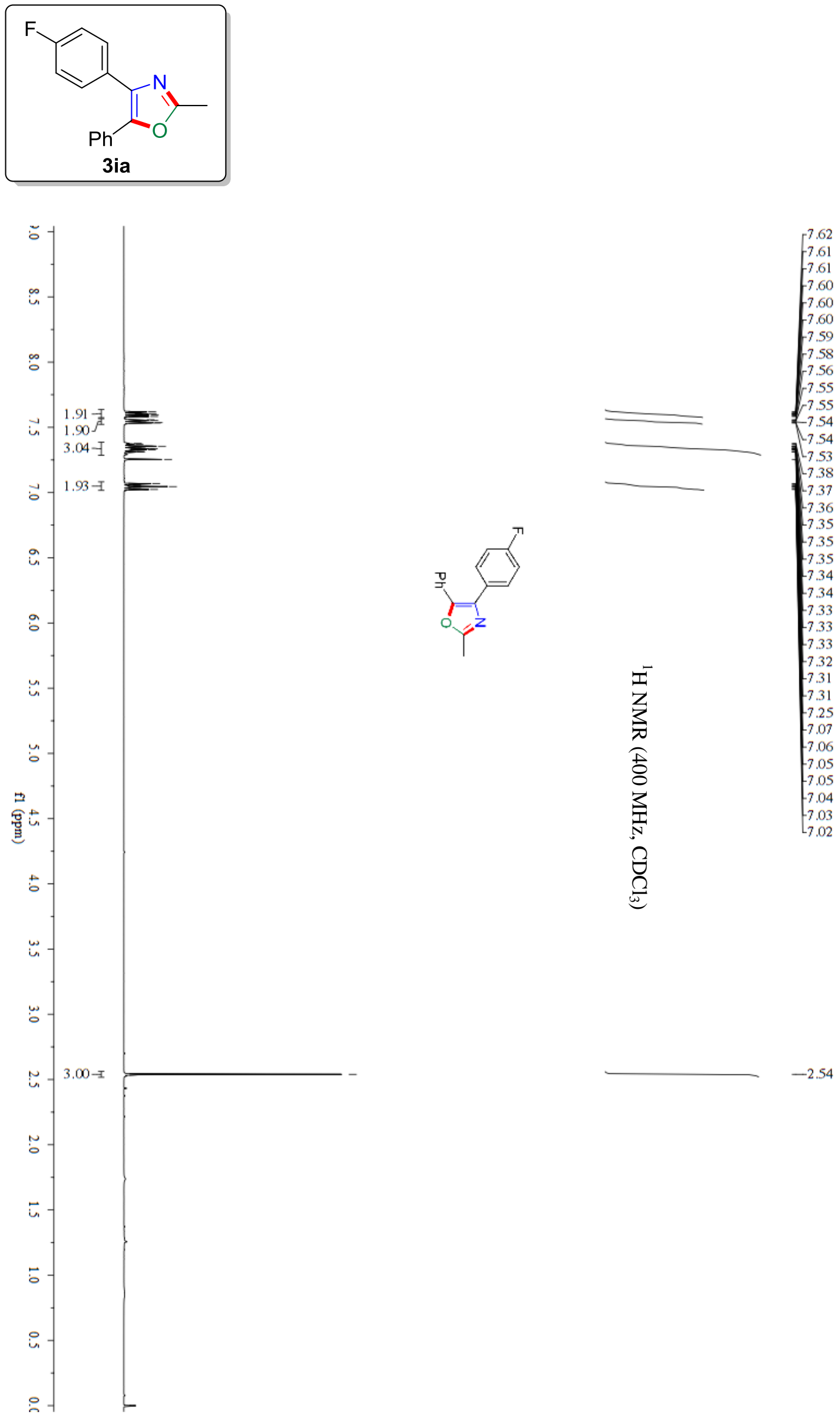

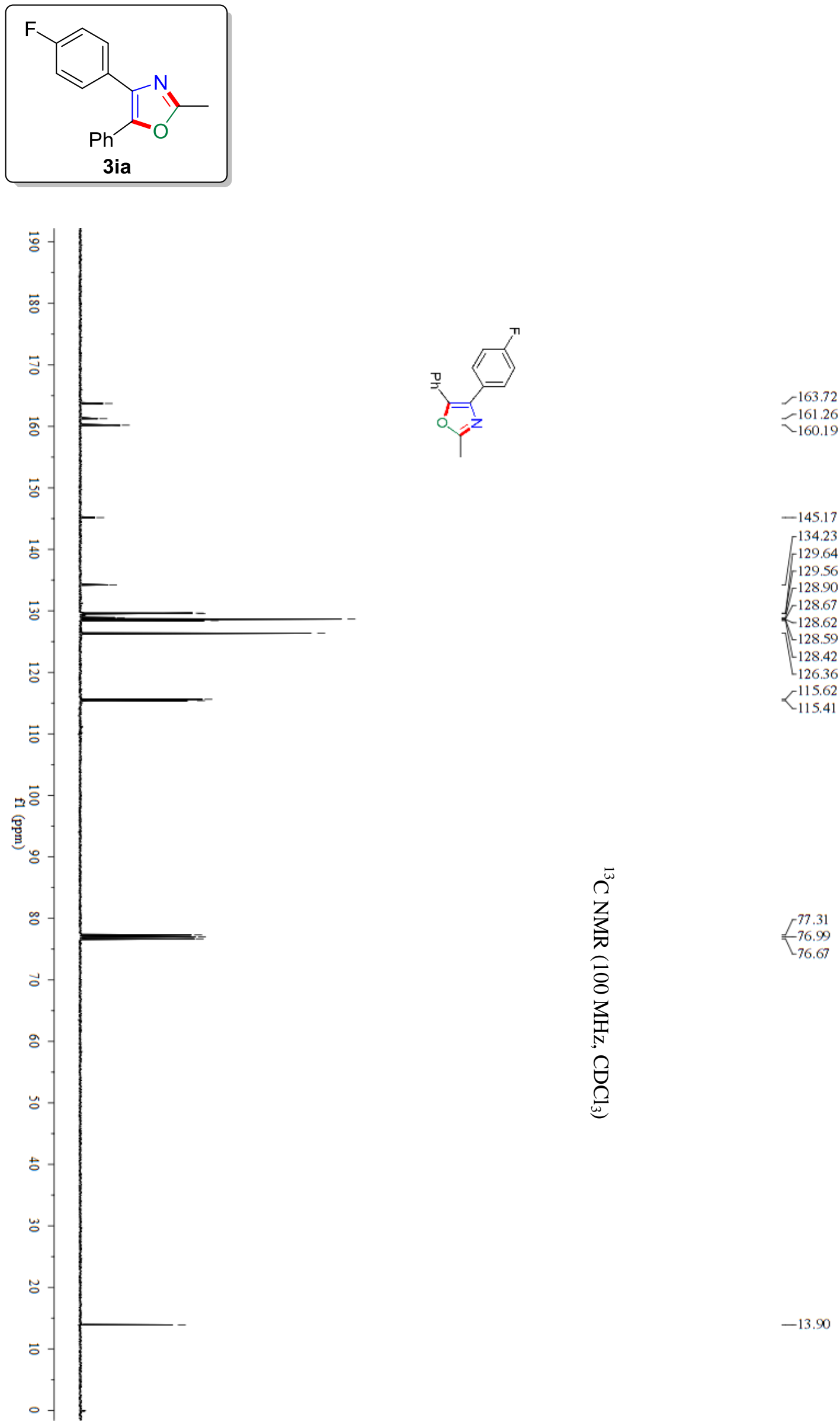

$-161.26$

$-145.17$

$-134.23$

$-129.64$

$-129.56$

$-128.90$

$-128.67$

$-128.62$

$-128.59$

$-128.42$

$-126.36$

$\gamma_{115.41}^{115.62}$

3
3
0
0
0
0
0
0
0
0
0

77.31
-76.99

$\backslash 76.67$

$-13.90$ 

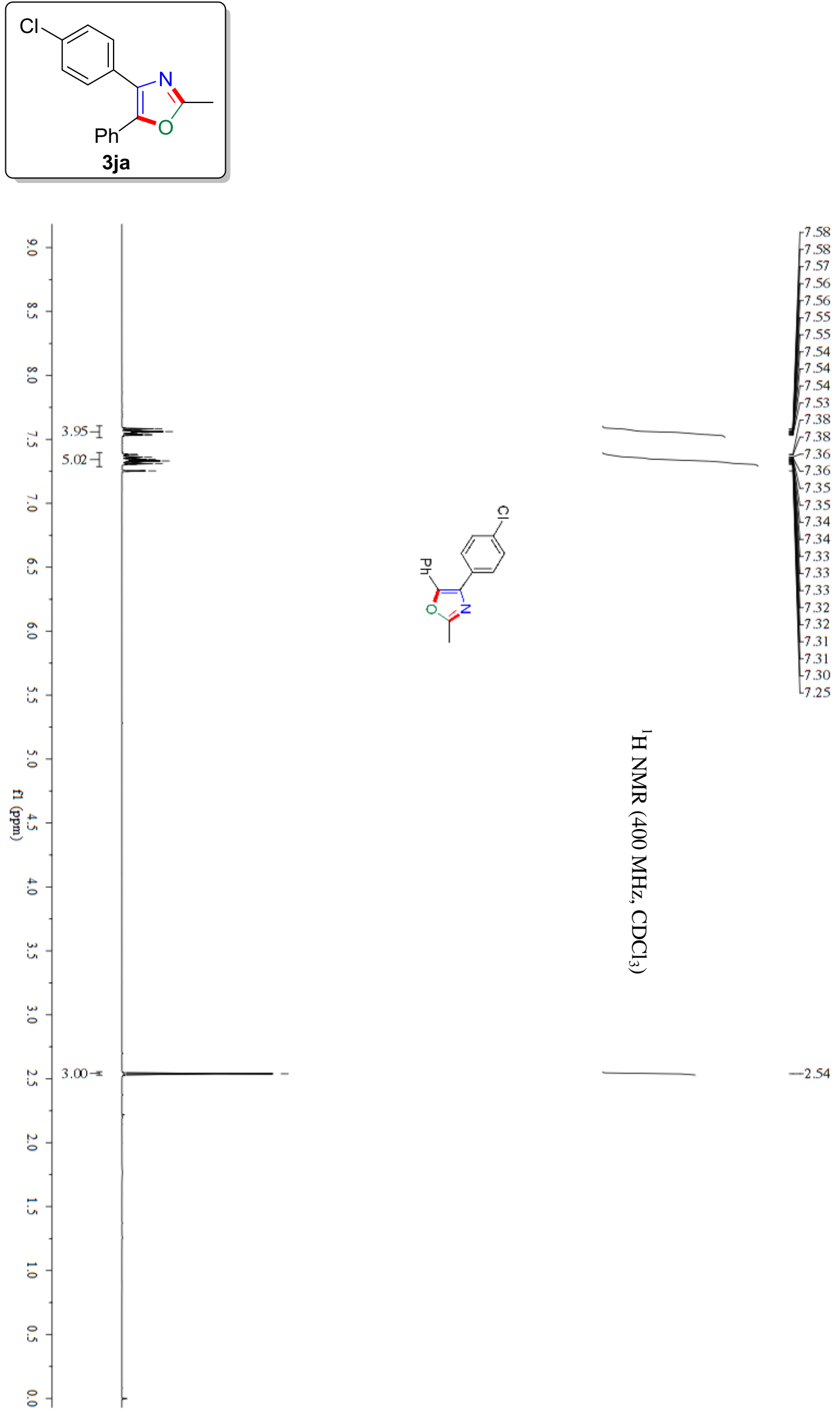

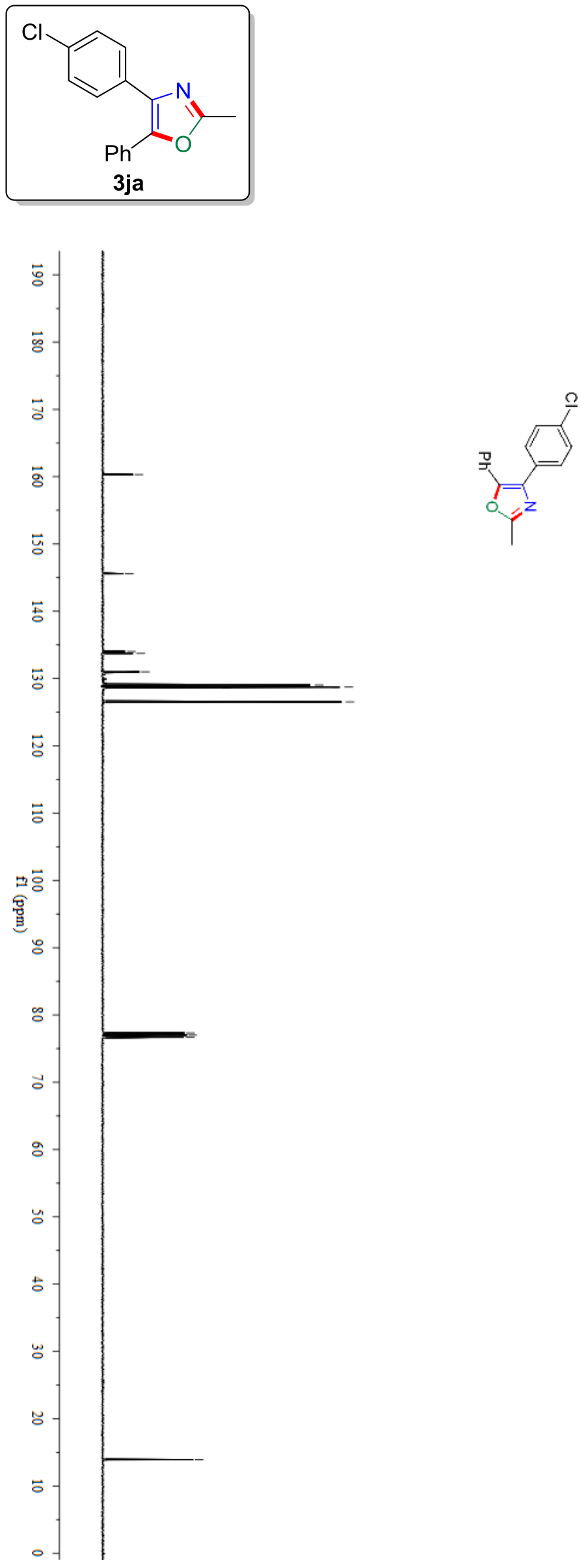

$-160.31$

$-145.56$

134.02

133.73

130.99

] 129.03

$-128.80$

$-128.73$

$-128.70$

$-128.59$
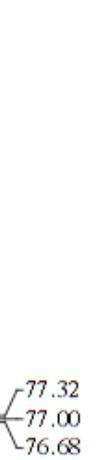

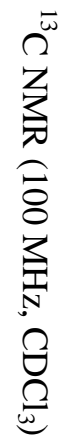



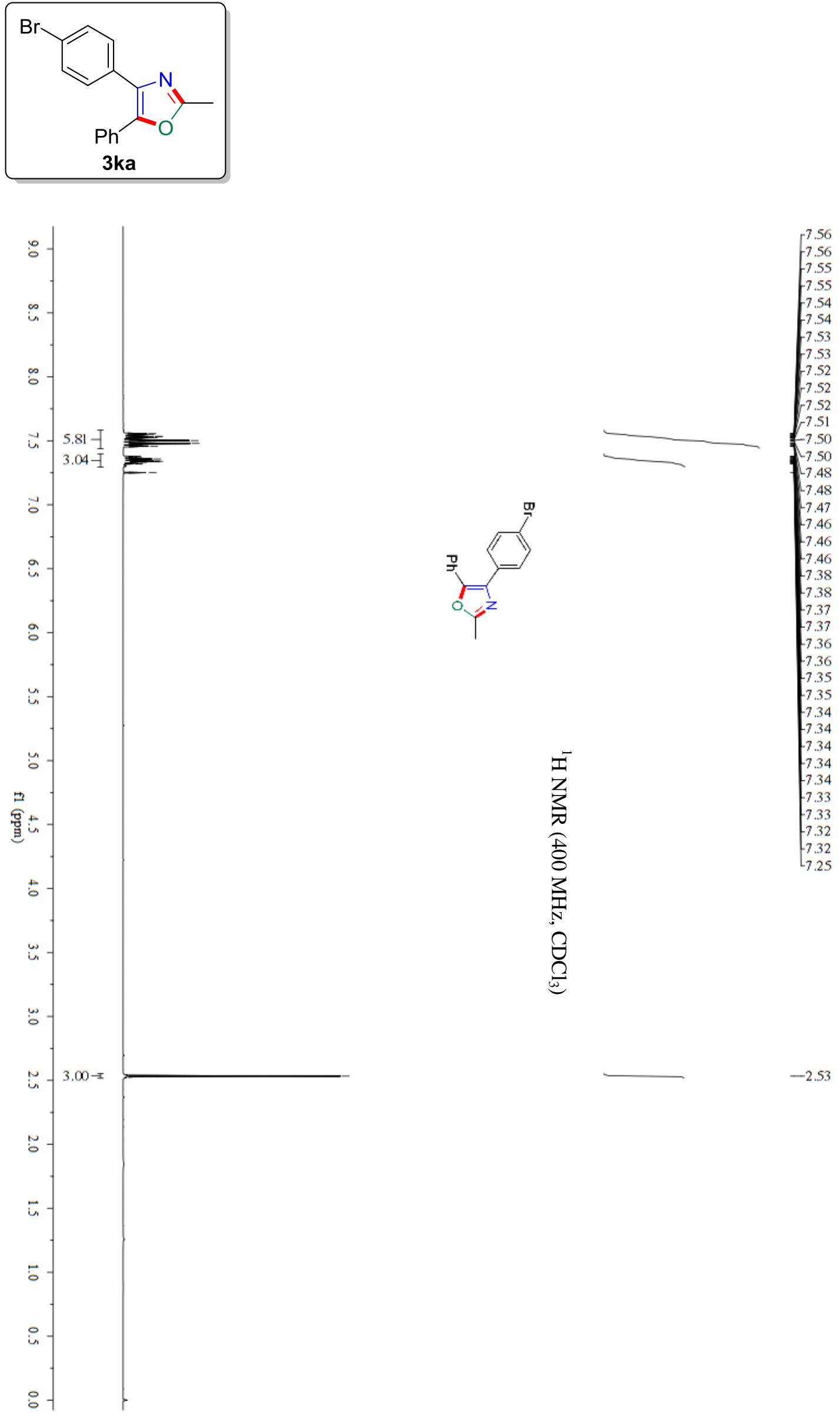

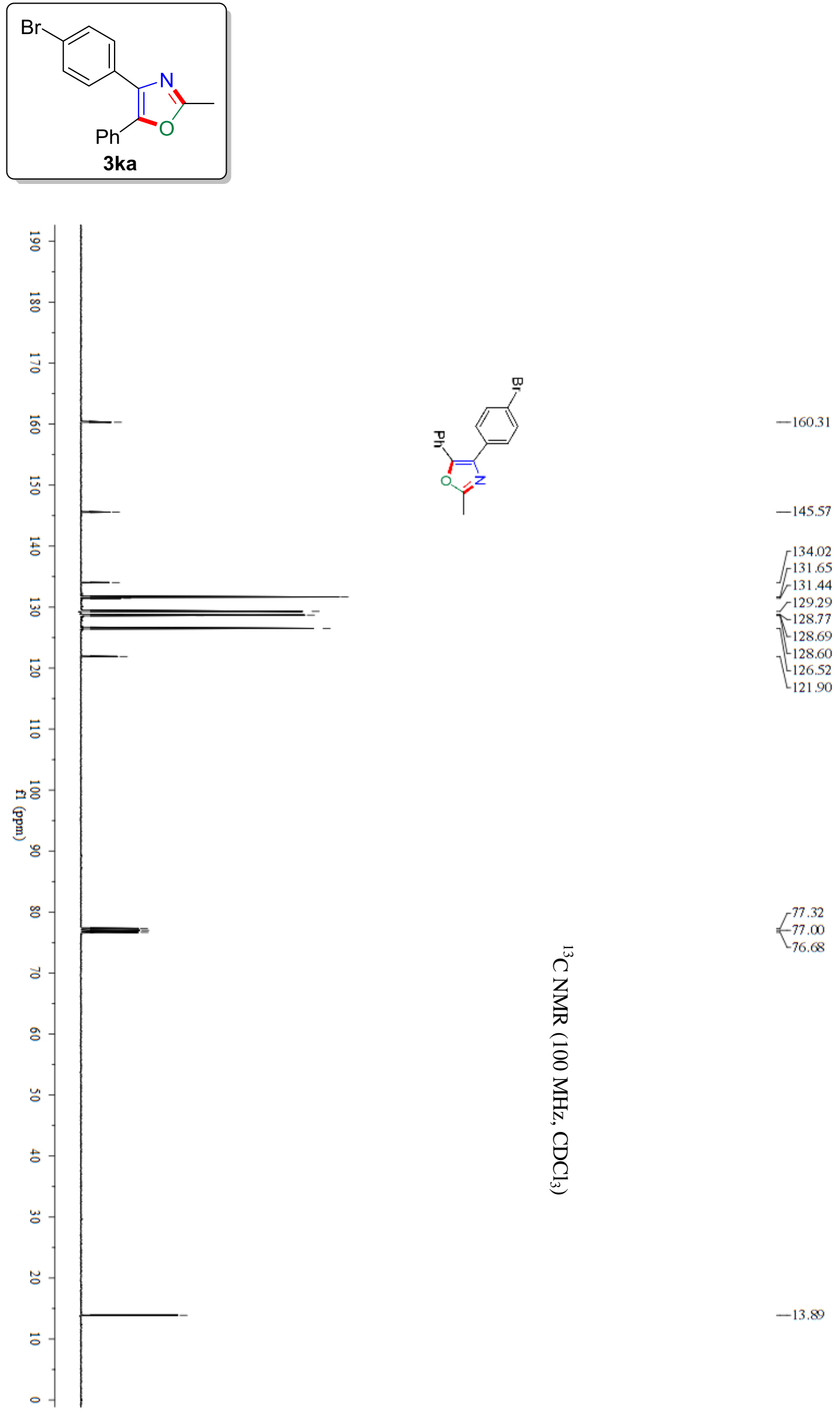

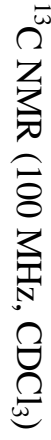

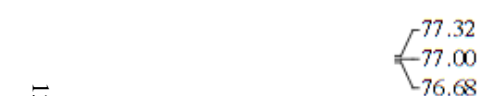



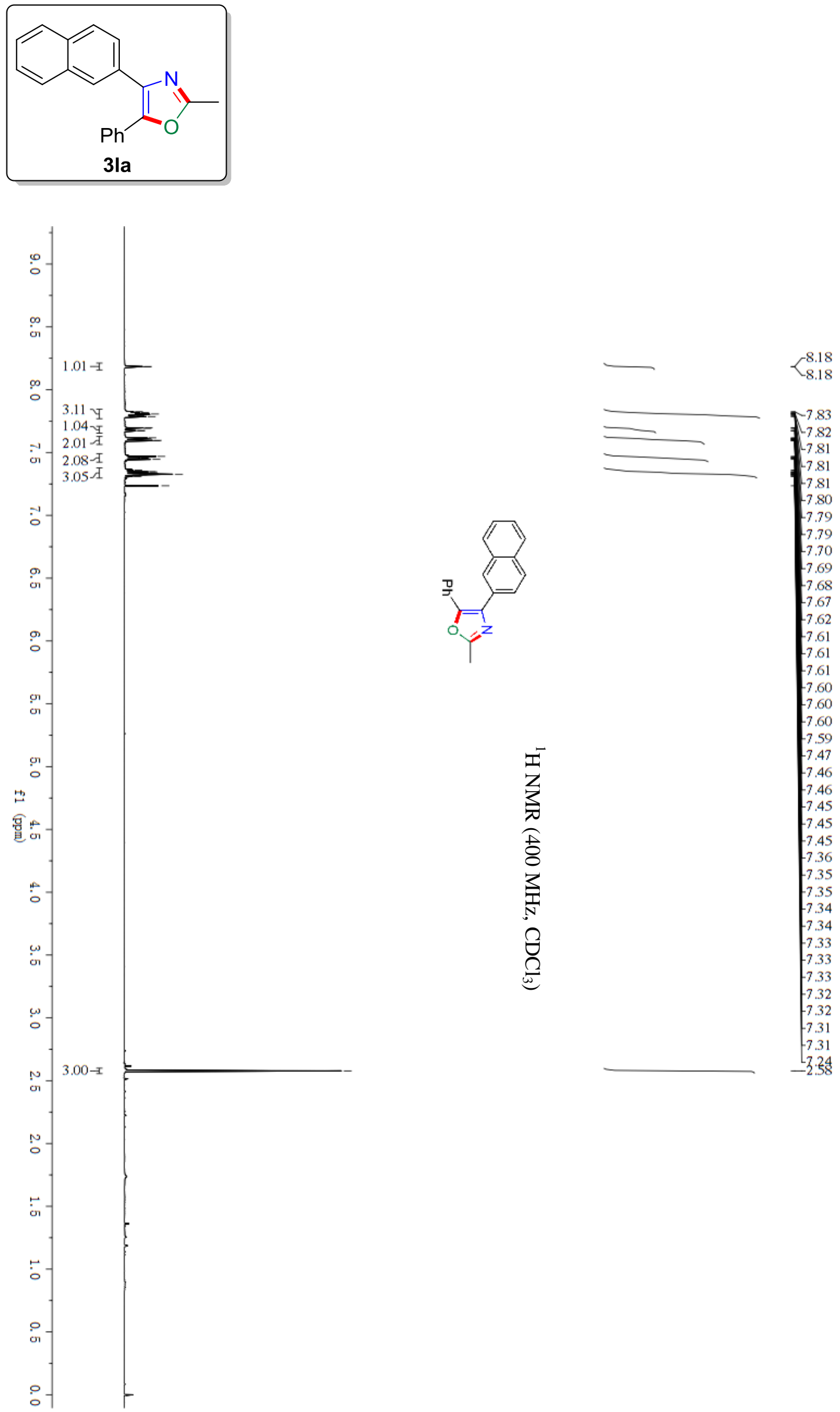

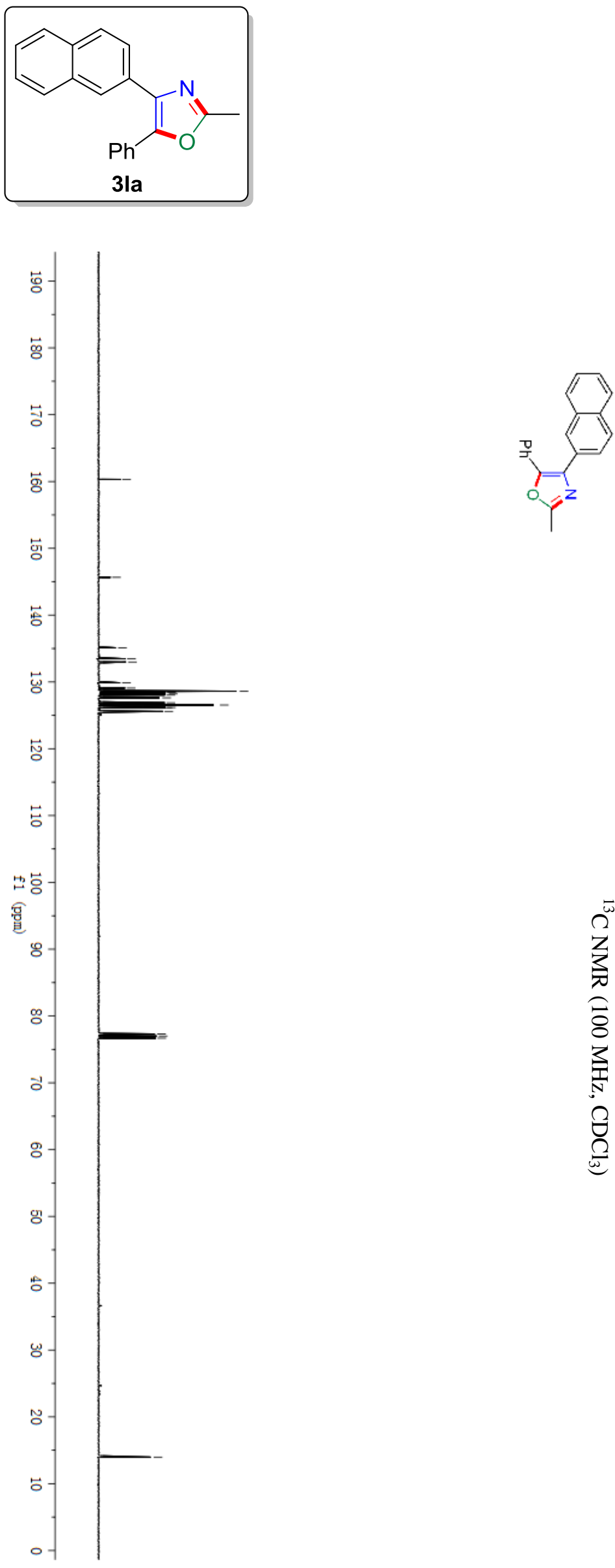

$-160.32$

$-145.65$

135.11
-133.46

133.46
-132.98

] 129.88

- 129.08

$-128.62$

$-128.44$

128.21

$-128.03$

$-126.54$

$-126.17$

$-126.14$

$-125.59$

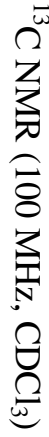

$\int_{-77.00}^{77.32}$

$-76.68$

$-13.97$ 

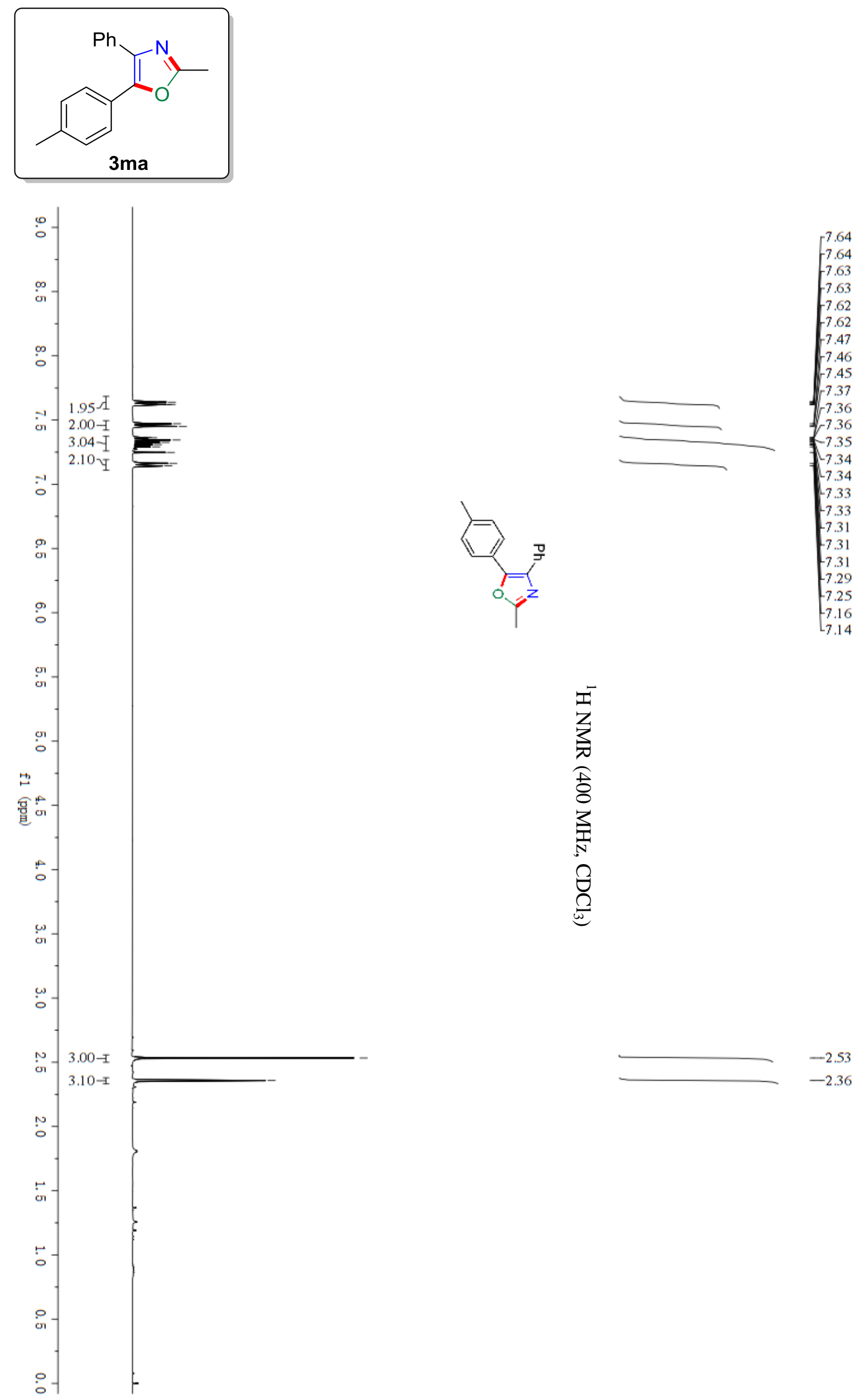

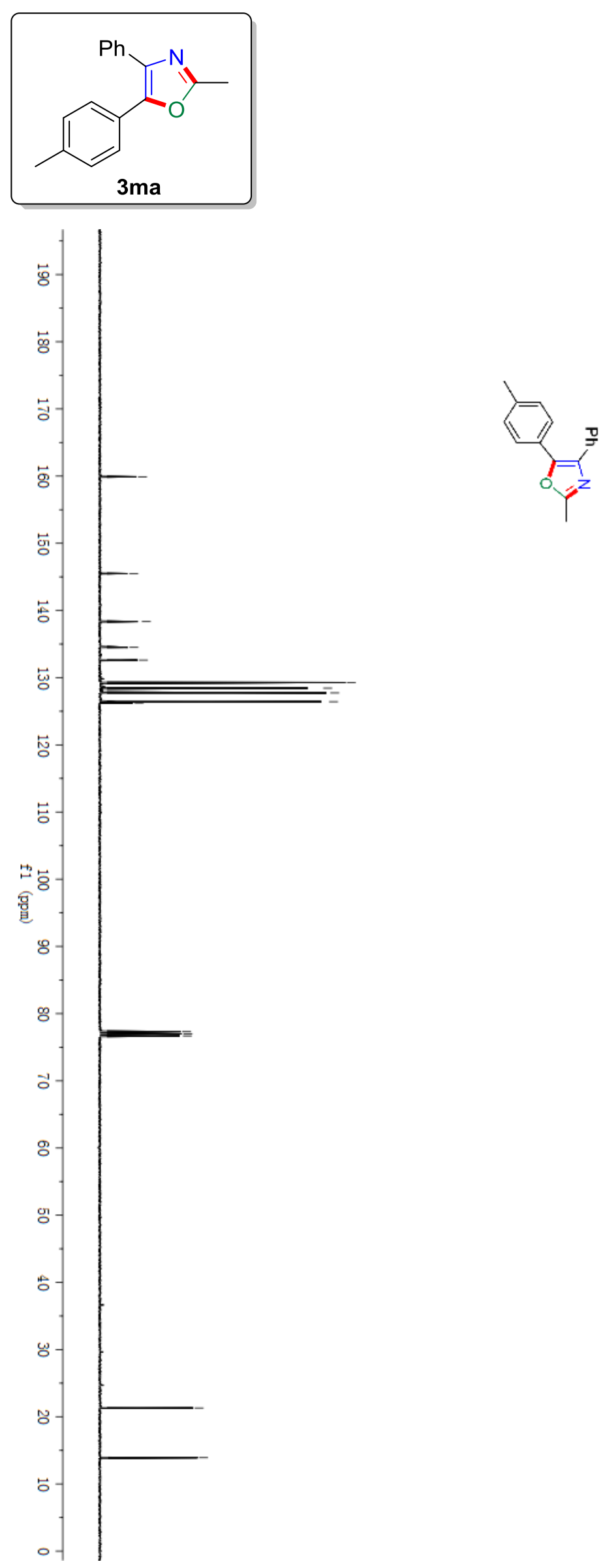

$-159.89$

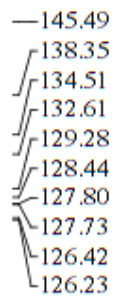

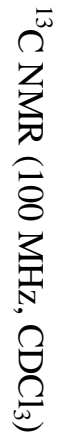

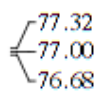

$-21.30$

$-13.91$

S29 

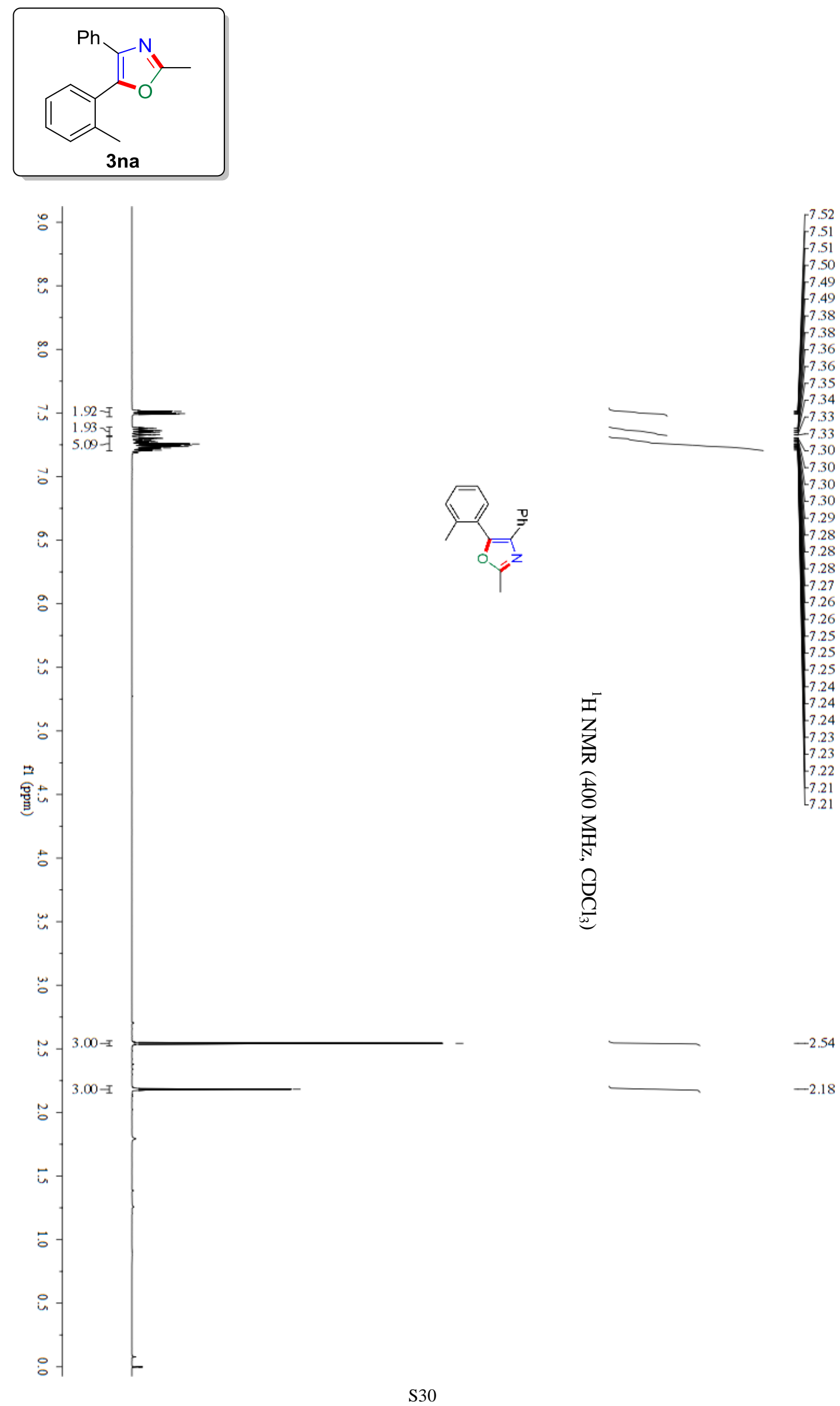

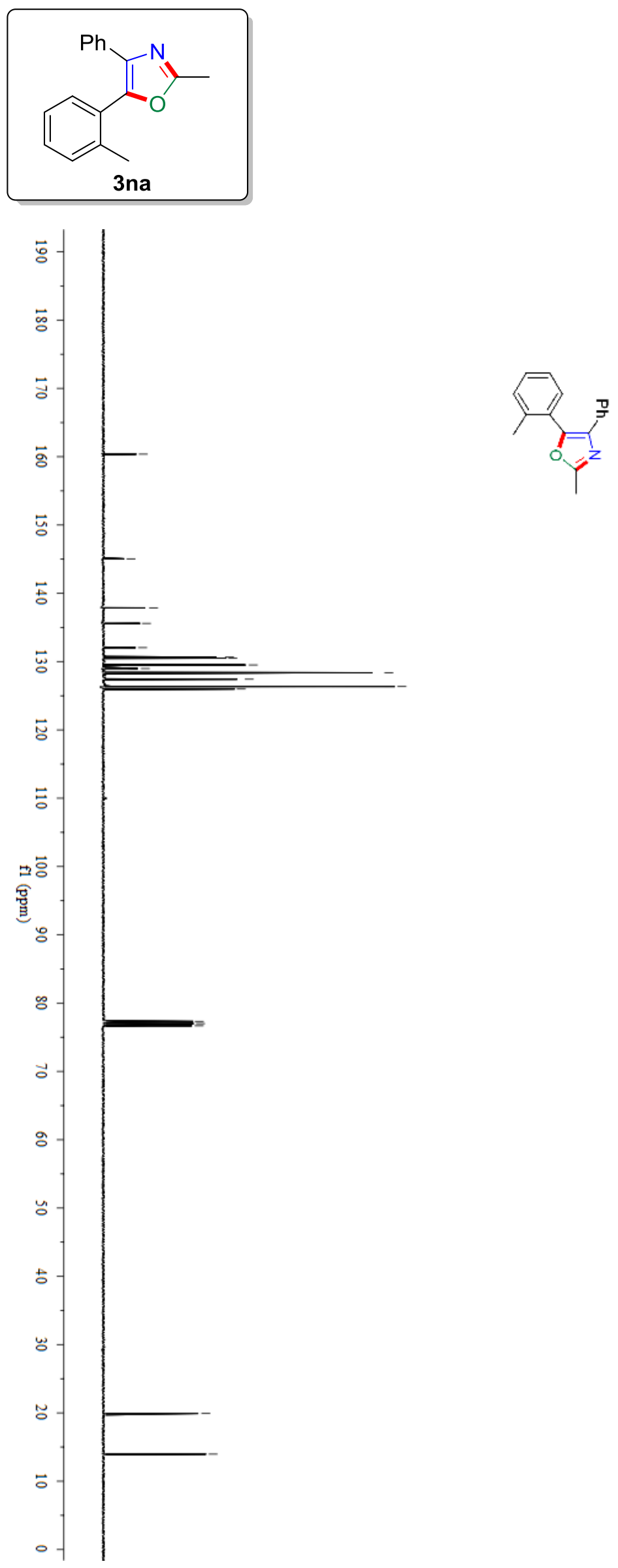

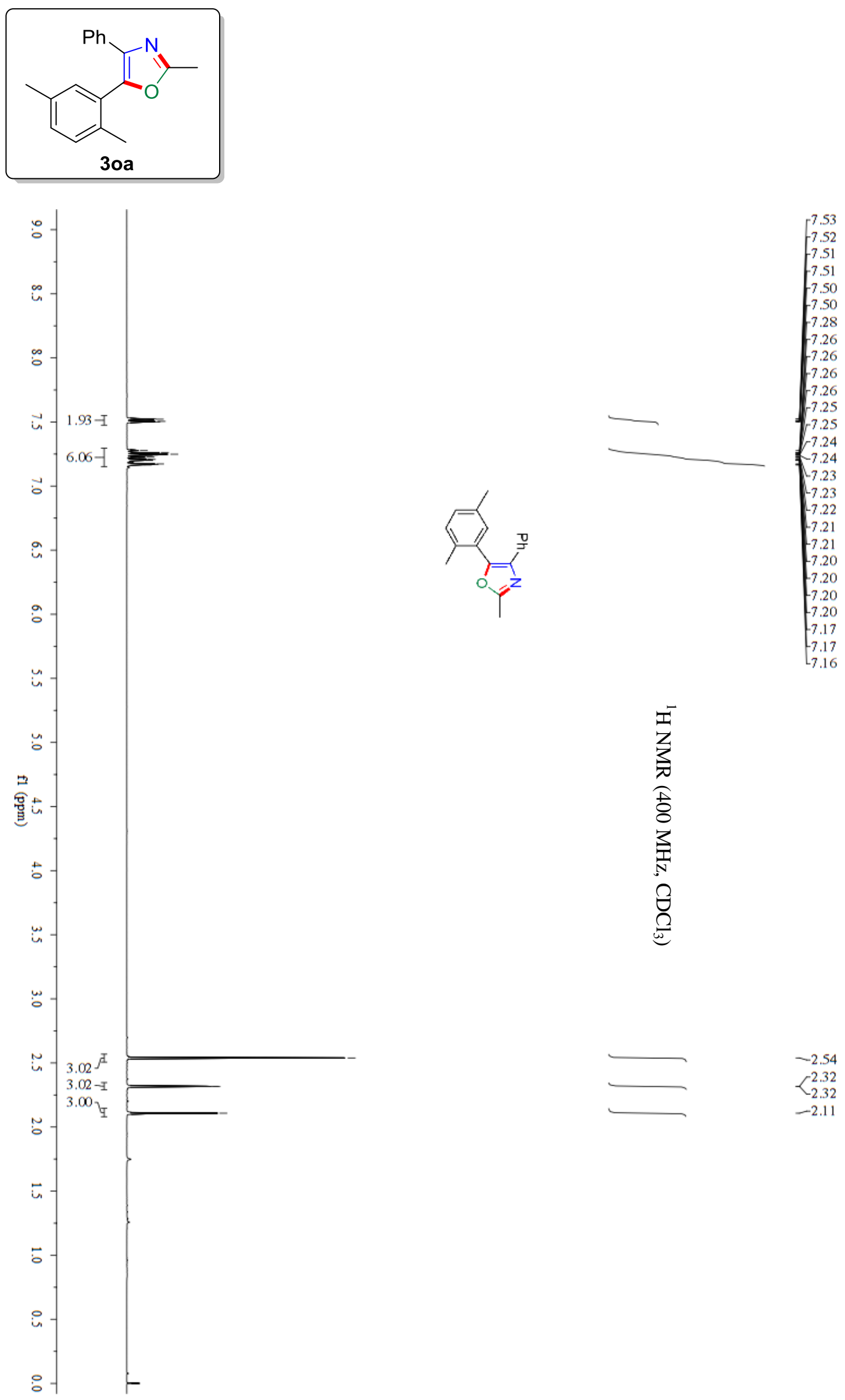

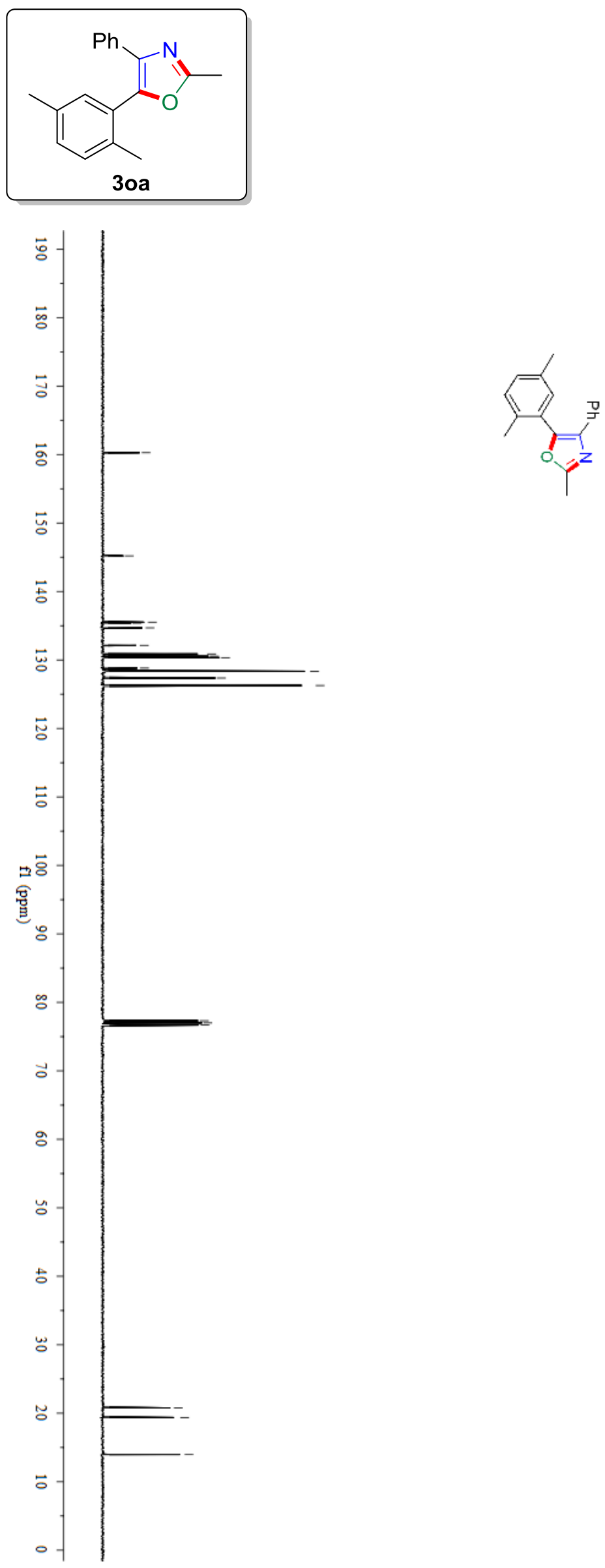

$-135.38$ f 134.69 $\sigma^{132.13}$

130.55

- 130.55

$-128.81$

$-128.36$

-127.36
126.27

3

$\left\{\begin{array}{r}77.32 \\ -77.00\end{array}\right.$

$-76.68$

$-20.78$

19.37
-13.96 

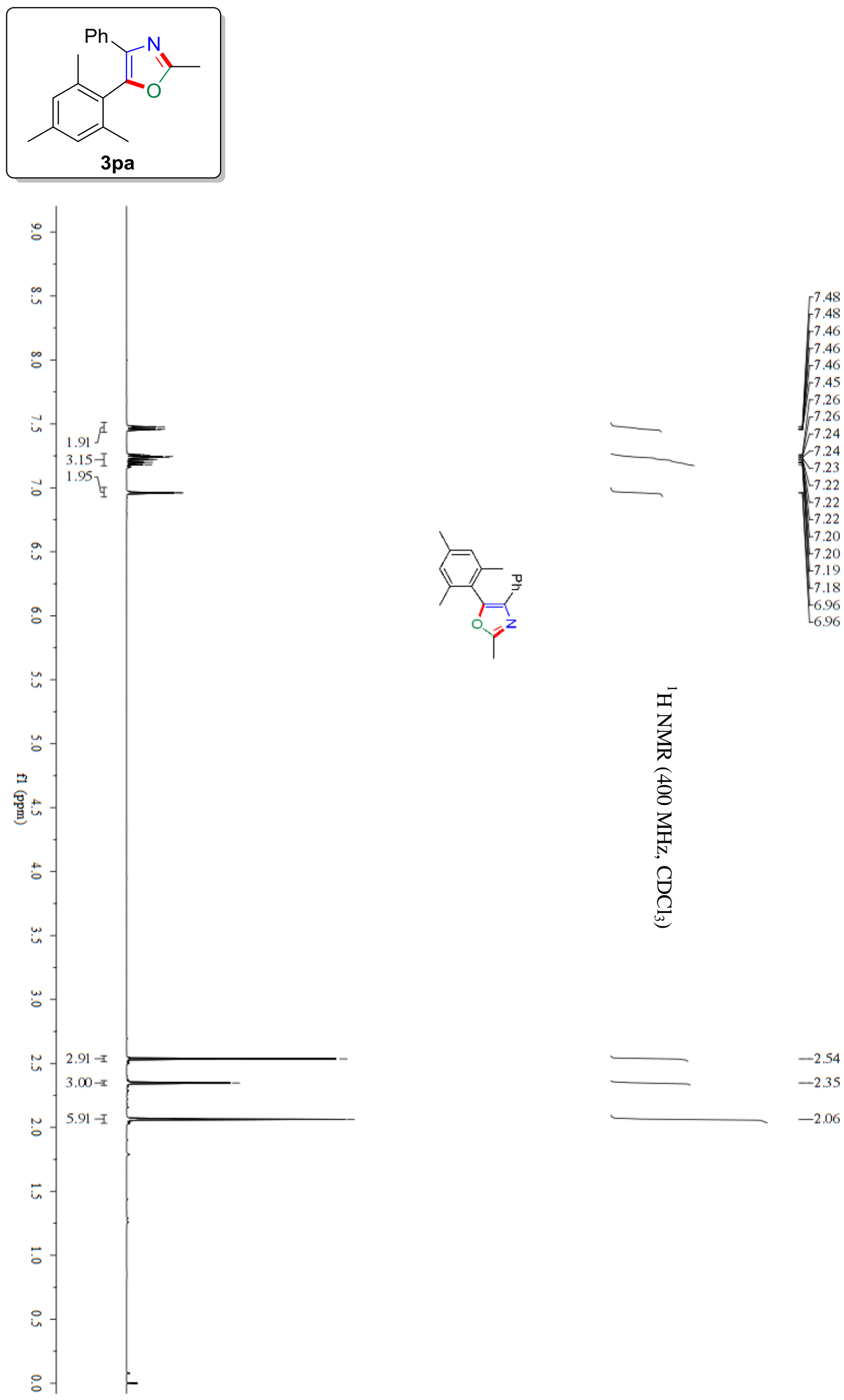

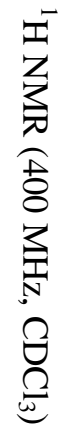

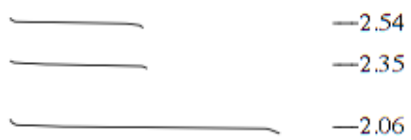



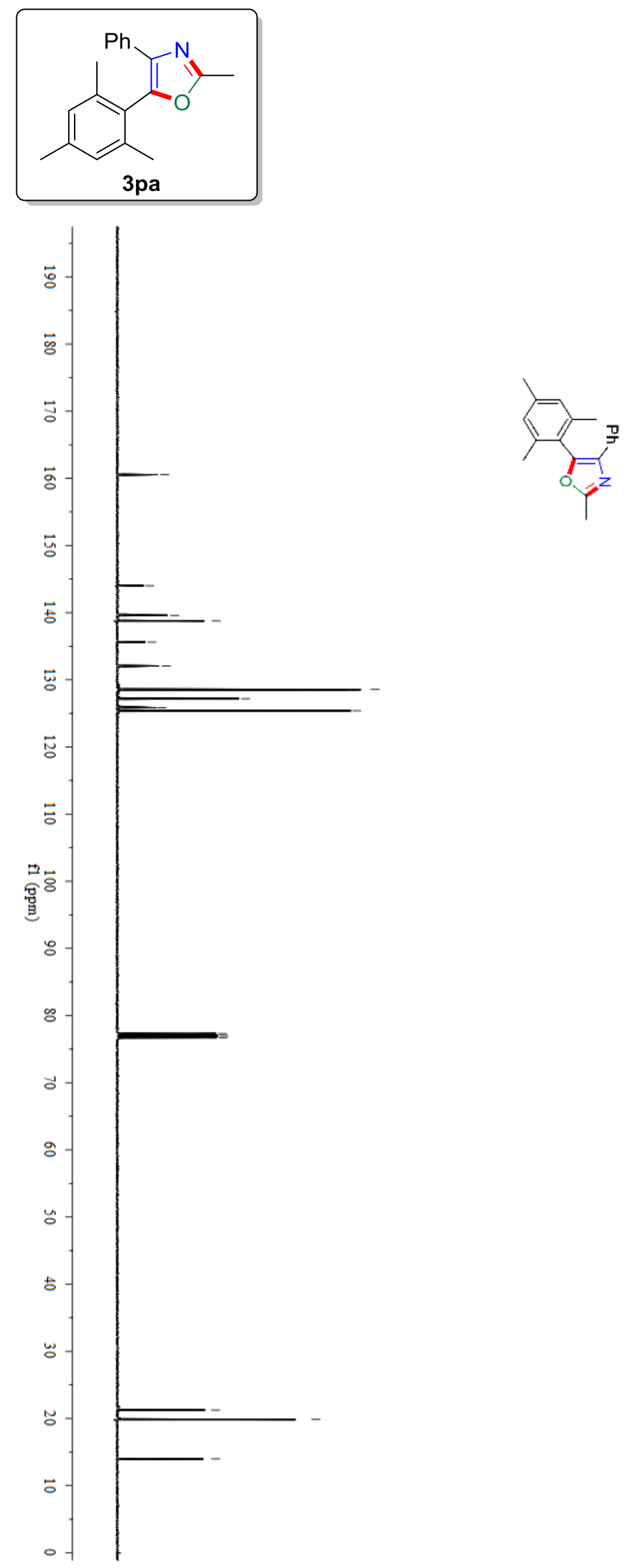

$-160.55$

$\Gamma^{144.02}$

$\int_{-139.59}$ 138.76 135.62

$J_{-132.07}$

$J^{128.56}$ $-128.45$ $-127.19$

$-125.84$

$L_{125.39}$

$\left\{\begin{array}{r}77.32 \\ -77.00\end{array}\right.$

$\left\lfloor_{76.68}\right.$

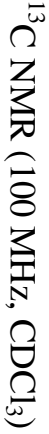

$-21.25$

$-19.85$

$-13.99$ 

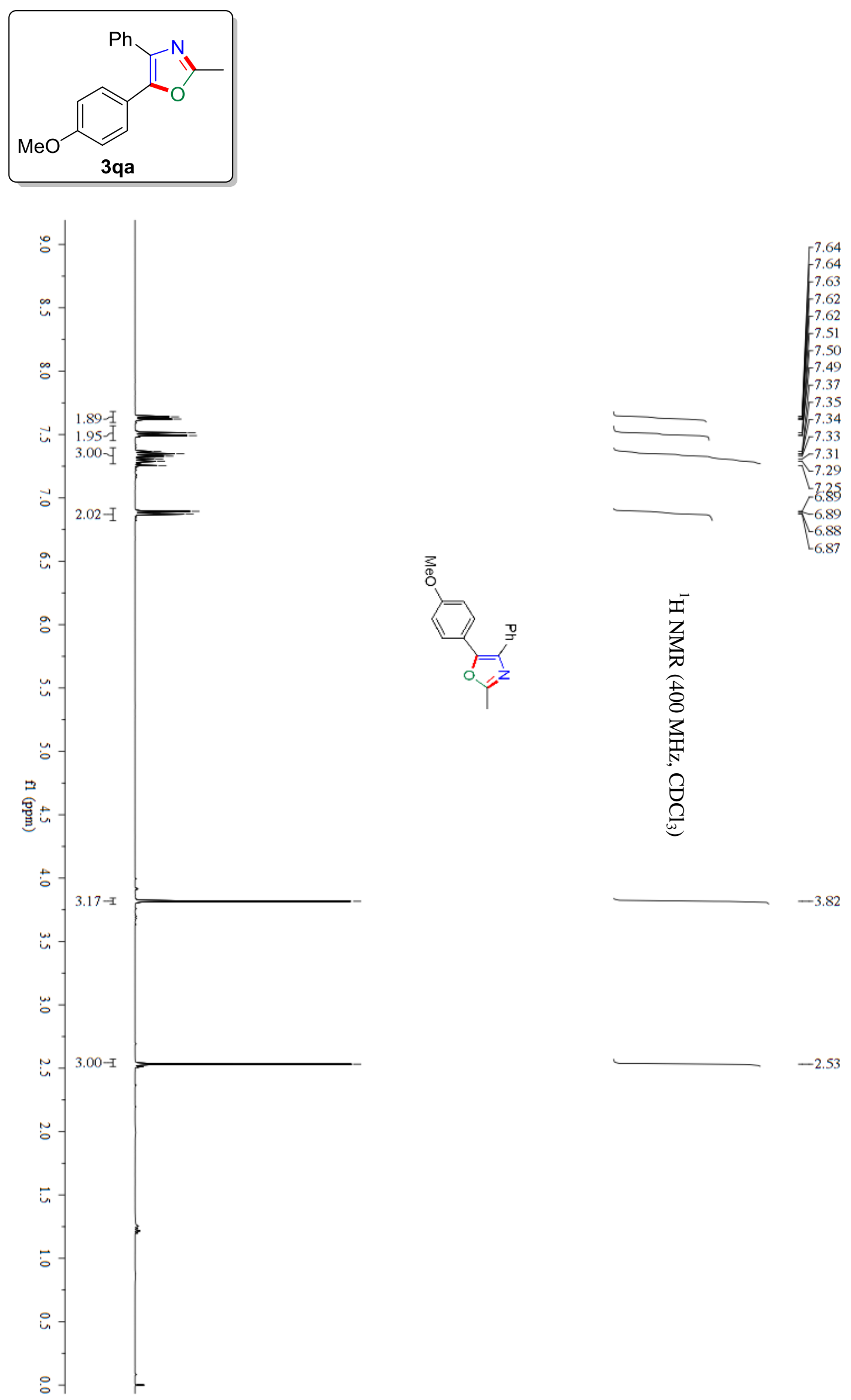

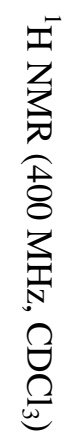

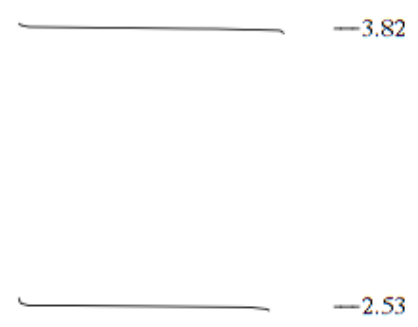

S36 

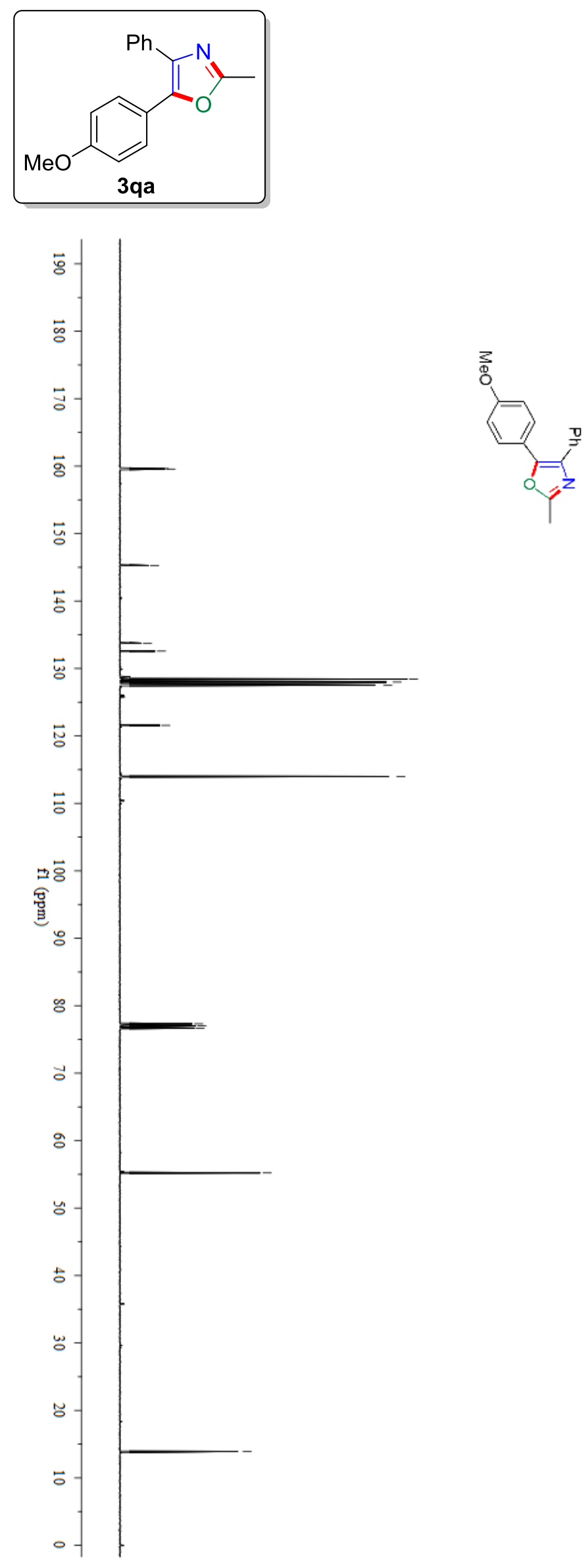

$\mathcal{K}_{159.56}^{159.64}$

$-145.27$

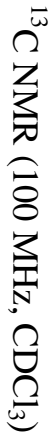

133.75

132.58

1 128.43

$-127.99$

-127.54
-121.56

$-113.99$

77.32
-77.00

$-76.68$

$-55.22$

$-13.93$ 

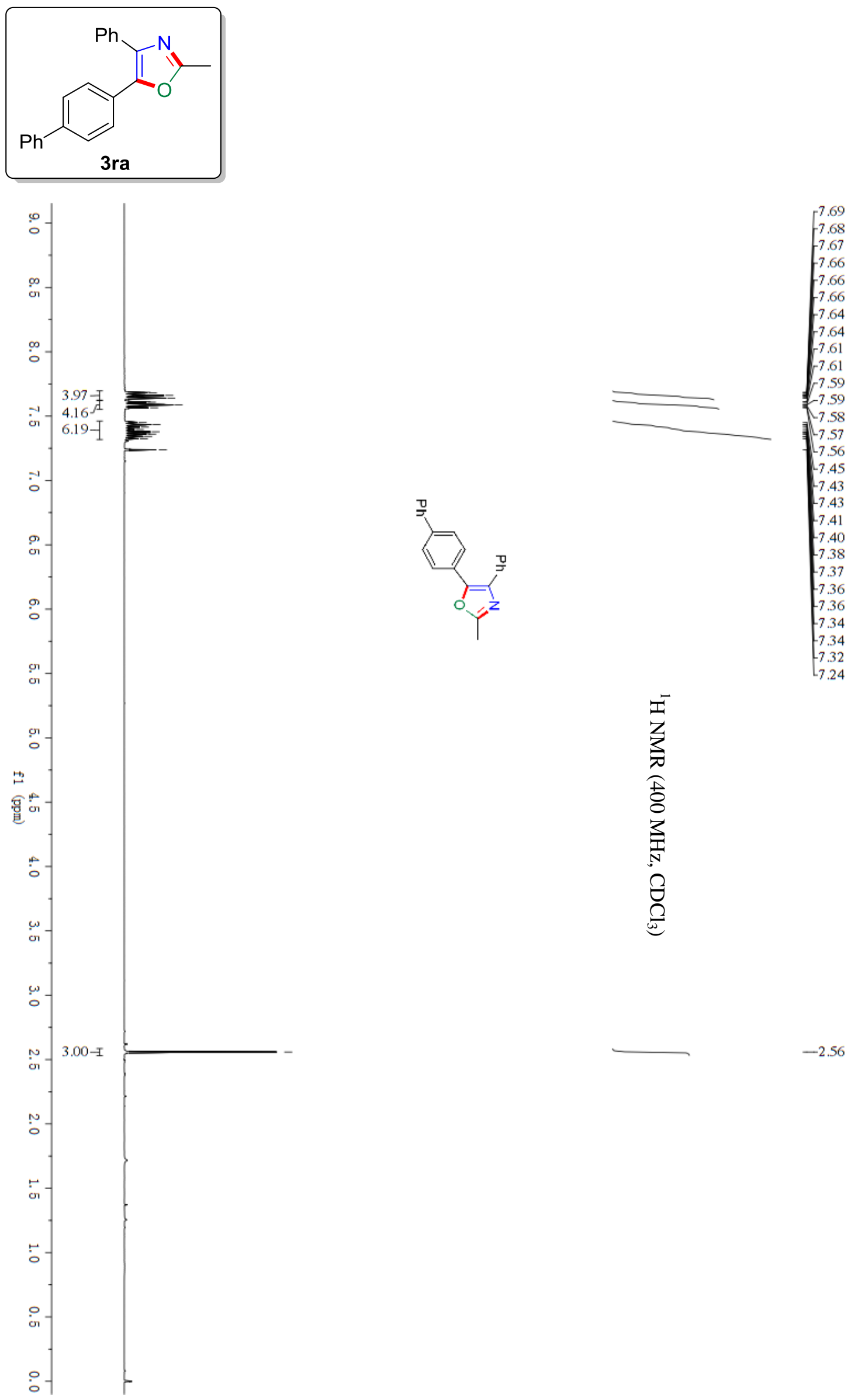

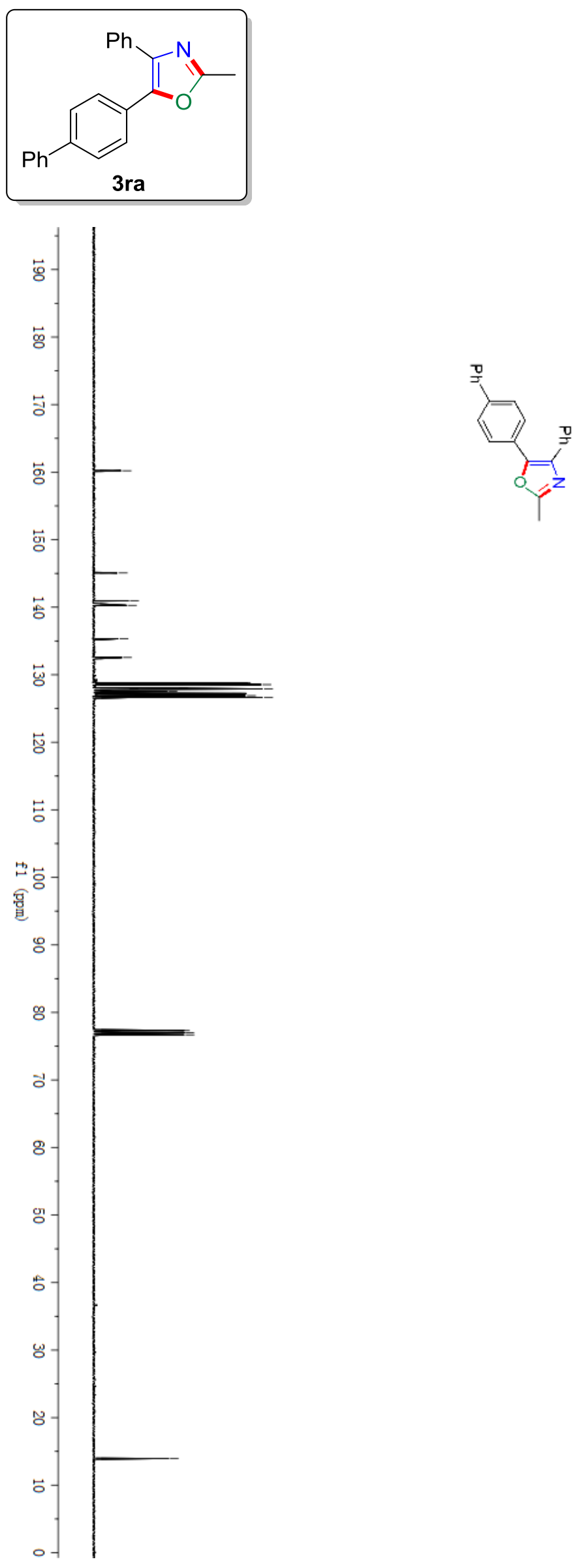

$-160.22$

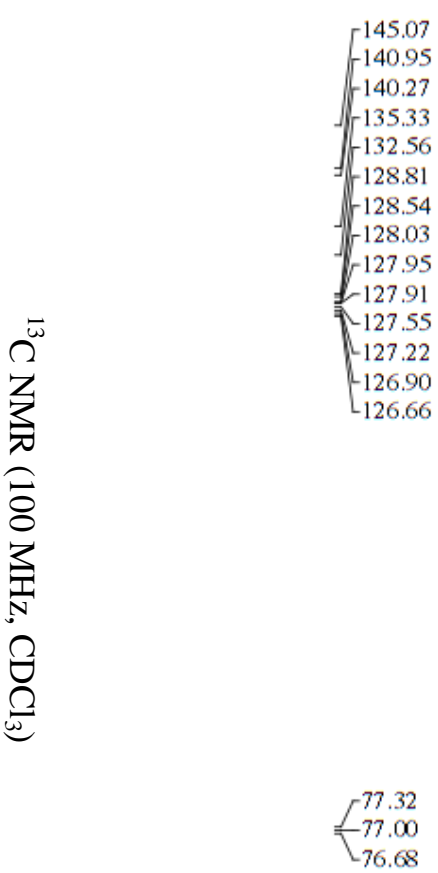



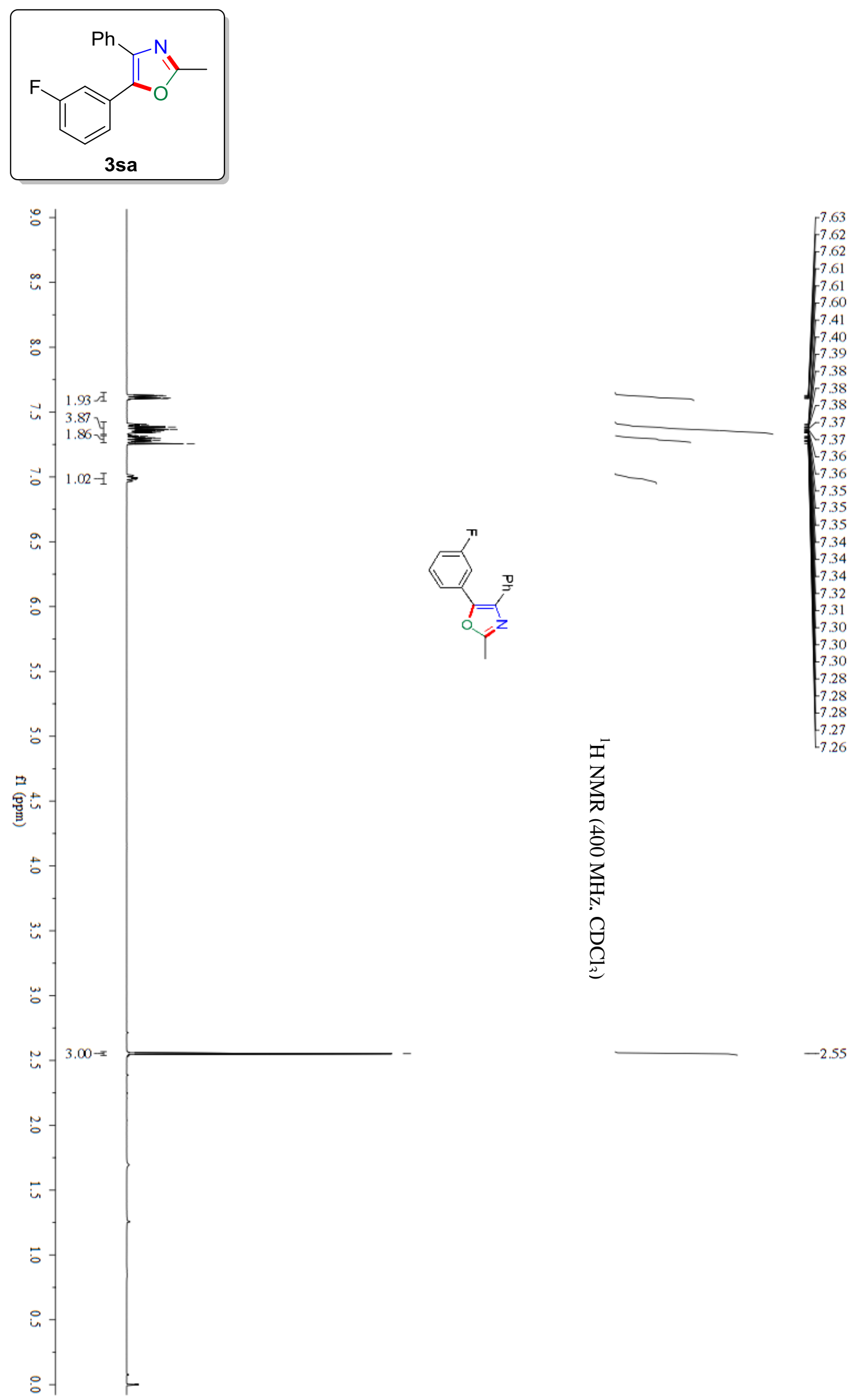

S40 

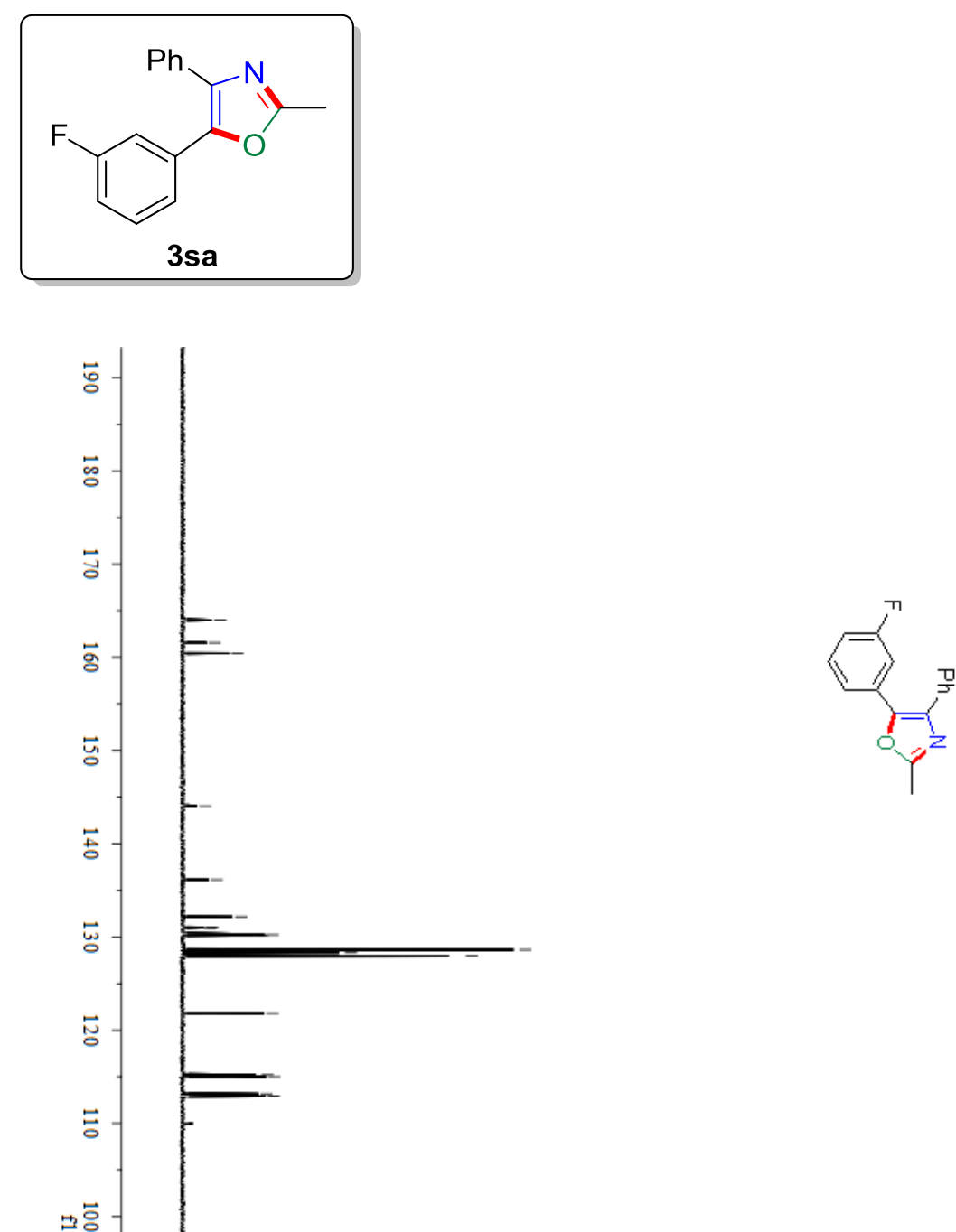

$-112.94$

:

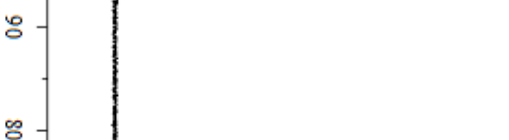

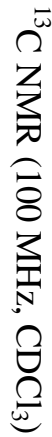

77.32
-77.00
76.08

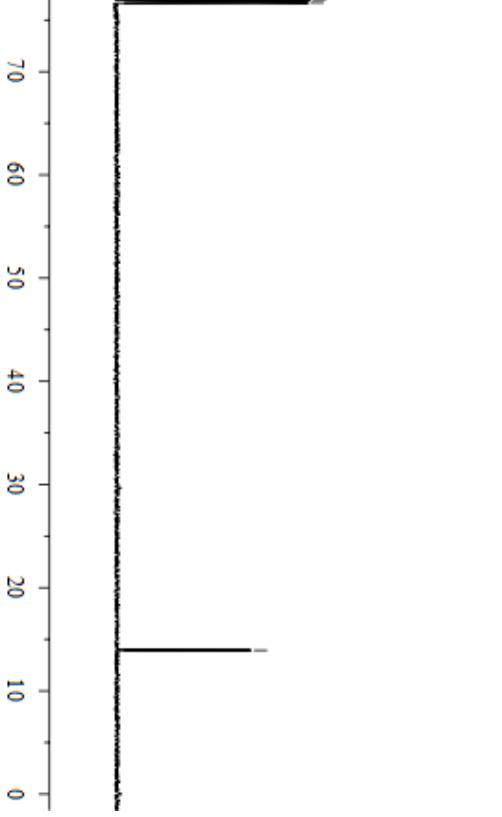



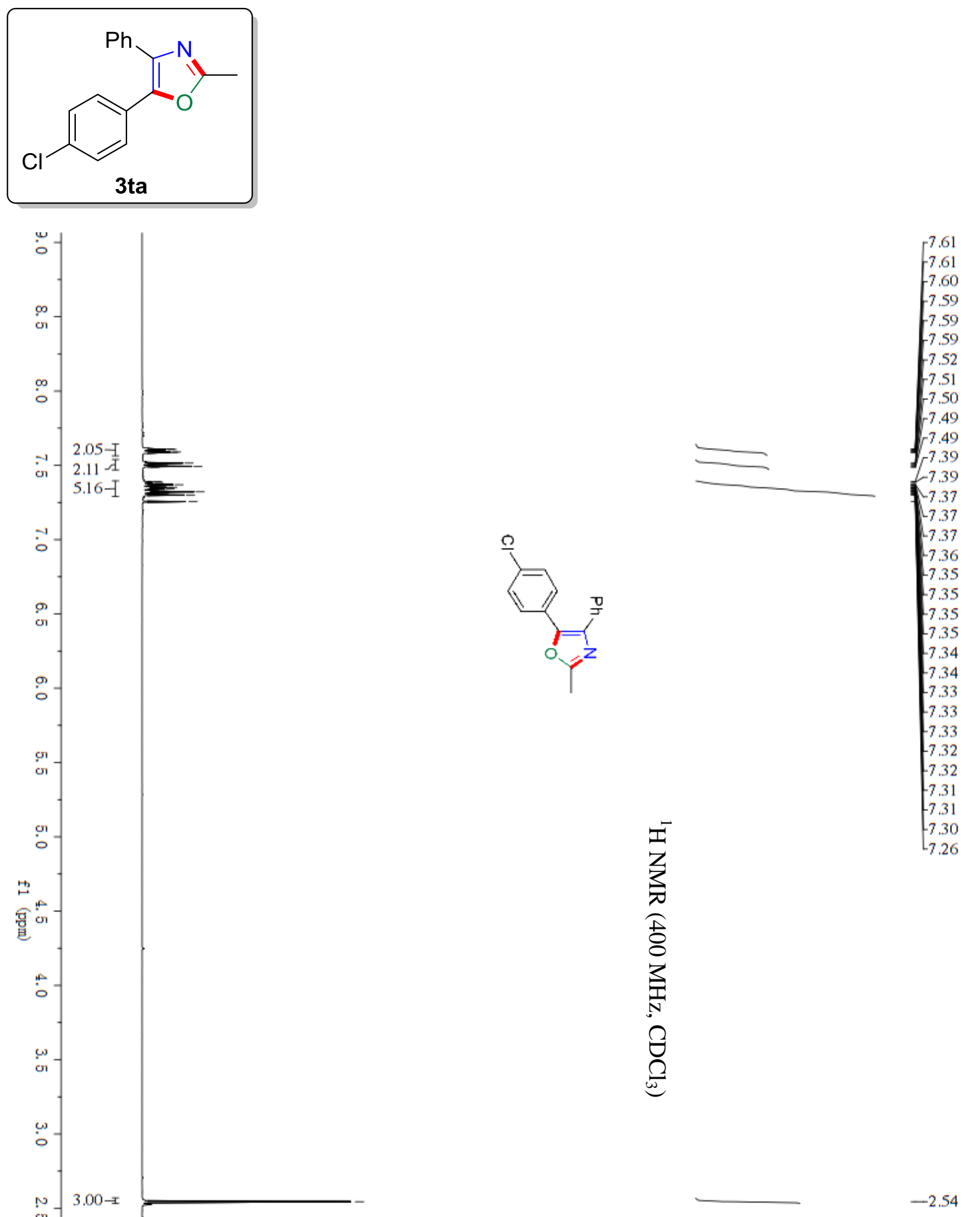

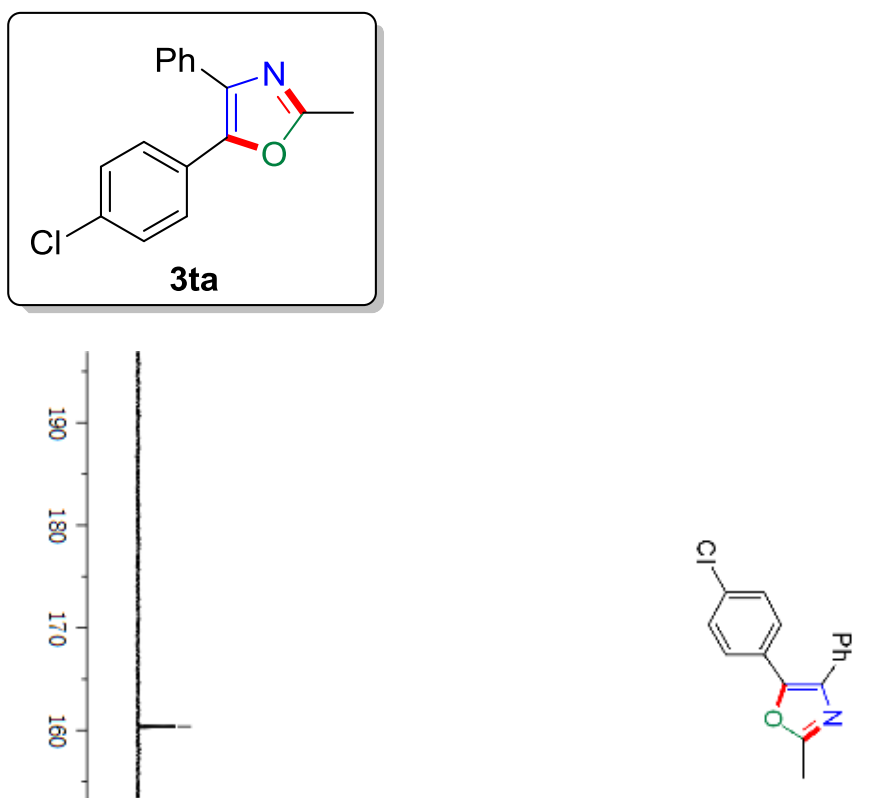

$-160.38$

$-144.22$

135.62

134.08

] 132.22

- 128.87

$-128.61$

$-128.21$

$-127.84$

-127.54
127.50

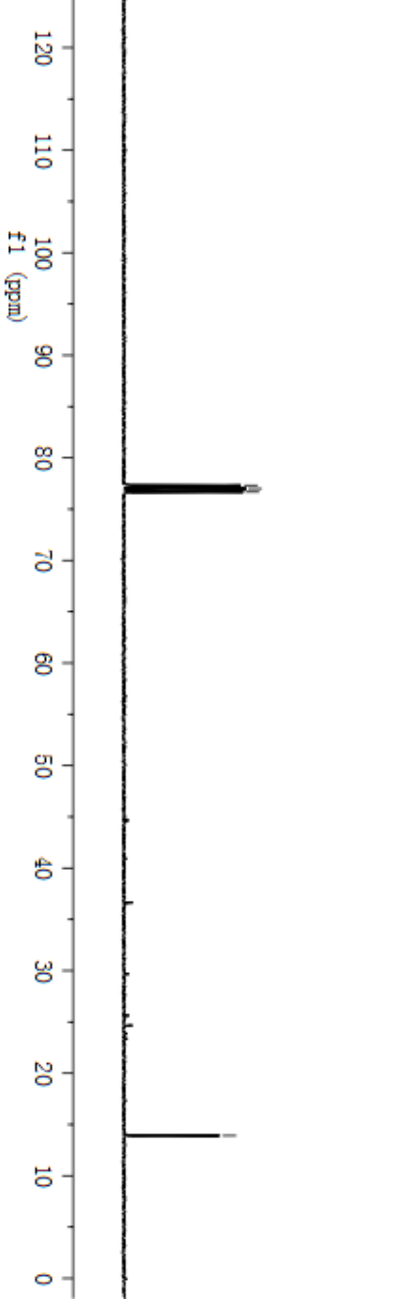

$\left\{\begin{array}{r}77.32 \\ -77.00 \\ -76.68\end{array}\right.$

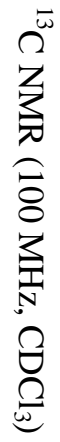



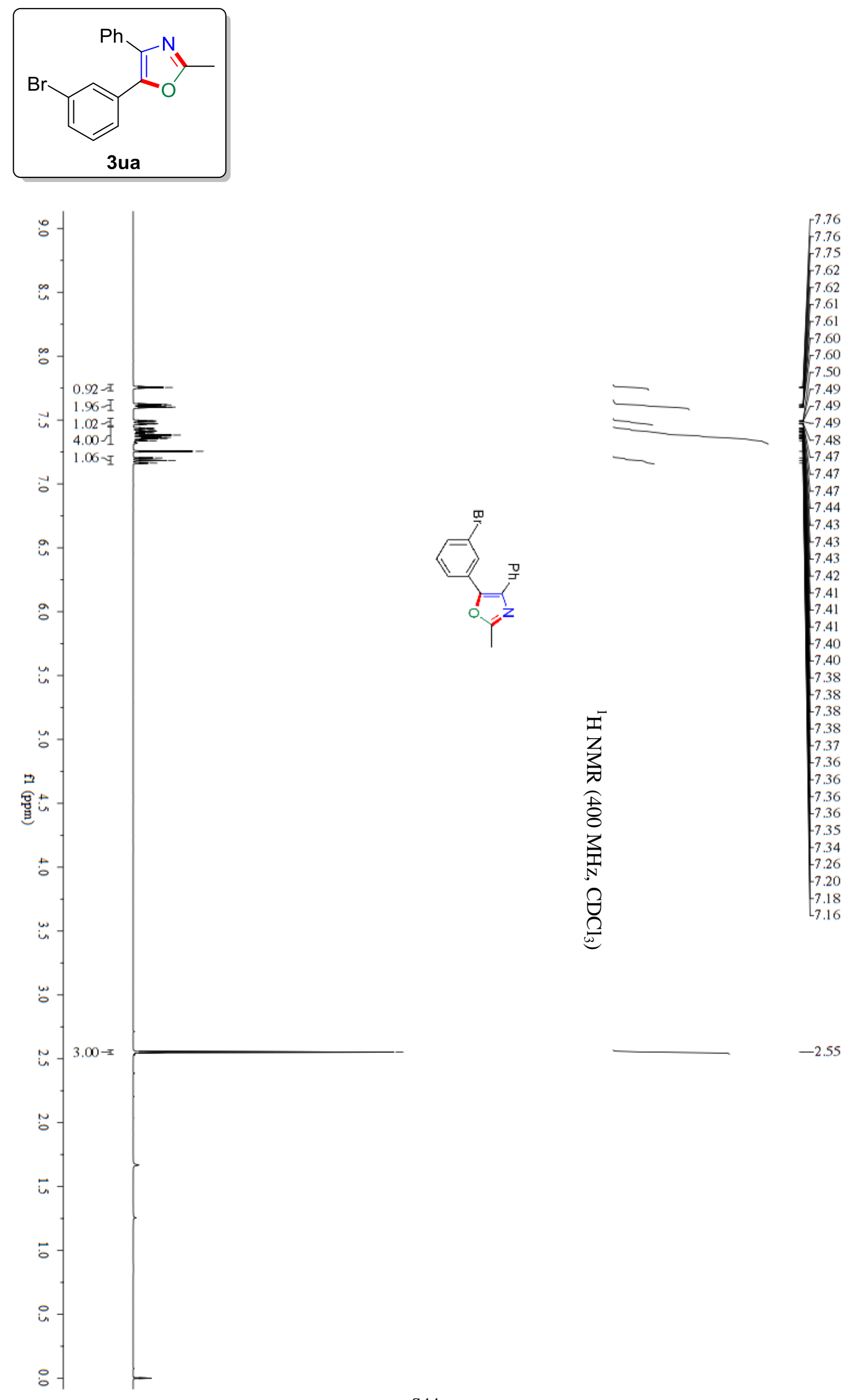

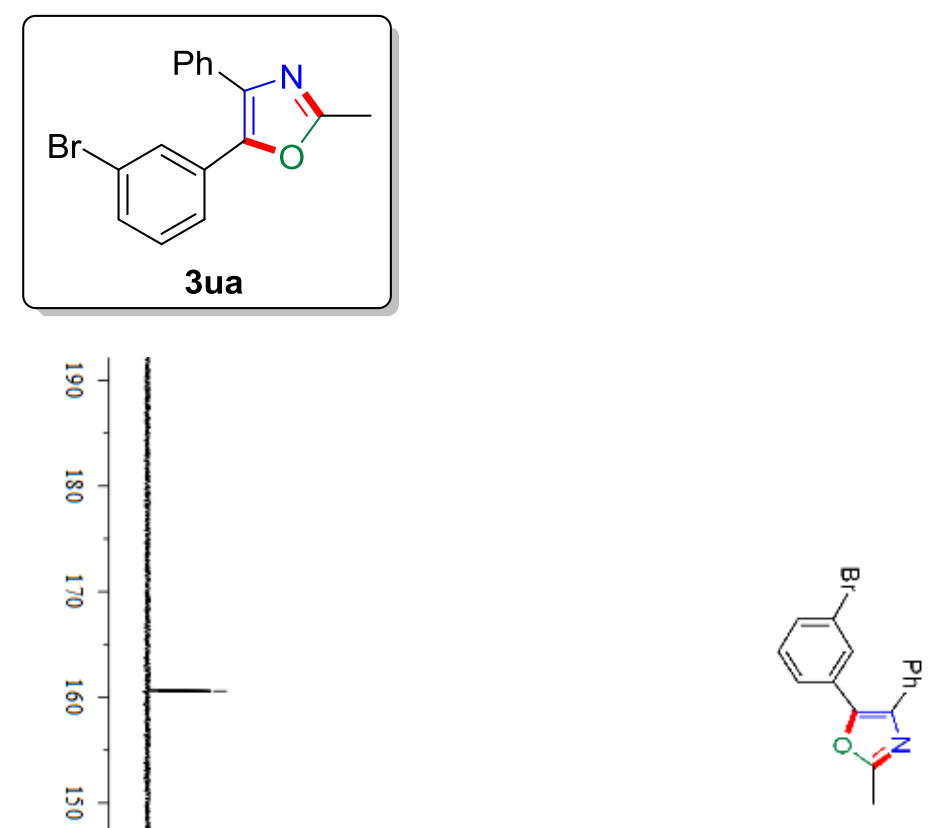

官

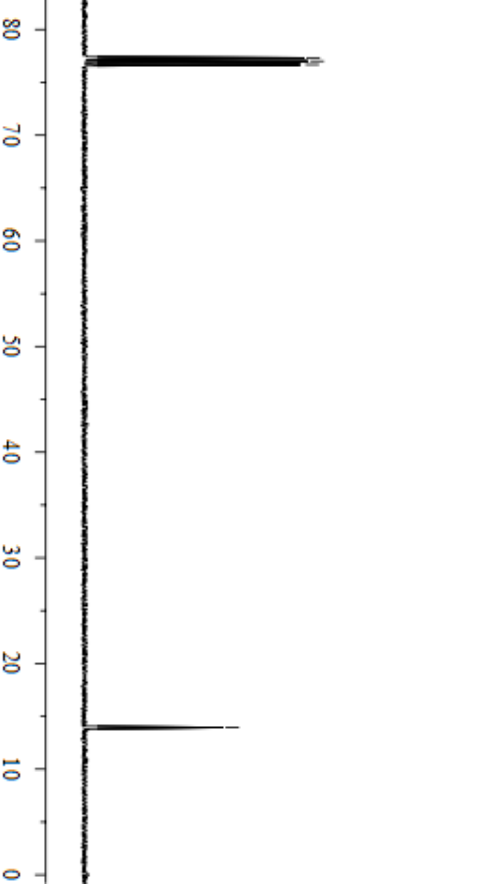



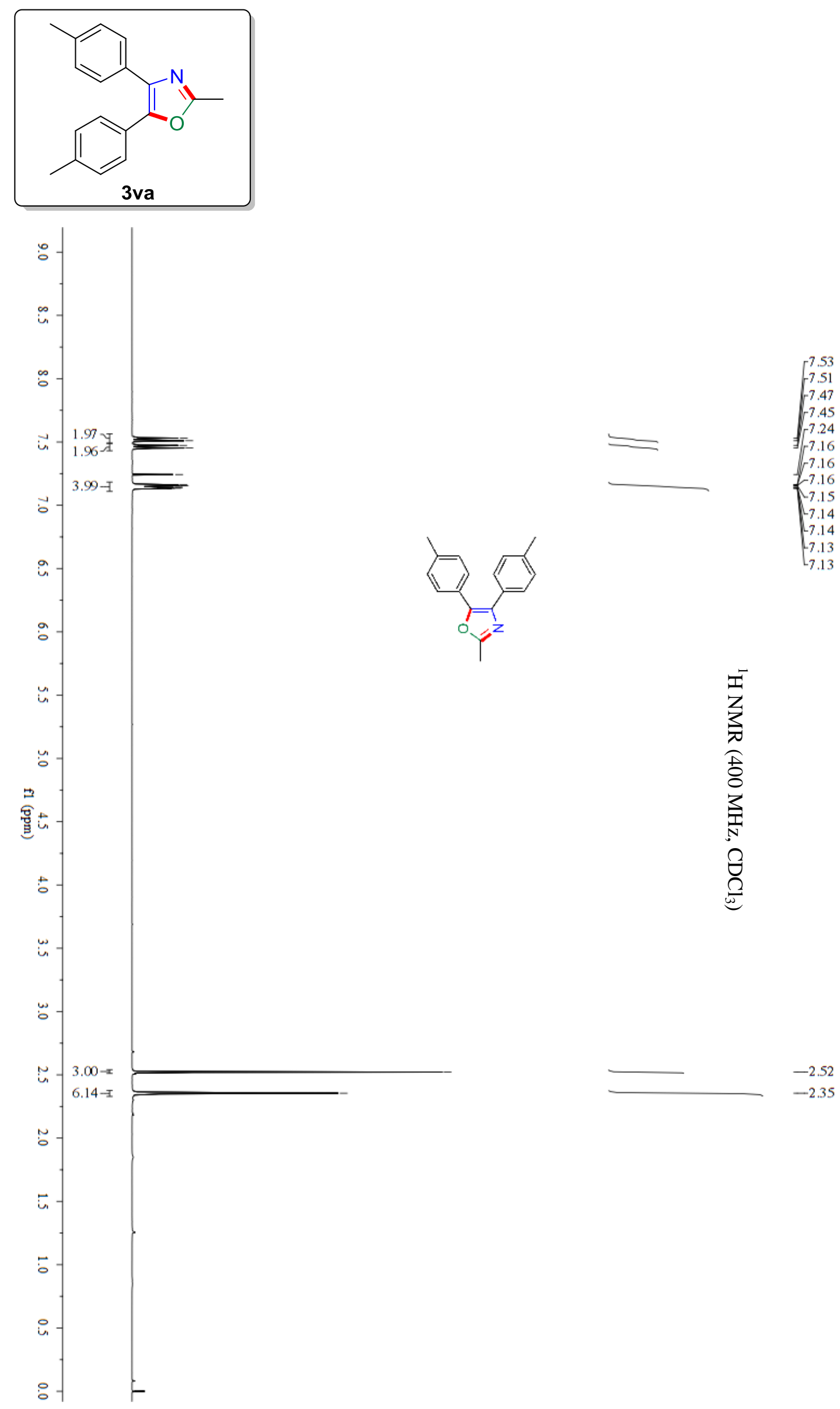

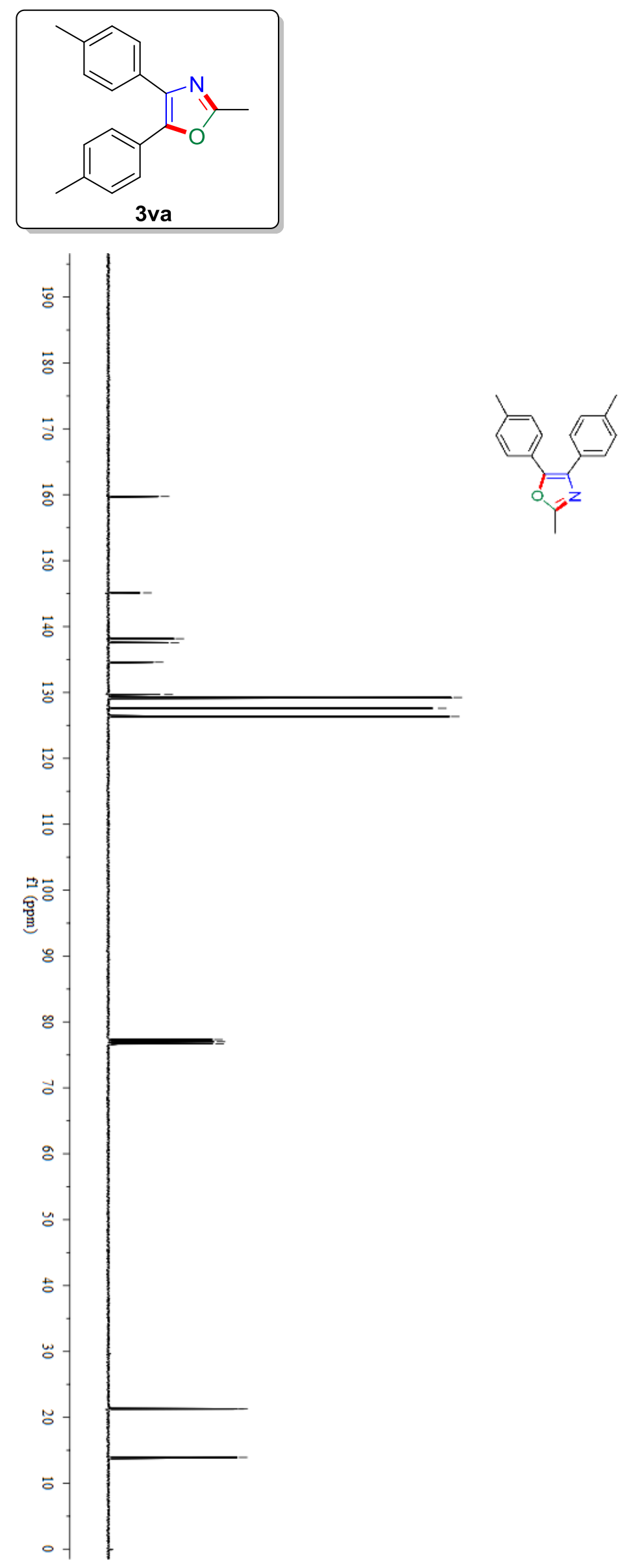

$-159.74$

$-145.11$

138.16
-137.56

134.59

129.71

$-129.23$

$-129.14$

$-127.60$

$L_{126.35}$

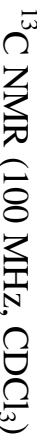

$\leftarrow_{-77.00}^{77.32}$

$\backslash 76.68$

$K_{21.26}^{21.29}$

$-13.92$ 

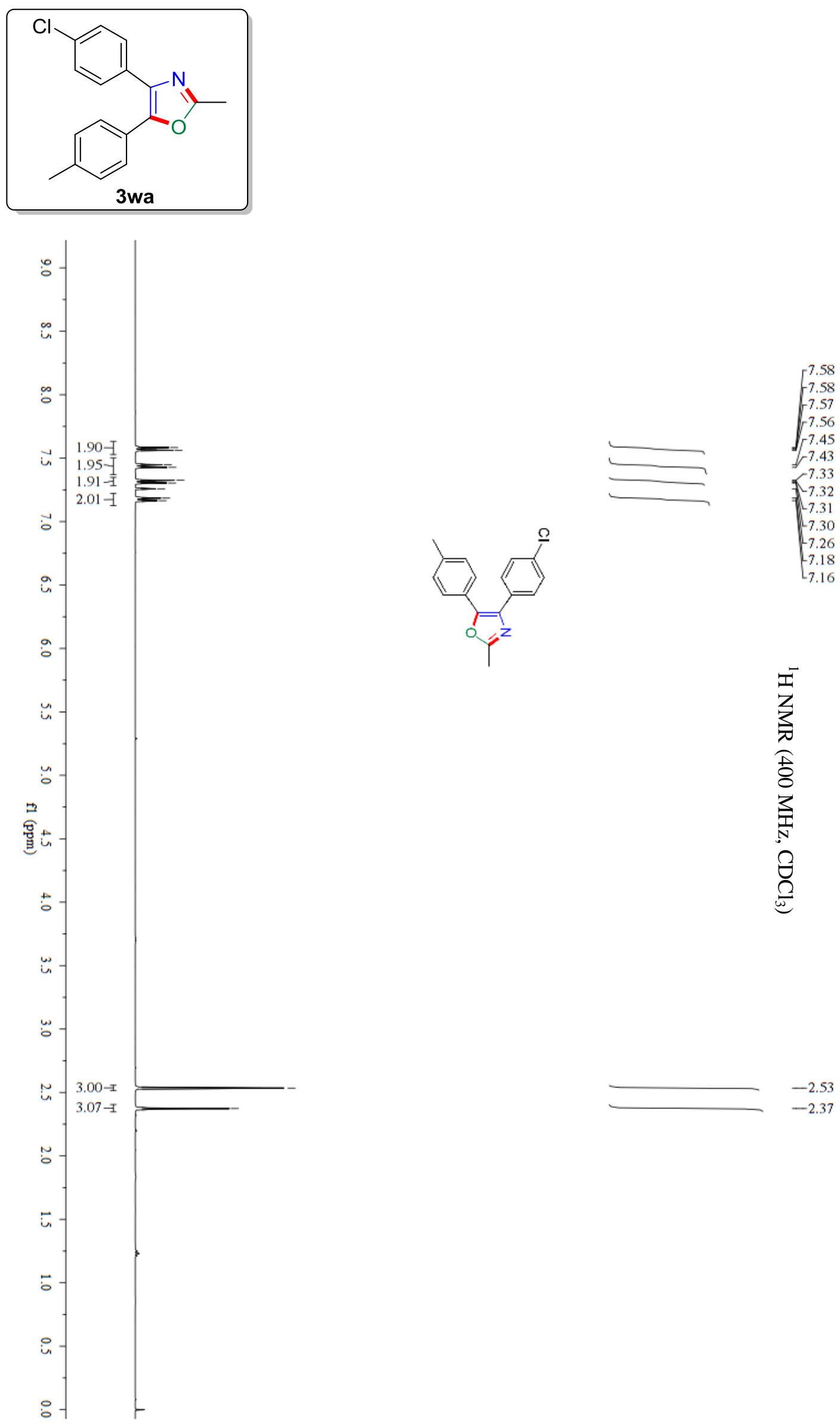

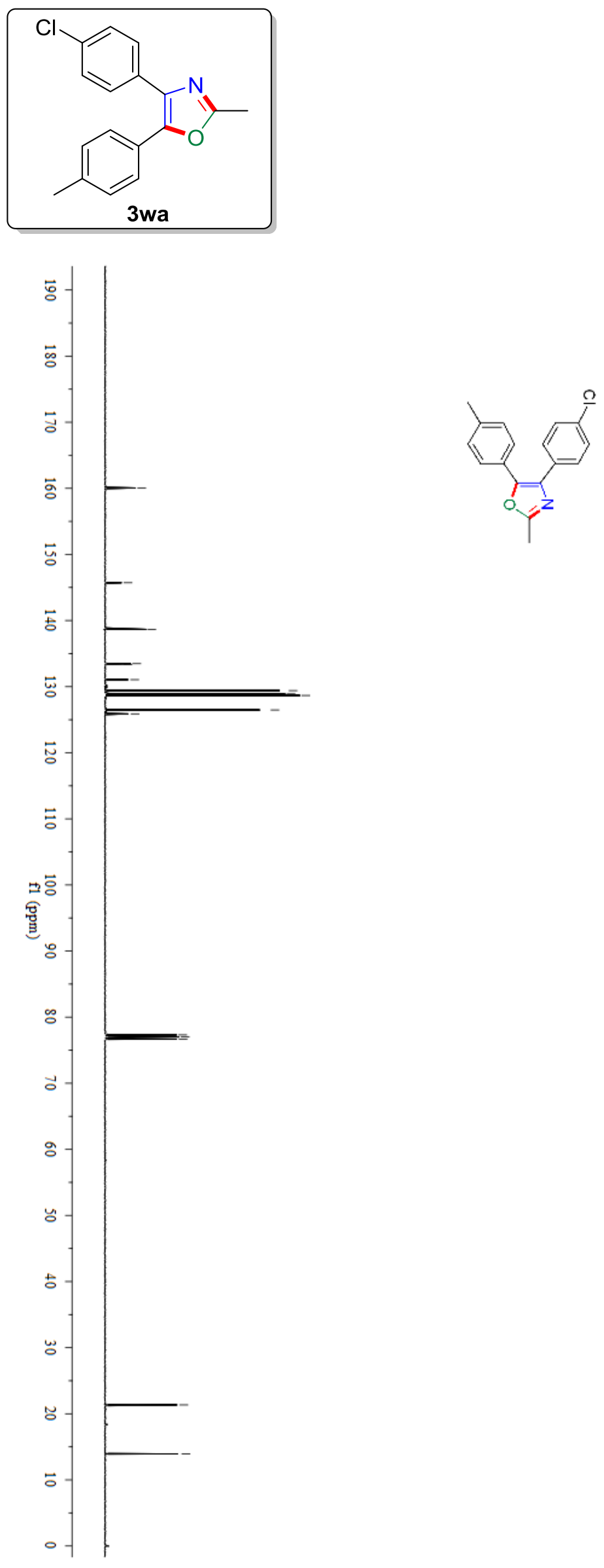

$-160.06$

$-145.72$

138.67

] 133.48

133.36
-131.05

I 131.05

129.39

$-128.90$

- -128.67

126.47

$\int_{77.00}^{77.32}$

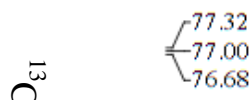

㝋

อ

8

紊

తి

$-21.35$

$-13.93$ 

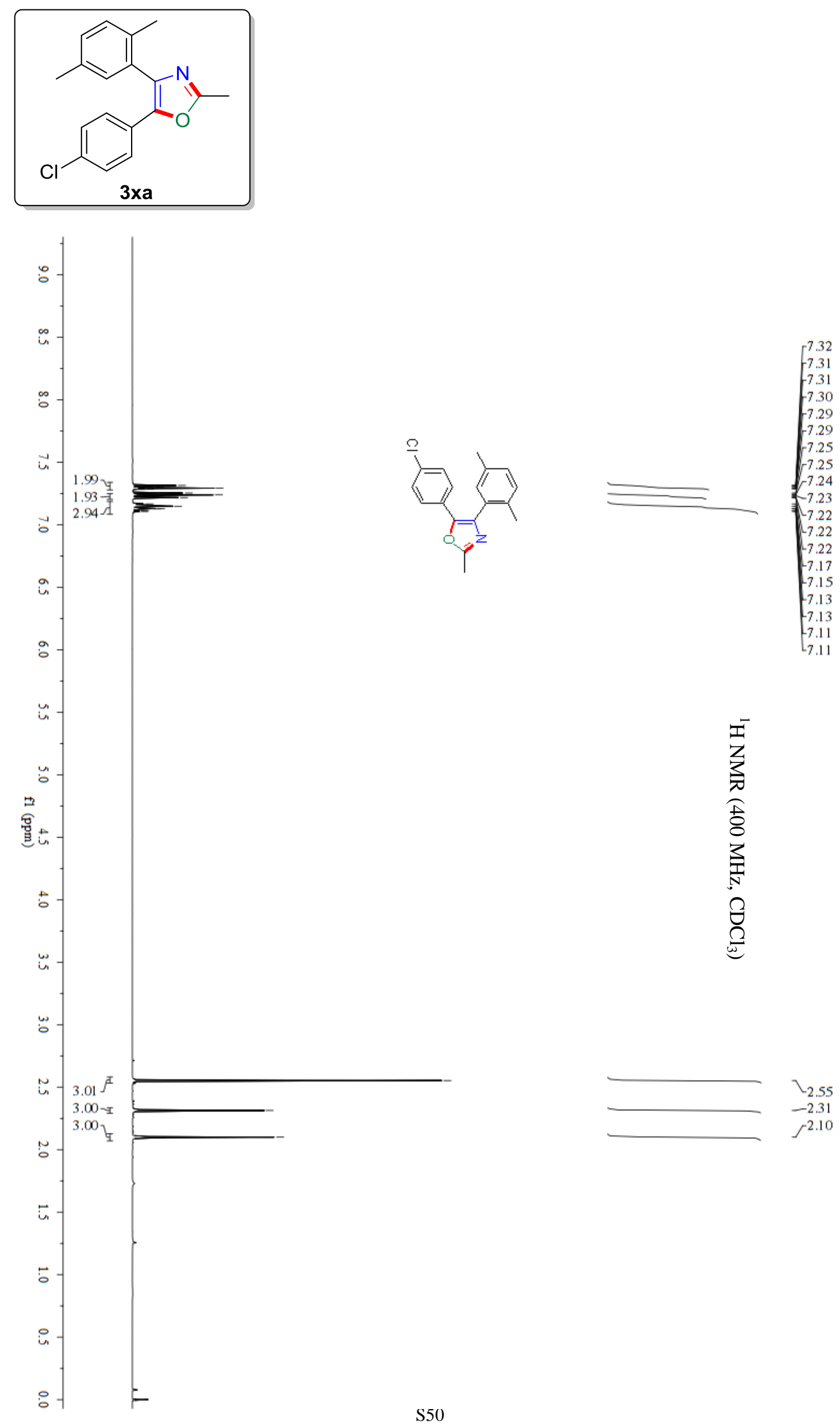

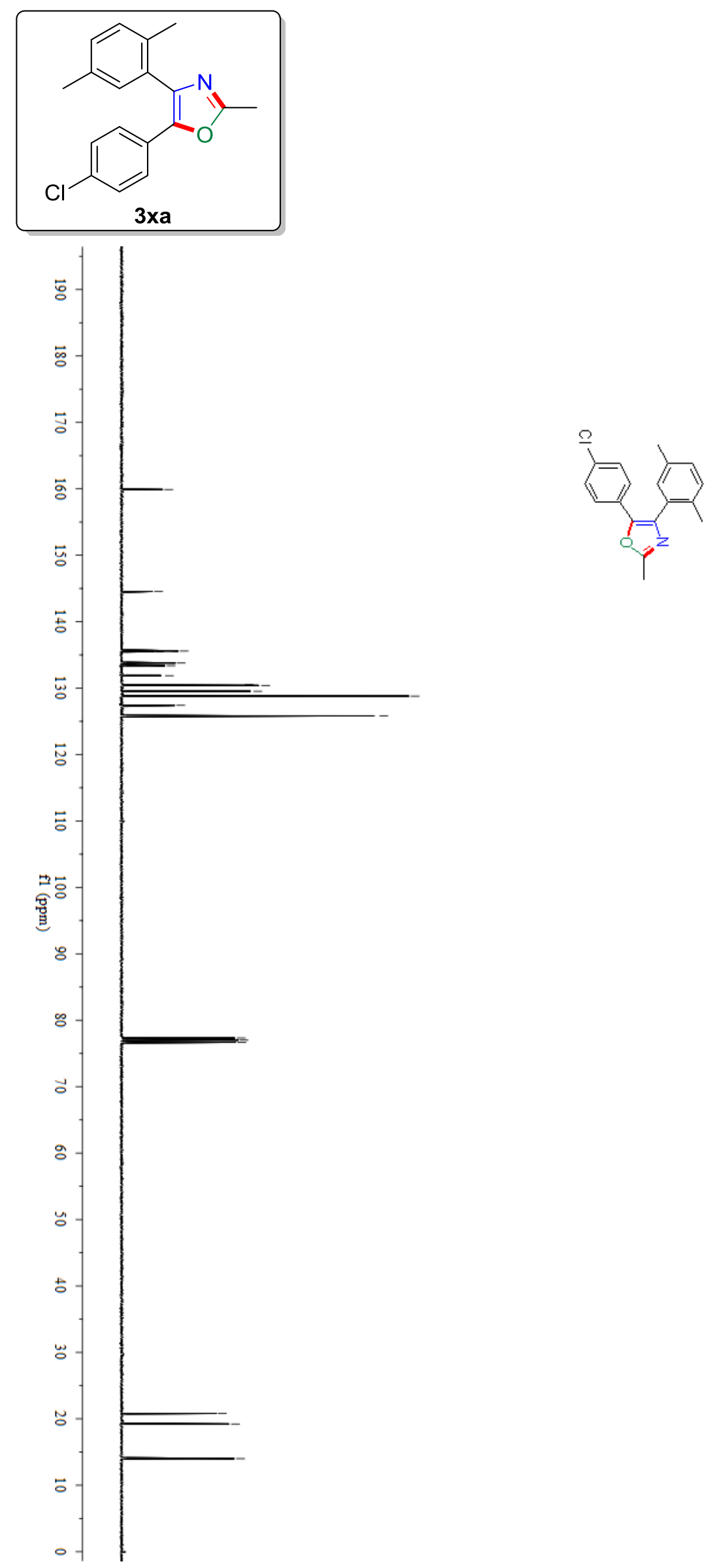

$-159.89$

$-144.56$

135.58

$-135.48$ 133.78

$-133.37$

- 131.87

$-130.53$

130.40

$-129.52$

$-128.79$

$-127.41$

$-125.83$

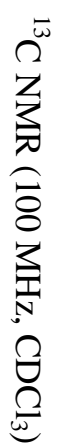

$<_{77.00}^{77.32}$

$-76.68$

-20.81
-19.21
-14.00 

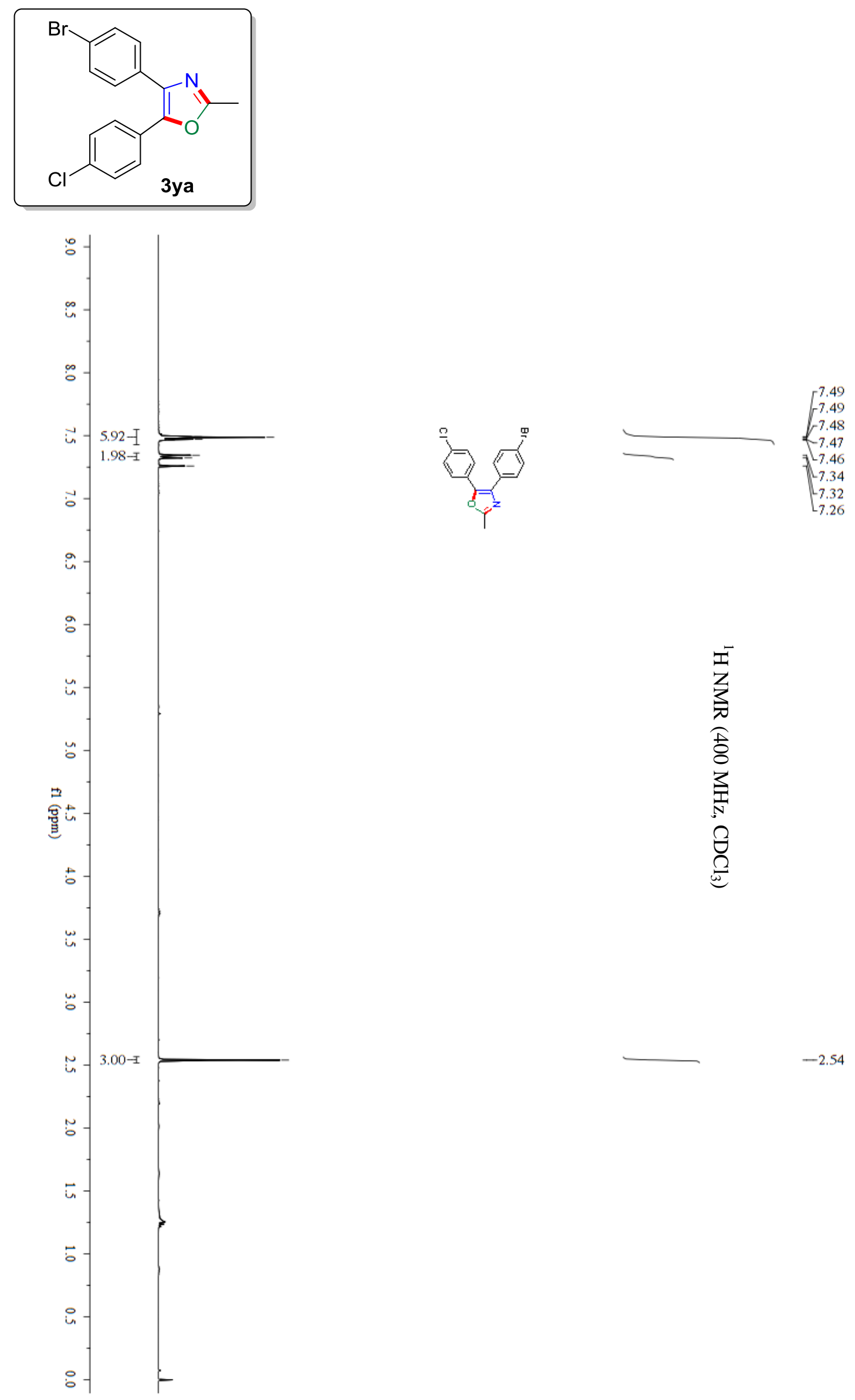

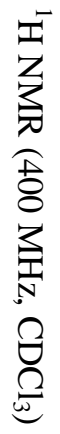



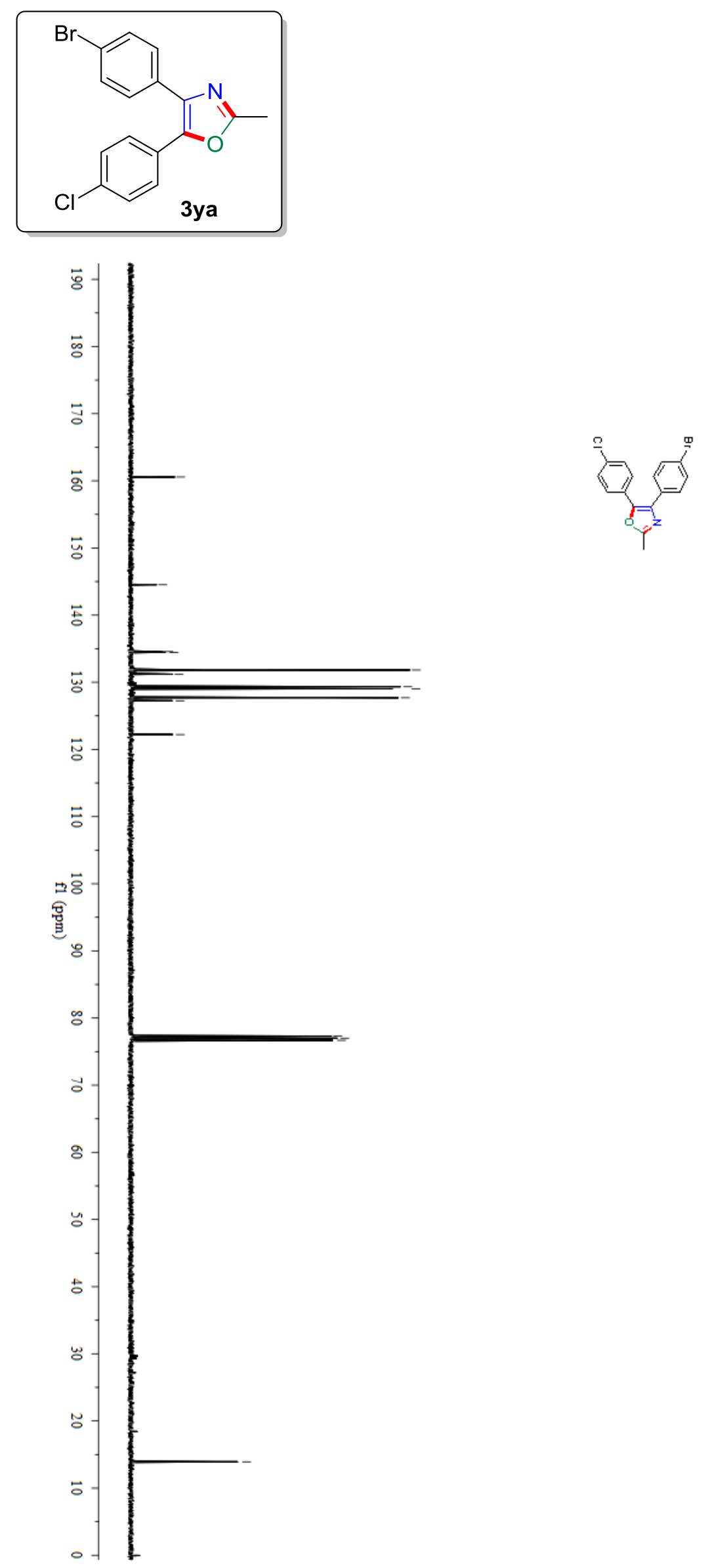

$-160.57$

$-144.52$

134.56

-134.45

131.82

$-131.21$

- 129.34

$-129.03$

427.69

$-127.25$

$-122.21$

77.32
-77.00
-76.68

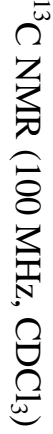



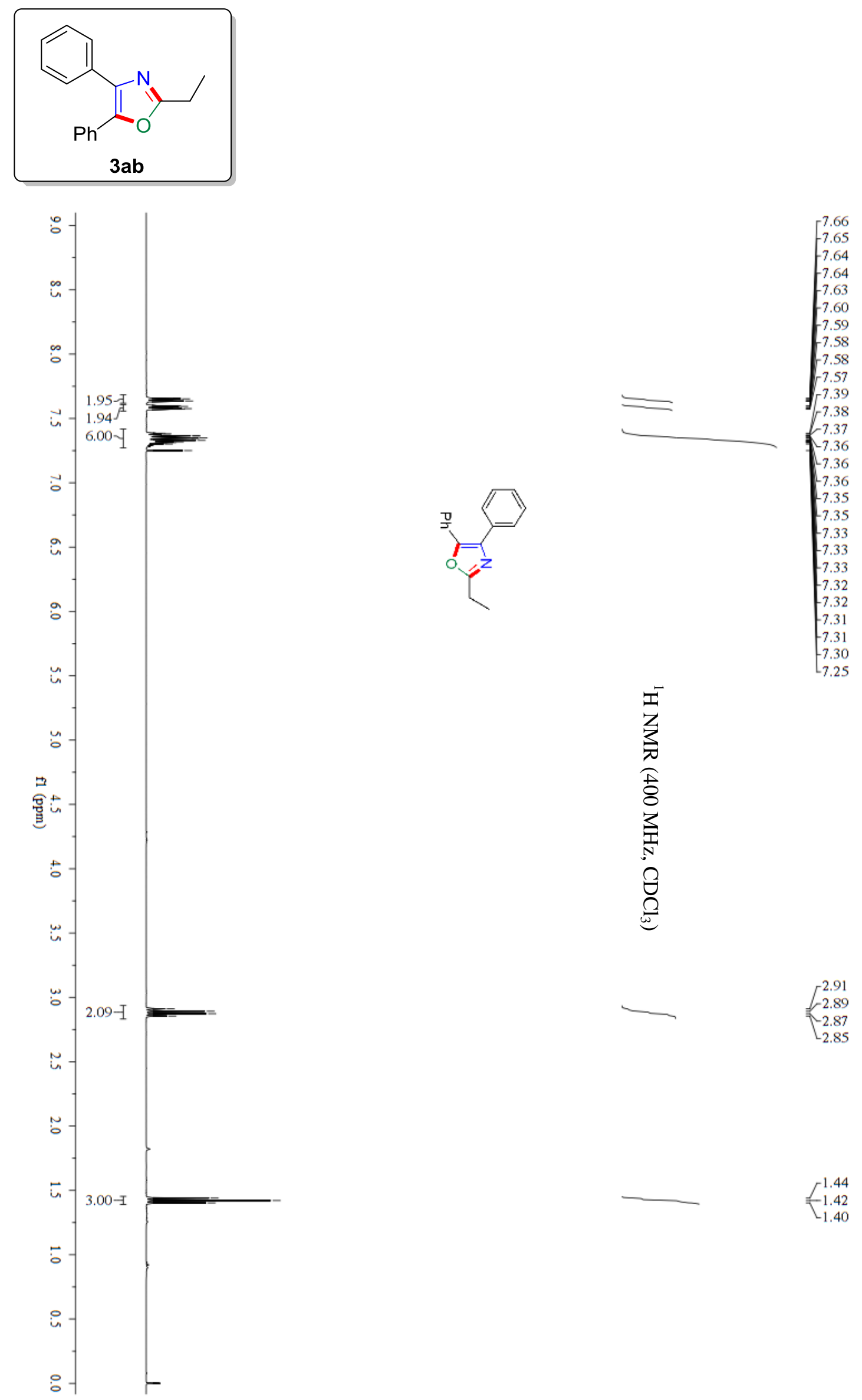

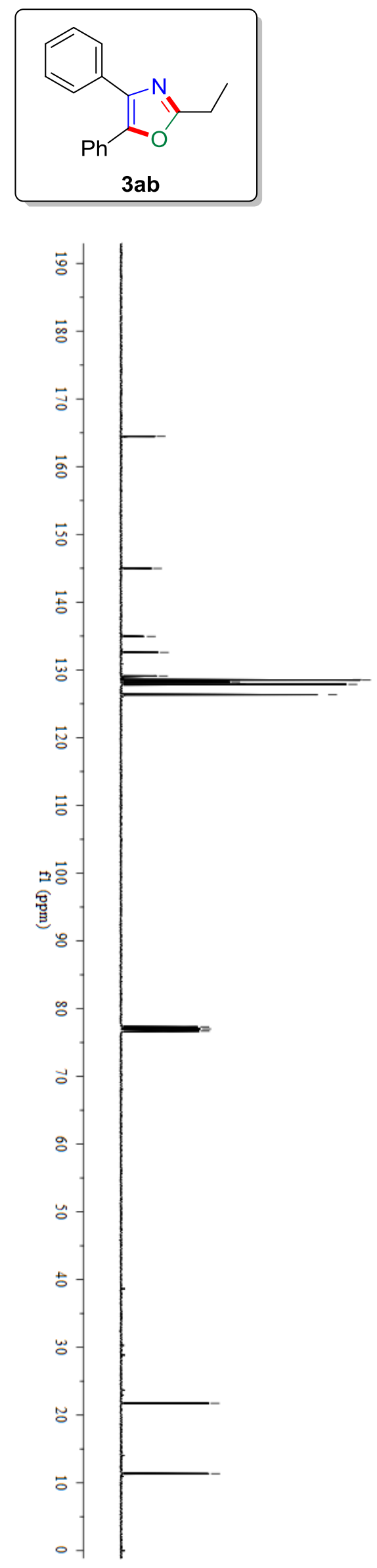

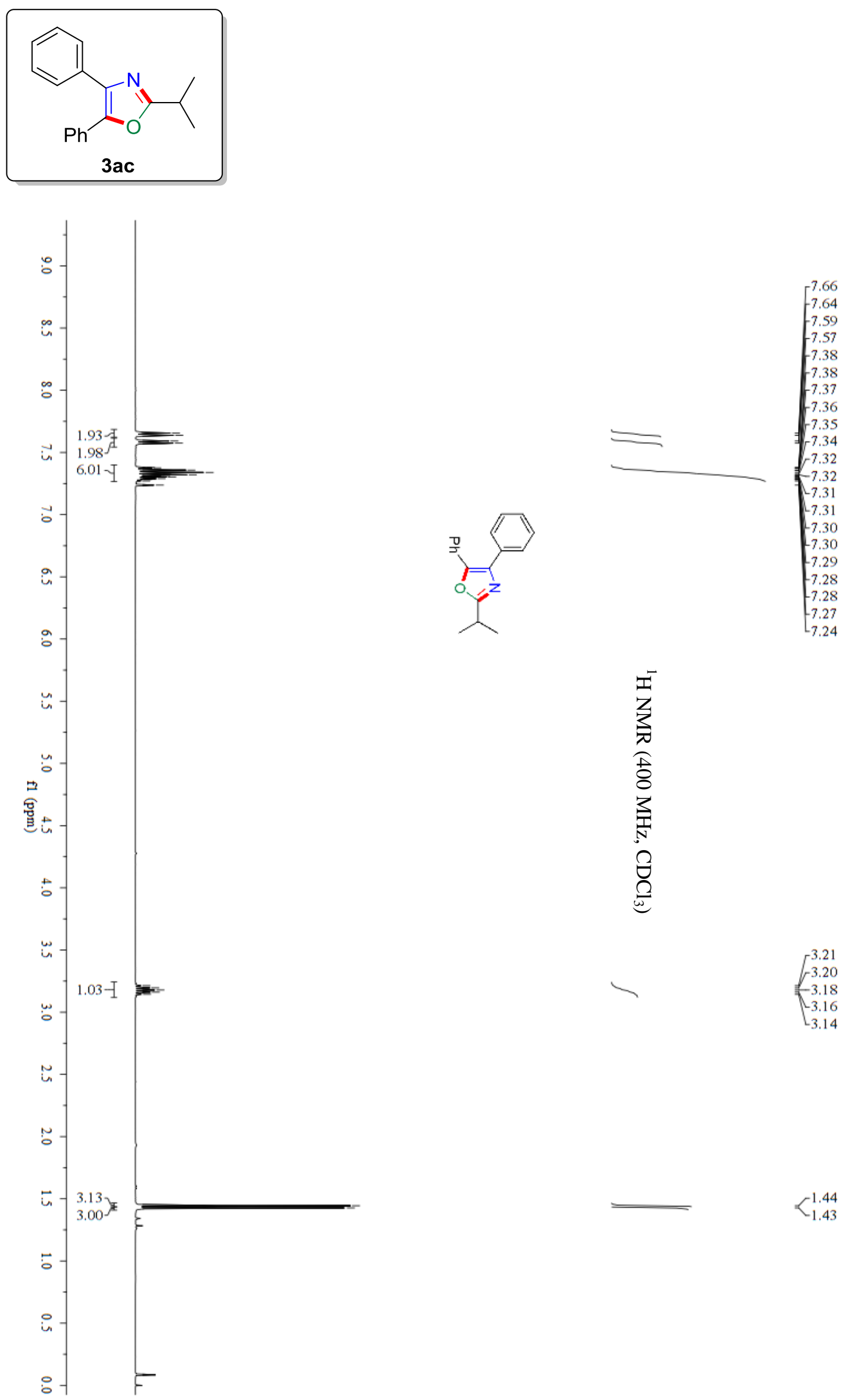

3
3
3
8
8
3
3
5
8
0
0
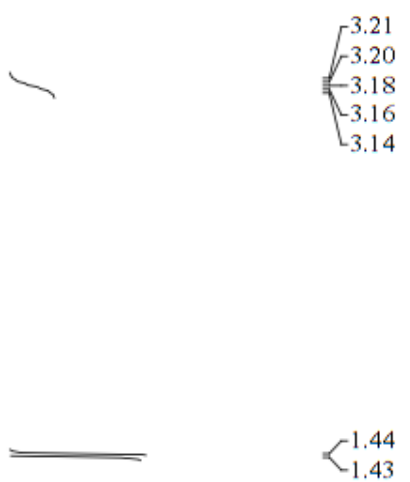

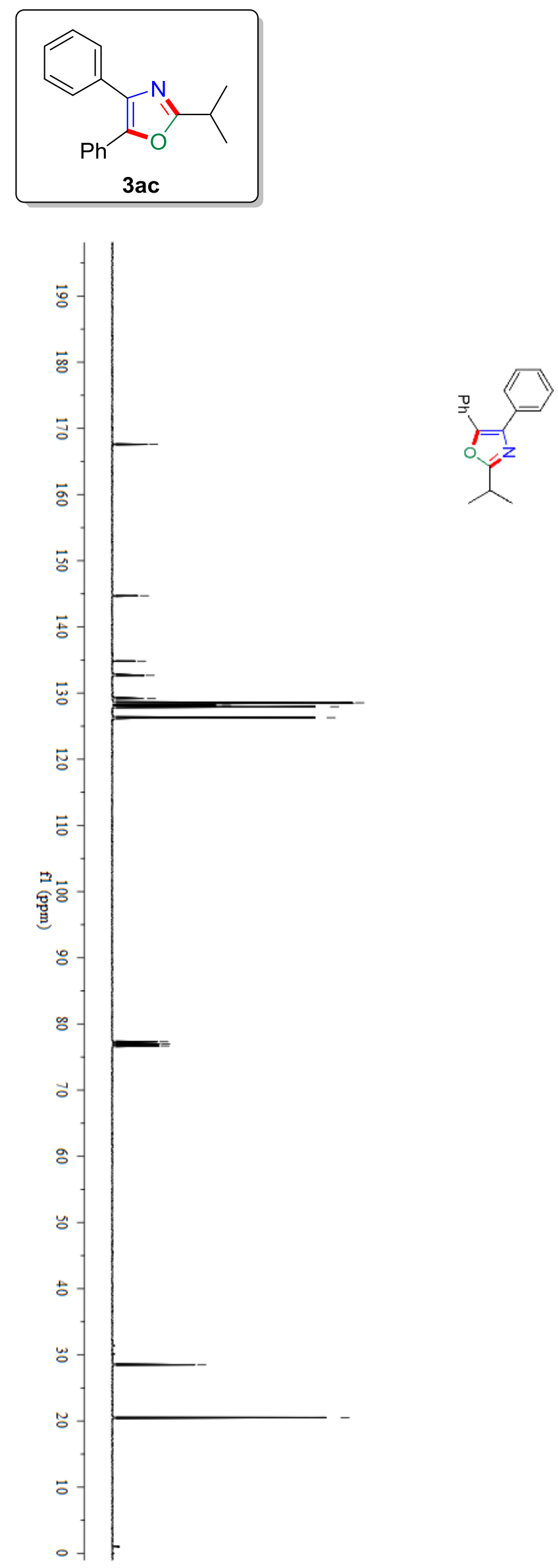

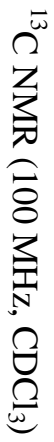

$-144.7$

134.82 132.68 ] 129.18

] 128.53

$-128.48$

$-128.16$

$-127.94$

427.87

126.28

$\int_{-77.00}^{77.32}$

$\nearrow_{76.68}$

$-28.48$

$-20.52$ 

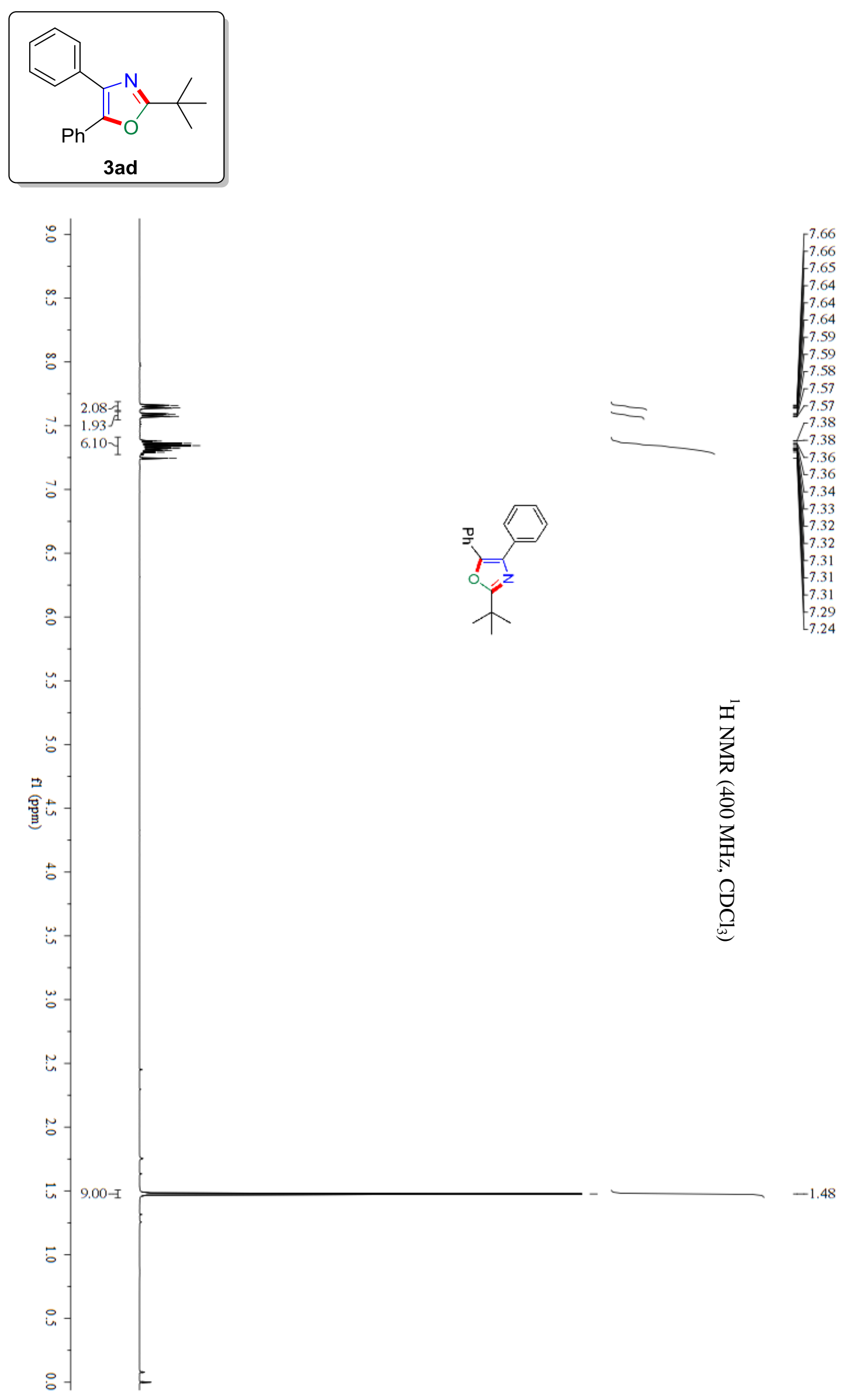

S58 

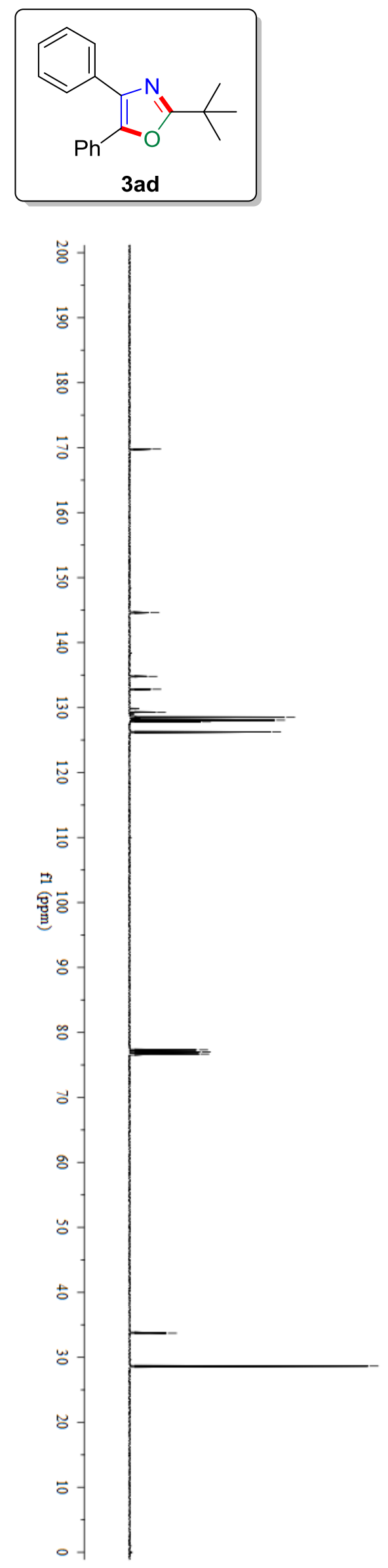

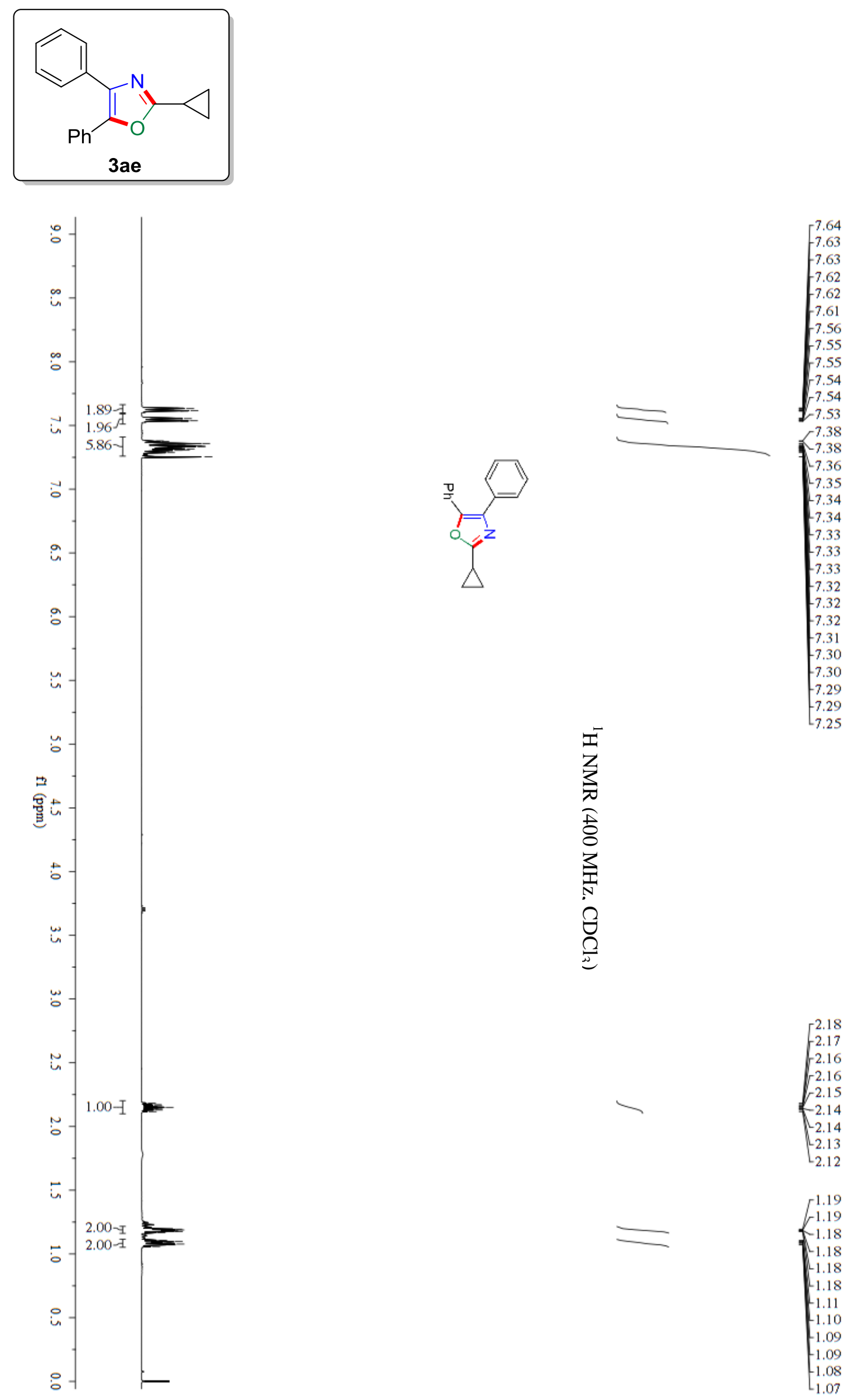

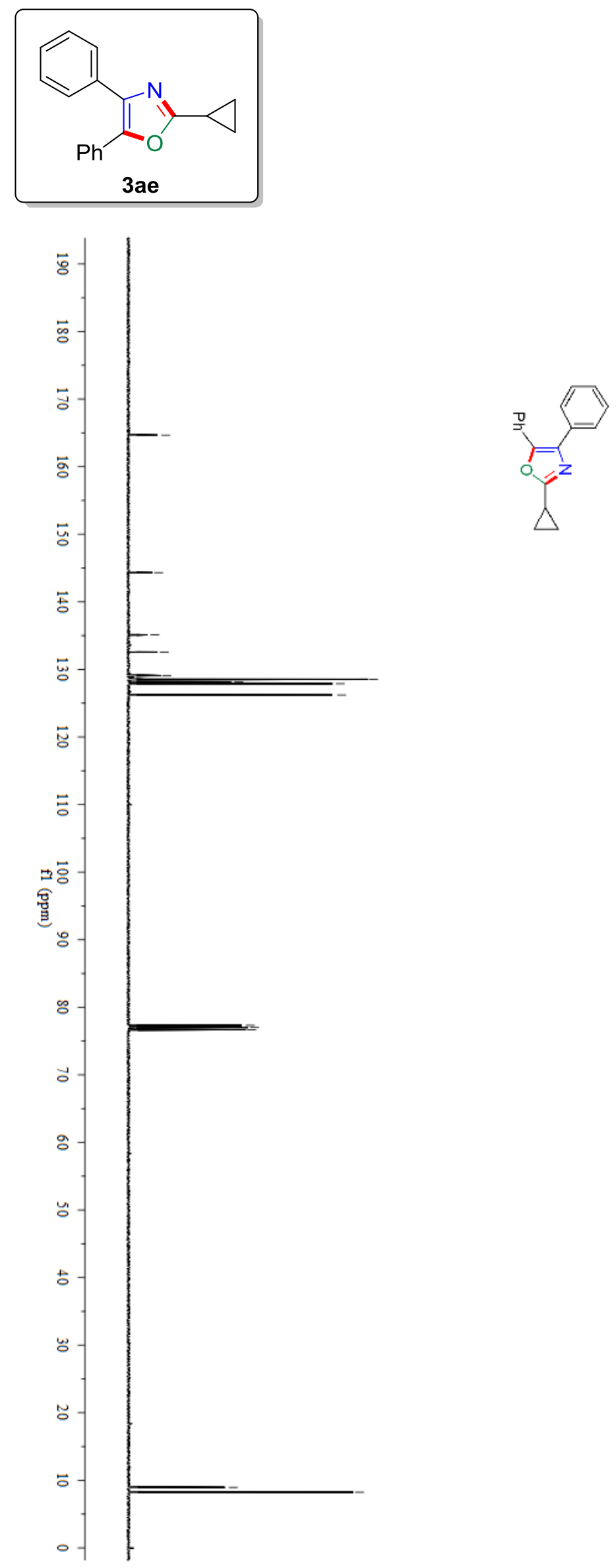

$-164.65$

$-144.32$

135.11

132.57

] 129.08

128.54

$-128.49$

- 128.12

$-127.93$

427.89

126.20

$\leftarrow_{-77.00}^{77.32}$

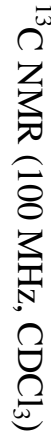

$-76.68$ 

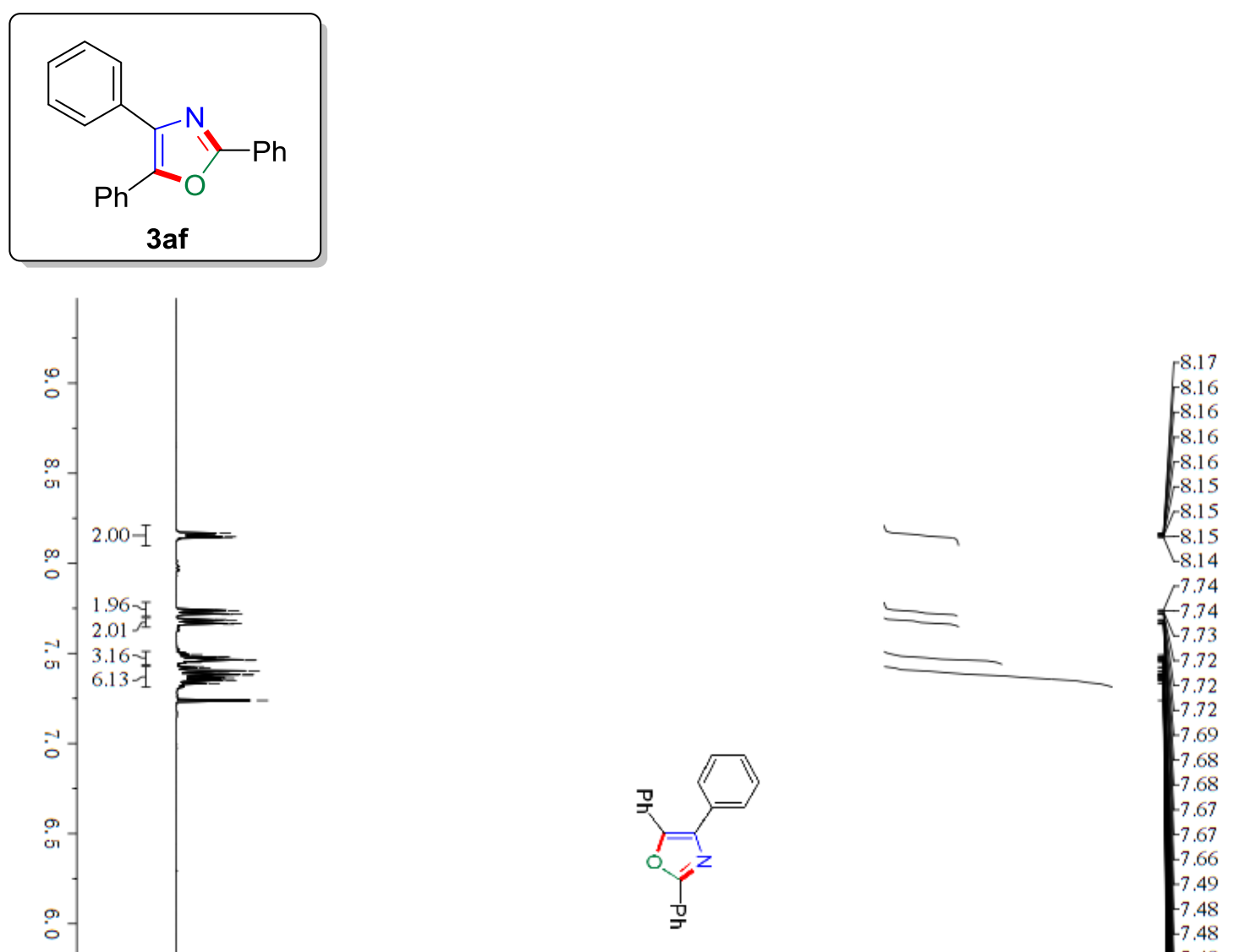

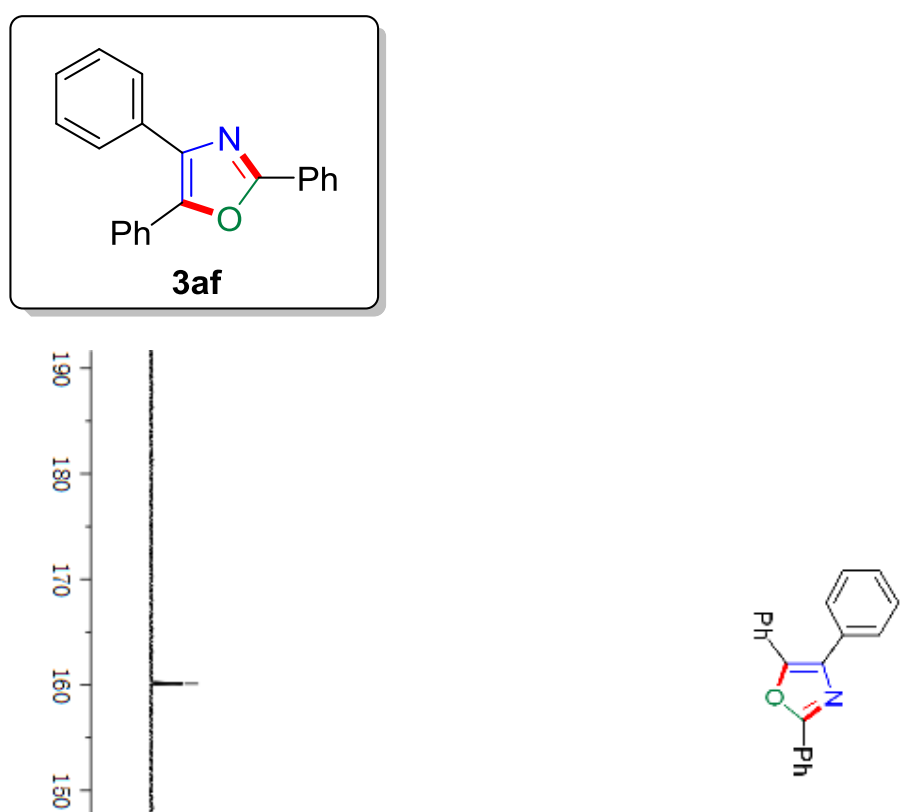

$-160.12$

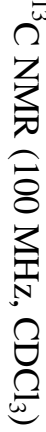

$-145.53$

$-136.77$

132.57

130.32

$-128.98$

$-128.73$

$-128.66$

$-128.59$

$-128.52$

$-128.20$

$-128.13$

$-127.38$

$-126.54$

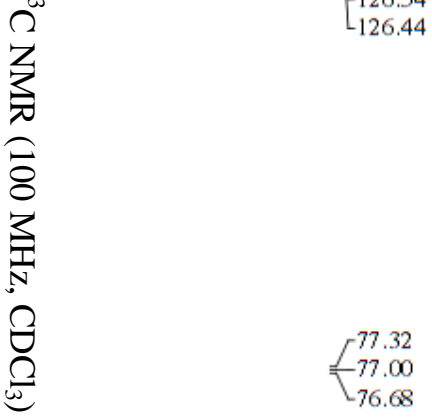

o'

76.68

8

용

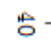

닝

'

。

$\circ-$ 

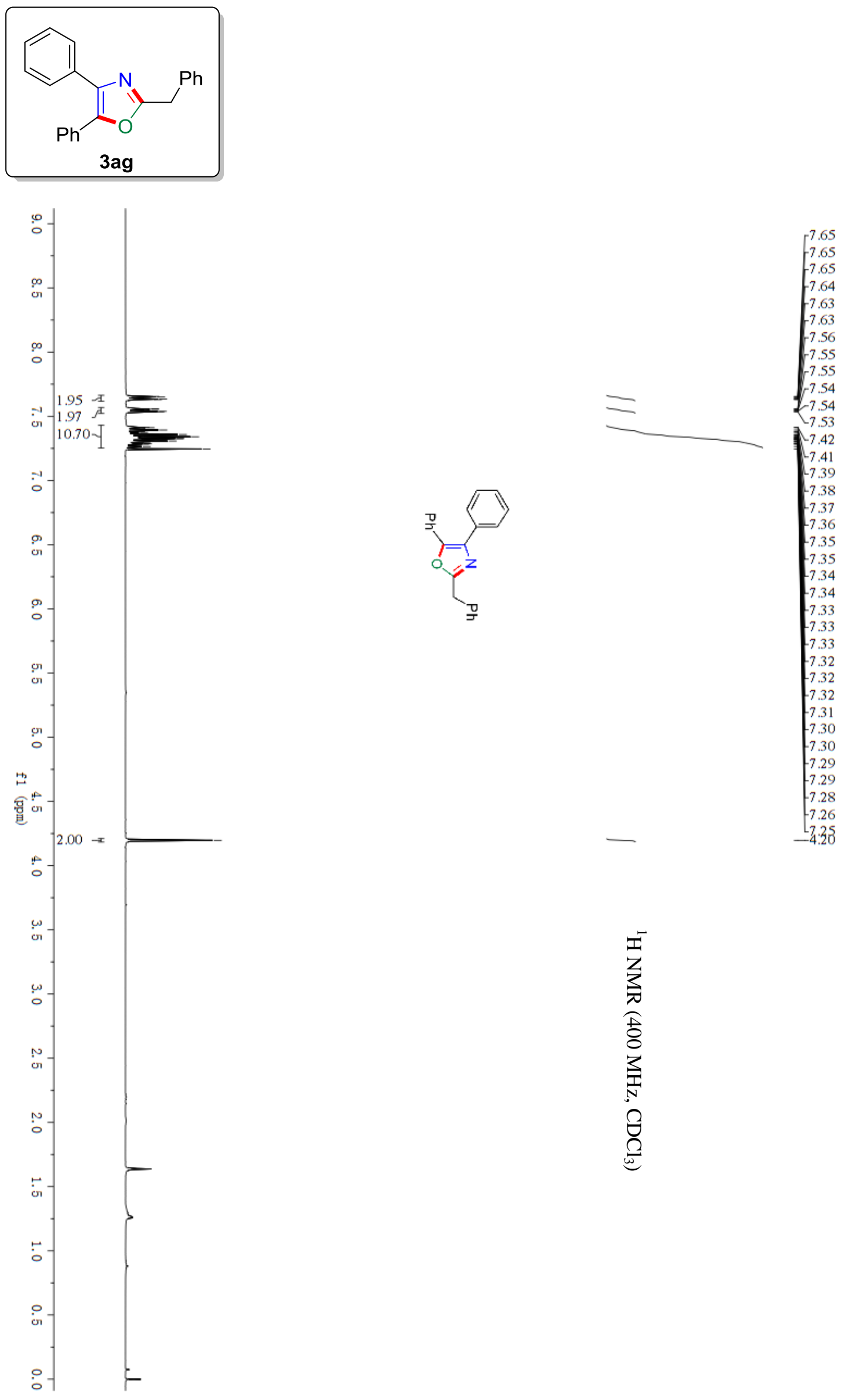

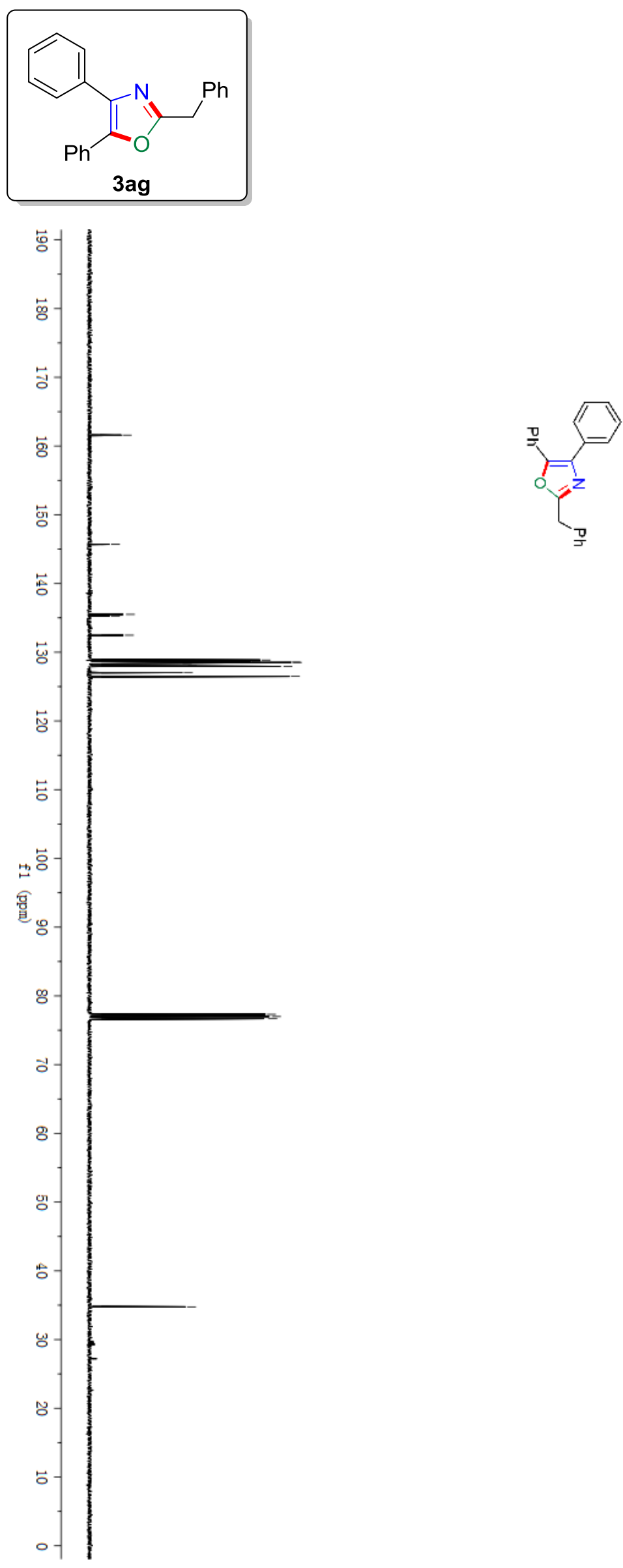

$-161.59$

$-145.71$

135.50

135.27

132.47

128.98

$-128.86$

$-128.70$

$-128.57$

$-128.51$

$-128.39$

$-128.02$

$-127.94$

-127.03
126.48

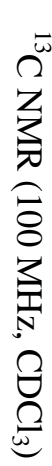

$<_{-77.00}^{77.32}$

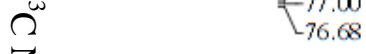

$-34.75$ 

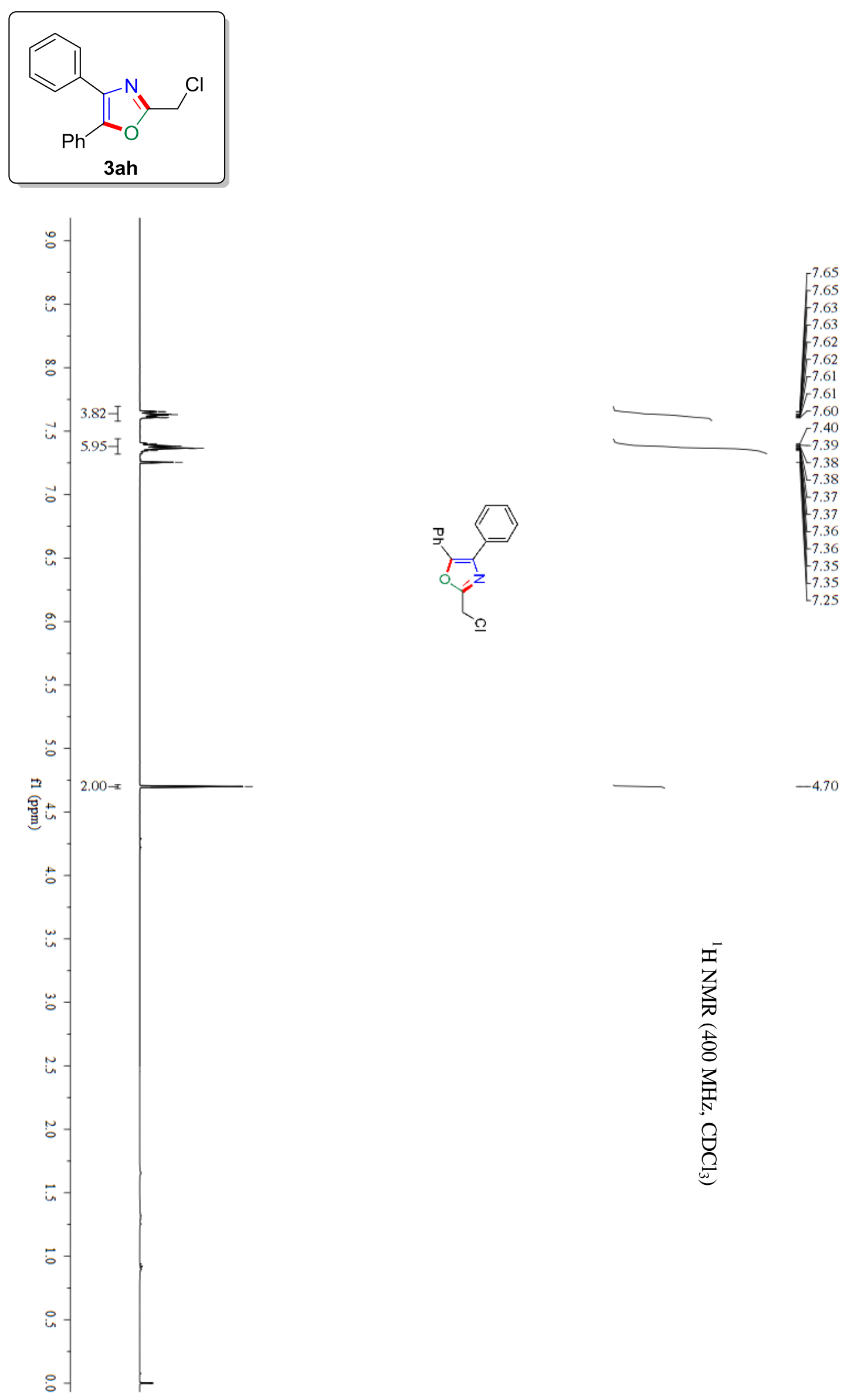

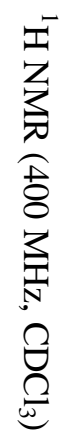

S66 

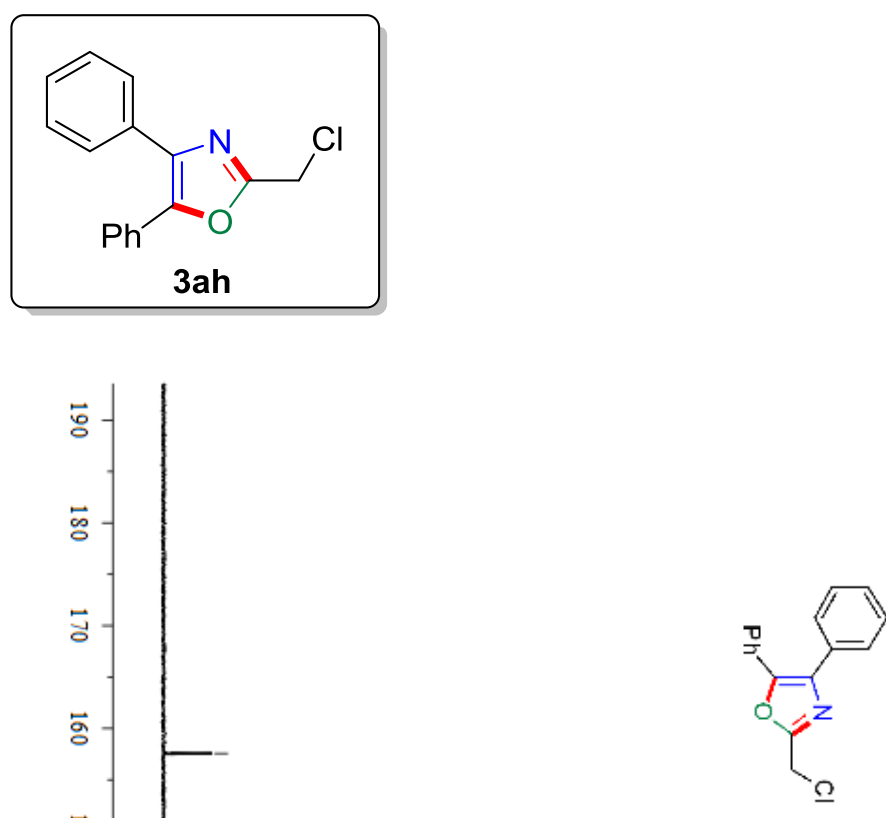

$-157.56$

$-146.95$

135.76

131.75 129.00 128.70 $-128.61$ $-128.37$

128.26

$-127.86$

Nㅗㅇ

$-126.69$

$\vec{\circ}$

붕ㅇㅇㅇ

害

8

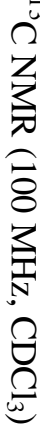

$\leftarrow_{77.00}^{77.32}$

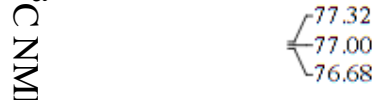

구

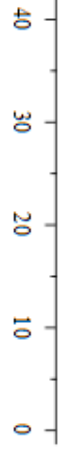

$-36.01$ 